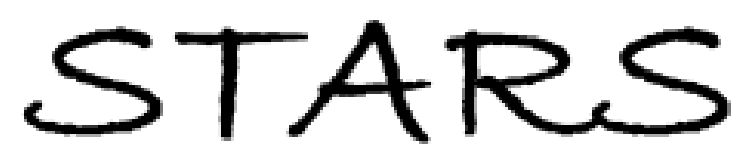

University of Central Florida

STARS

Electronic Theses and Dissertations, 2004-2019

2008

Hurricane Evacuation: Origin, Route And Destination

Vinayak Dixit

University of Central Florida

Part of the Civil Engineering Commons

Find similar works at: https://stars.library.ucf.edu/etd

University of Central Florida Libraries http://library.ucf.edu

This Doctoral Dissertation (Open Access) is brought to you for free and open access by STARS. It has been accepted for inclusion in Electronic Theses and Dissertations, 2004-2019 by an authorized administrator of STARS. For more information, please contact STARS@ucf.edu.

\title{
STARS Citation
}

Dixit, Vinayak, "Hurricane Evacuation: Origin, Route And Destination" (2008). Electronic Theses and Dissertations, 2004-2019. 3484.

https://stars.library.ucf.edu/etd/3484

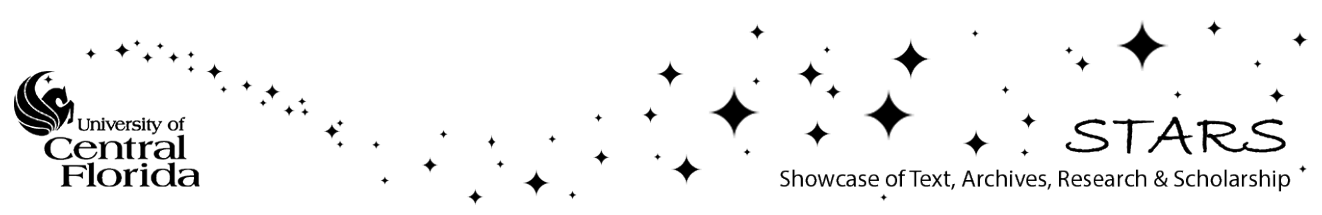




\title{
HURRICANE EVACUATION: ORIGIN, ROUTE AND DESTINATION
}

by

VINAYAK V. DIXIT

Integrated M.Tech. Indian Institute of Technology Delhi, 2005

\begin{abstract}
A dissertation submitted in partial fulfillment of the requirements for the degree of Doctor of Philosophy in the Department of Civil and Environmental Engineering in the College of Engineering and Computer Science at the University of Central Florida Orlando, Florida
\end{abstract}

Spring Term 2008

\author{
Major Professor \\ Essam A. Radwan
}


(C) 2008 Vinayak V. Dixit 


\begin{abstract}
Recent natural disasters have highlighted the need to evacuate people as quickly as possible. During hurricane Rita in 2005, people were stuck in queue buildups and large scale congestions, due to improper use of capacity, planning and inadequate response to vehicle breakdown, flooding and accidents. Every minute is precious in situation of such disaster scenarios.
\end{abstract}

Understanding evacuation demand loading is an essential part of any evacuation planning. One of the factors often understood to effect evacuation, but not modeled has been the effect of a previous hurricane. This has also been termed as the 'Katrina Effect', where, due to the devastation caused by hurricane Katrina, large number of people decided to evacuate during Hurricane Rita, which hit Texas three weeks after Katrina hit Louisiana. An important aspect influencing the rate of evacuation loading is Evacuation Preparation Time also referred to as 'Mobilization time' in literature. A methodology to model the effect of a recent past hurricane on the mobilization times for evacuees in an evacuation has been presented utilizing simultaneous estimation techniques. The errors for the two simultaneously estimated models were significantly correlated, confirming the idea that a previous hurricane does significantly affect evacuation during a subsequent hurricane. The results show that the home ownership, number of individuals in the household, income levels, and level/risk of surge were significant in the model explaining the mobilization times for the households. Pet ownership and number of kids in the households, known to increase the mobilization times during isolated hurricanes, were not found to be significant in the model. 
Evacuation operations are marred by unexpected blockages, breakdown of vehicles and sudden flooding of transportation infrastructure. A fast and accurate simulation model to incorporate flexibility into the evacuation planning procedure is required to react to such situations. Presently evacuation guidelines are prepared by the local emergency management, by testing various scenarios utilizing micro-simulation, which is extremely time consuming and do not provide flexibility to evacuation plans. To gain computational speed there is a need to move away from the level of detail of a micro-simulation to more aggregated simulation models. The Cell Transmission Model which is a mesoscopic simulation model is considered, and compared with VISSIM a microscopic simulation model. It was observed that the Cell Transmission Model was significantly faster compared to VISSIM, and was found to be accurate.

The Cell Transmission model has a nice linear structure, which is utilized to construct Linear Programming Problems to determine optimal strategies. Optimization models were developed to determine strategies for optimal scheduling of evacuation orders and optimal crossover locations for contraflow operations on freeways. A new strategy termed as 'Dynamic Crossovers Strategy' is proposed to alleviate congestion due to lane blockages (due to vehicle breakdowns, incidents etc.). This research finds that the strategy of implementing dynamic crossovers in the event of lane blockages does improve evacuation operations. The optimization model provides a framework within which optimal strategies are determined quickly, without the need to test multiple scenarios using simulation. 
Destination networks are the cause of the main bottlenecks for evacuation routes, such aspects of transportation networks are rarely studied as part of evacuation operations. This research studies destination networks from a macroscopic perspective. Various relationships between network level macroscopic variables (Average Flow, Average Density and Average speed) over the network were studied. Utilizing these relationships, a "Network Breathing Strategy" was proposed to improve dissipation of evacuating traffic into the destination networks. The network breathing strategy is a cyclic process of allowing vehicles to enter the network till the network reaches congestion, which is followed by closure of their entry into the network until the network reaches an acceptable state. After which entrance into the network is allowed again. The intuitive motivation behind this methodology is to ensure that the network does not remain in congested conditions. The term 'Network Breathing' was coined due to the analogy seen between this strategy to the process of breathing, where vehicles are inhaled by the network (vehicles allowed in) and dissipated by the network (vehicles are not allowed in). It is shown that the network breathing improves the dissipation of vehicle into the destination network.

Evacuation operations can be divided into three main levels: at the origin (region at risk), routes and destination. This research encompasses all the three aspects and proposes a framework to assess the whole system in its entirety. At the Origin the demand dictates when to schedule evacuation orders, it also dictates the capacity required on different routes. These breakthroughs will provide a framework for a real time Decision Support 
System which will help emergency management official make decisions faster and on the

fly. 


\section{ACKNOWLEDGMENTS}

Firstly I would like express my gratitude to my advisor Dr. Essam Radwan for being a constant support and keeping me real during my research. The research freedom he provided, with valuable guidance has made my experience during the Ph.D. very endearing. I would like to thank Dr. Mohamed Abdel-Aty, Dr. Anurag Pande and Shankar Ramasamy for being part of my research group. I would also like to acknowledge the support of my committee members, Dr. Haitham Al-Deek, Dr. Yasser Hosni and Dr. Xiaogang Su. I would like to express my gratefulness to Dr. Jay Baker for providing data regarding evacuees of hurricane Frances. I would also like to thank Nezamuddin, Vikash, Rami, Dr. Yan and Ravi for discussing issues related to research and having many productive discussions over coffee. No amount of gratitude can be sufficient to acknowledge my parents for my existence and for their hard work in making me understand the value of education, hard work and honesty. I would like to thank Pallavi for being a huge support through my work. I also want to thank my friends Varun, Piyush, Gauravdeep, Albinder, Amit, John and Abhishek for being there when I needed them. 


\section{TABLE OF CONTENTS}

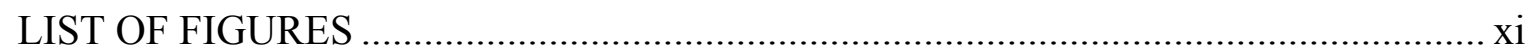

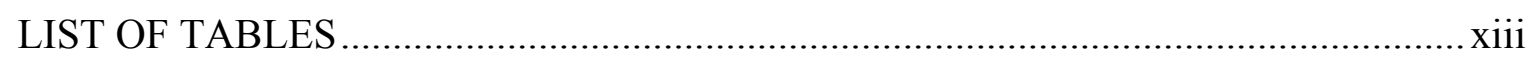

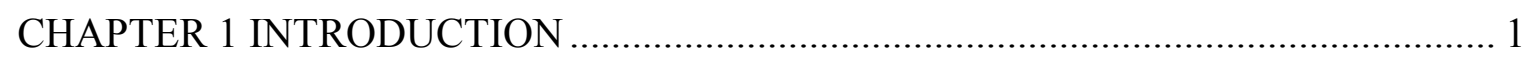

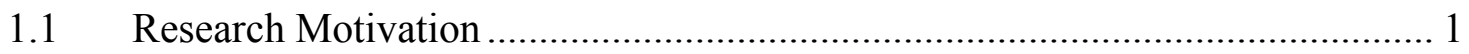

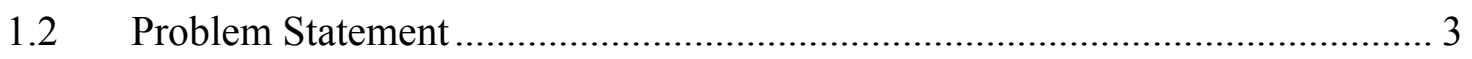

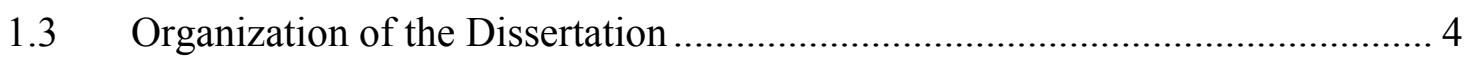

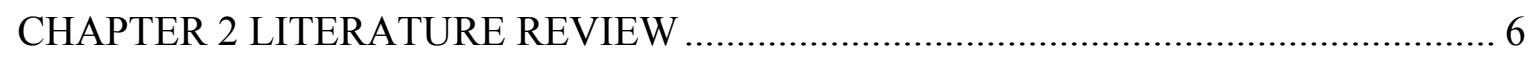

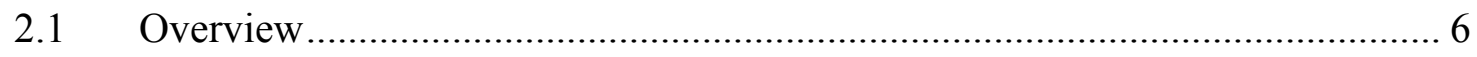

2.2 Evacuation Behavior ................................................................................. 7

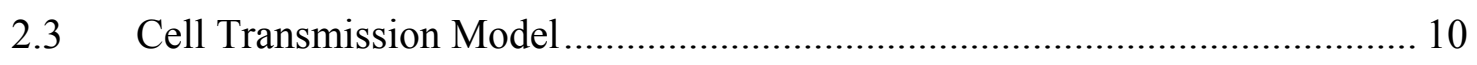

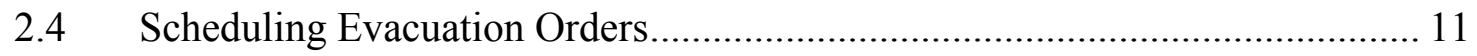

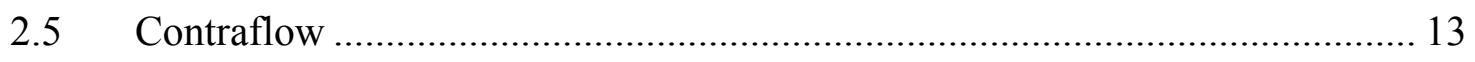

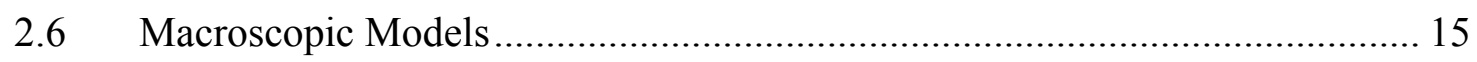

CHAPTER 3 EFFECT OF A RECENT HURICANE ON EVACUATION BEHAVIOR

DURING A SUBSEQUENT HURRICANE ............................................................. 19

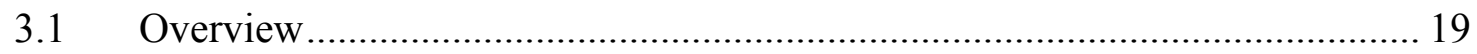

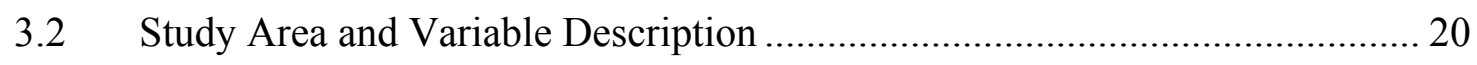

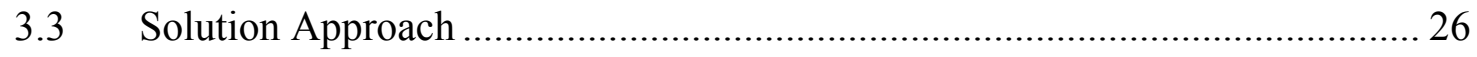

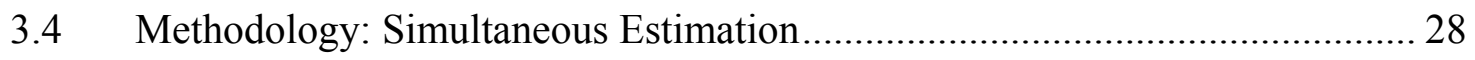

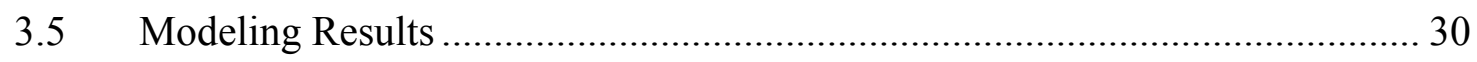

3.6 Qualitative Comparison of Response Curve ................................................. 36

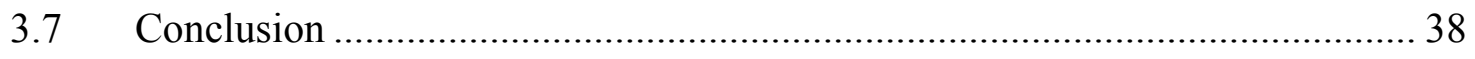




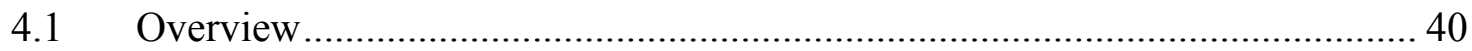

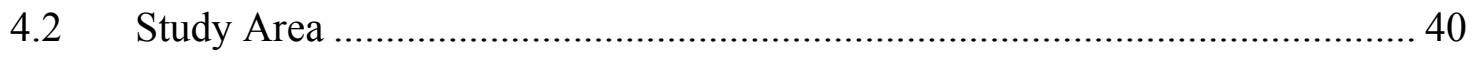

4.3 Microscopic Simulation Approach ..................................................... 41

4.4 Calibration of Cell Transmission Model...................................................... 49

4.5 Results of Cell Transmission Model for Interstate-4 .................................. 50

4.6 Comparison of Cell Transmission Model with VISSIM ................................ 53

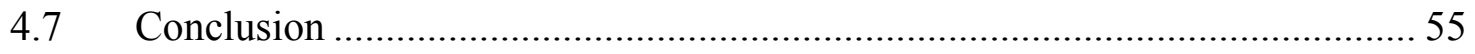

CHAPTER 5 SCHEDULING EVACUATION ORDERS ......................................... 57

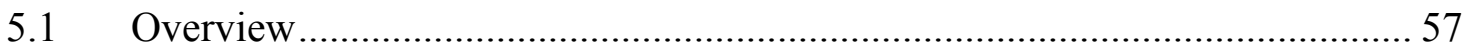

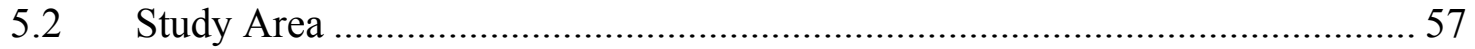

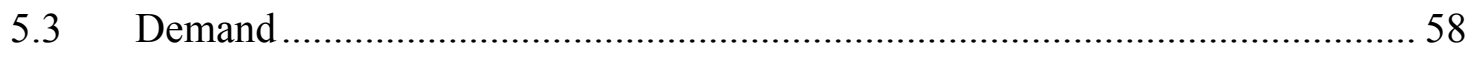

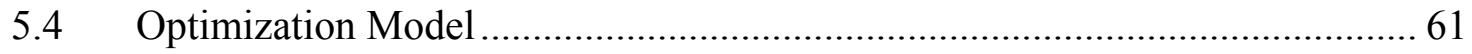

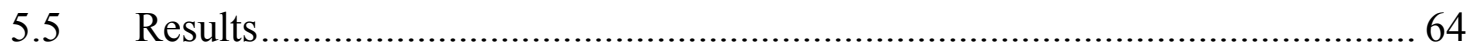

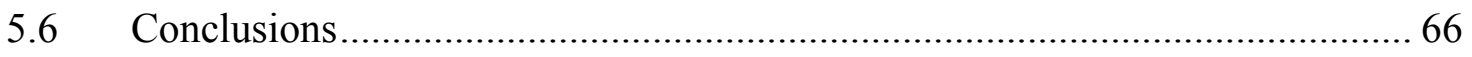

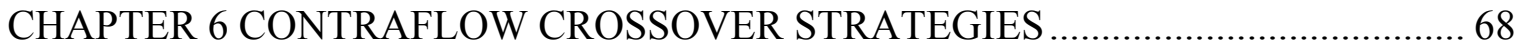

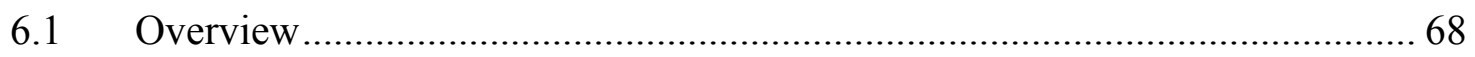

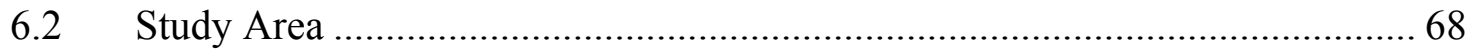

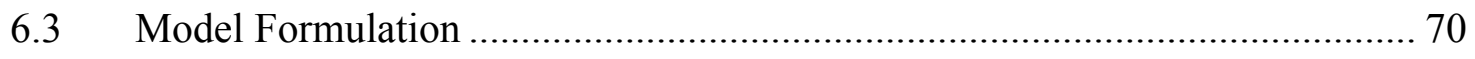

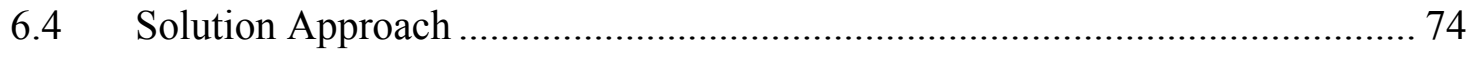

6.4.1 Optimal Crossover Location ............................................................ 74

6.4.2 Dynamic Crossover for Incidents ................................................ 76

6.4.2.1 Maximum of Two Crossovers ....................................................... 77 
6.4.2.2 Maximum of Two Crossovers ….................................................. 78

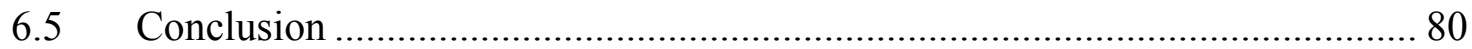

CHAPTER 7 STRATEGIES TO IMPROVE DISSIPATION INTO DESTINATION

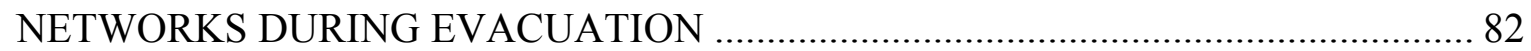

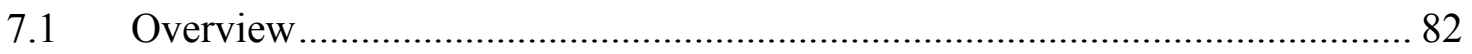

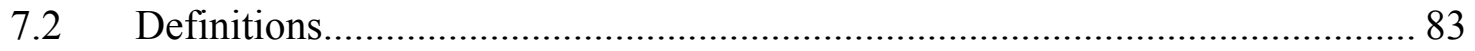

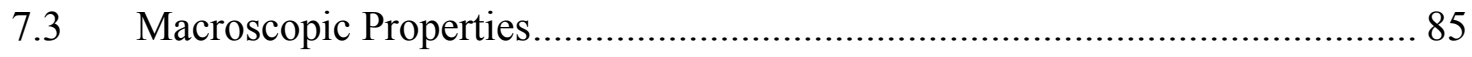

7.3.1 Fundamental Network Speed/Flow/Concentration Relationship............. 87

7.3.2 Speed-Accumulation Relationship at Network Level........................... 89

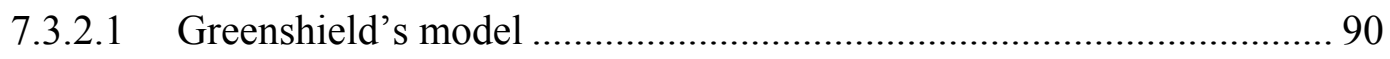

7.3.2.2 Greenberg's model............................................................. 90

7.3.2.3 Bell-shaped Relationship ..................................................... 91

7.3.3 Outflow-Accumulation Relationship at Network Level ......................... 94

7.3.4 Inflow-Accumulation Relationship at Network Level........................... 95

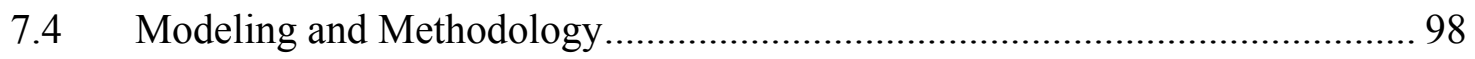

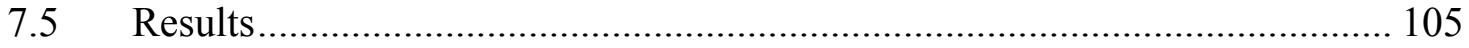

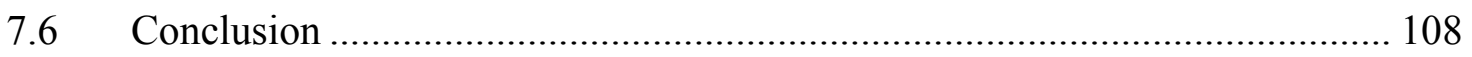

CHAPTER 8 SUMMARY, CONCLUSIONS AND FUTURE SCOPE ....................... 110

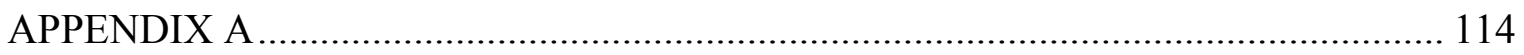

SAS code for Data Analysis of Frances data ..................................................... 115

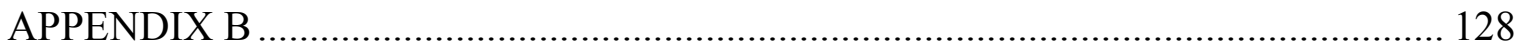

MATLAB Code for I-4 Cell Transmission Model ............................................. 129

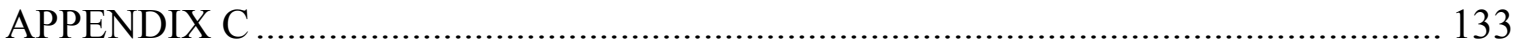


Optimization model for Evacuation Scheduling.................................................. 134

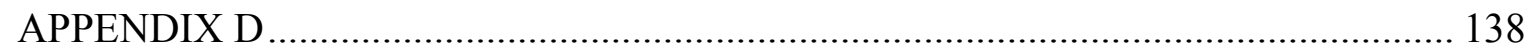

Optimization model for optimal crossover ...................................................... 139

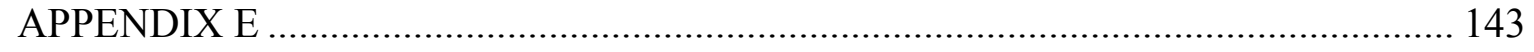

Destination Network and MATLAB code for data extraction................................ 144

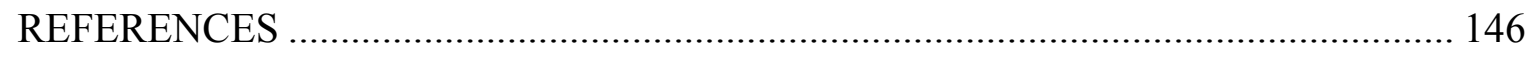




\section{LIST OF FIGURES}

Figure 3-1: Areas affected by Hurricane Frances [USACE, 2000] .................................. 21

Figure 3-2: Areas affected by Hurricane Charley [USACE, 2000] …………………..... 25

Figure 3-3: Response curve for evacuees belonging to different regions during hurricane Charley (USACE, 2000) 36

Figure 3-4: Response curve for evacuees belonging to different regions during hurricane Frances (USACE, 2000) 37

Figure 4-1: The map of Interstate-4 extending from Tampa to Orlando 42

Figure 4-2: Plots of measure of effectiveness for various strategies using microscopic simulation (VISSIM) 47

Figure 4-3: Plots of measure of effectiveness for various strategies using mesoscopic simulation 52

Figure 4-4: Plots of measure of effectiveness for various strategies using mesoscopic simulation 54

Figure 5-1: Cell transmission Model for the Network. 58

Figure 5-2: Cumulative probability of number of people that have left for orders given at different times 60

Figure 5-3: Demand Flow profile from each of the cities 61

Figure 5-4: Comparison between Staged Evacuation Order and Simultaneous Order.... 66

Figure 5-5: Real Time Framework 66

Figure 6-1: Cell transmission Model for Evacuation Route Interstate 4. 69

Figure 6-2: Comparison of having one optimal crossover with two optimal crossovers. 75 
Figure 6-3: Comparison of total vehicle time between fixed crossovers and dynamic crossovers, for a maximum of two crossovers. 78

Figure 6-4: Comparison between fixed and dynamic crossovers, for one maximum crossover. 80

Figure 7-1: Simulation network considered for the study 86

Figure 7-2: Observed flow vs. flow calculated using speed and density in equation 7-13.

Figure 7-3: Model fits for various speed-density relationships 93

Figure 7-4: Plot of Inflow and outflow vs. accumulation and the trend assumed 94

Figure 7-5: Conceptualization of relationship between outflow and accumulation 95

Figure 7-6: Plots describing relationships between inflow and accumulation 97

Figure 7-7: The plot between the number of vehicles dissipated into the network and time allowed for the network to relax. 106

Figure 7-8: Results between prediction of number of vehicles dissipated into the network through theoretical methodology and actual observed number of vehicles dissipated. 107

Figure 8-1: Real Time Integrated Framework 113 


\section{LIST OF TABLES}

Table 3-1: Description of Variables.

Table 3-2: Evacuation participation during hurricane Charley. 25

Table 3-3: Parameter Estimates for simultaneous estimation of "charley" and "delay" .. 34

Table 4-1: Demand from each location to Orlando on I-4........ 41

Table 4-2: VISSIM results for base case and four strategies 43

Table 4-3: Cell transmission Model results for each of the five strategies 51

Table 4-4: Percentage errors between estimates of Microscopic Simulation (VISSIM) and Mesoscopic simulation (Cell Transmission Model) 53

Table 4-5: Cell transmission Model results for each of the five strategies with dissipation of all vehicles into the network 54

Table 5-1: Total vehicular demand in each city. 60

Table 5-2: Time of Evacuation Orders 65

Table 5-3: Comparison of Total vehicle hours between simultaneous loading vs. optimal staging. 65

Table 6-1: Demand from each location to Orlando on I-4.......................................... 70

Table 6-2: Optimal crossovers for different cases 75

Table 6-3: Dynamic crossovers strategies for incidents, maximum crossovers allowed are two. 77

Table 6-4: Dynamic crossovers strategies for incidents, maximum crossovers allowed are one. 79 


\section{CHAPTER 1 INTRODUCTION}

\subsection{Research Motivation}

Under the threat of a hurricane, evacuation is necessitated. Evacuation is the activity of temporary migration from a region due to the risk of being harmed.

Over the years hurricanes have become stronger and hit harder on the U.S. coasts. In 2004 a series of hurricanes (Charley, Frances, Ivan and Jeanne) battered the Florida coasts. In 2005 hurricane Katrina and Rita affected Southern Louisiana, Mississippi and Texas. These hurricanes resulted in millions of people leaving their homes and evacuating to safer locations. These events, brought to light the need for having an effective evacuation plan.

Wolshon et. al. (2003) published a comprehensive review of evacuation plans of all states affected by hurricanes. In the review, they pointed out the need to control evacuation demand and increase the capacity of evacuation routes and develop a standard set of evacuation guidelines. They also found a significant need to make evacuation plans more flexible to handle eventualities. This need to handle eventualities during a hurricane evacuation resulted in investigation of faster simulation models that would provide flexibility in evacuation planning. 
Multiple hurricanes making landfall and affecting a common geographical region seems to have become a common phenomenon. Some examples from recent past include hurricane Frances within three weeks of hurricane Charley (in 2004) and Hurricane Rita within a month after the devastating hurricane Katrina (in 2005). It has been observed that evacuation behavior during a subsequent major hurricane might be significantly affected by the one preceding it. For example, the behavior of evacuees during evacuation of Houston (TX) due to hurricane Rita may have been affected by the memory and the infrastructural devastation of hurricane Katrina. In the words of Houston's Mayor Billy White “... with Katrina, the number of voluntary evacuees couldn't be predicted."(September, 23, 2005). The devastating effects of hurricane Katrina not only resulted in heavy infrastructural losses in terms of electricity and water supply etc., but also possibly caused fear among people. It in turn resulted in larger than expected evacuation participation rates during hurricane Rita causing huge delays and disrupted traffic operations during evacuation. This helplessness in the ability to determine the demand due to the effect of a previous hurricane lead to a research effort to evaluate the effect of an immediately preceding storm, while assessing the evacuation behavior during a subsequent storm in the same season.

During the South East U.S. Regional Transportation Analysis Meeting in 2000, it was observed that "More than half the evacuees felt like it took them more than five hours longer to reach their destination than they thought that it would" (March, 7-8, 2000). This is mainly due to the limited capacity of the exit ramps as well as congestion caused due to the large number of vehicles in the destination network. Usually evacuation routes 
terminate at large cities, and road networks in these cities are not designed to handle the large number of vehicles entering them during evacuation. This results in congestion which in turn leads to backups that extend for miles on the evacuation route. Though such phenomena have been observed repeatedly, limited literature on evacuation seems to have addressed this issue of network congestion at the termination node. Most simulation studies tend to assume ideal destinations, where vehicles leave the system as soon as they reach the destination irrespective of the number of vehicles already present in the destination road network. This provides a myopic perspective of analyzing evacuation routes. Therefore it is important to understand network level properties of traffic variables

These needs derived from experiences and studies have been the specific motivations in asking research questions regarding evacuation behavior, providing flexibility in evacuation planning, optimal evacuation operations and understanding destination networks during evacuation..

\subsection{Problem Statement}

This research attempts at addressing the following issues:

1. Modeling the effect of a recent previous hurricane on the mobilization time during an evacuation in a subsequent hurricane.

2. Comparing Mesoscopic models with Microscopic simulation in order to determine its efficiency to be part of a real time system. 
3. Developing an optimization model to determine optimal scheduling of evacuation orders also referred to as optimal staging of evacuation.

4. Developing an optimization model to determine optimal locations for contraflow crossovers.

5. Analyzing relationships between network level macroscopic variables (Average Flow, Average Density and Average speed). Utilizing these relationships to propose a strategy for improving dissipation of evacuees into the destination network. A new concept called "Network Breathing Strategy" is proposed and studied.

\subsection{Organization of the Dissertation}

The introductory chapter is followed by a critical review of relevant literature. This task helped identify disconnects and the various aspects that need to be taken care of while modeling evacuation.

The third chapter describes a methodology to determine the effects of a recent previous hurricane on the evacuation of a subsequent hurricane. The variable that was modeled was 'Mobilization time', also referred to as 'Evacuation preparation time'. The various demographic factors affecting mobilization time were also identified.

The fourth chapter contains a comparison between a mesoscopic simulation model (Cell Transmission Model (Daganzo, 1994a, 1994b)) and a microscopic simulation model 
(VISSIM), to explore the capabilities of these two models to be part of a real time system, that shall help provide flexibility to evacuation operations.

The fifth chapter proposes and tests an optimization model to determine optimal scheduling of evacuation orders. The results are promising, and indicate that scheduling of evacuation orders in fact do help provide benefits to evacuation operations.

The sixth chapter proposes and tests an optimization model to determine optimal location of crossovers for contraflow operations. The results identified the optimal crossover locations. Taking this concept one step further, a dynamic crossover strategy was proposed to improve operations in the event of an incident. This concept was tested using numerical examples, and was found to be very promising.

The seventh chapter focuses on one of the most neglected aspects of evacuation, Evacuation destination networks. This chapter investigates relationship between various network level variables and then utilizing these relationships and proposes a strategy to improve dissipation through a destination network. This strategy is referred to as "The Network Breathing" strategy.

Finally the chapter on conclusions, a summary of the entire research and future scope is discussed. 


\section{CHAPTER 2 LITERATURE REVIEW}

\subsection{Overview}

This chapter provides a critical review of literature. It helps identify the drawbacks in the current literature and the areas that require further research. It provided a strong knowledge base to start.

The evacuation literature can be essentially divided based on which part of the network is being observed:

1. Origin: Evacuation Behavior, Scheduling of Evacuation order

2. Routes: Capacity of routes, identification of evacuation routes, contraflow operations

3. Destination: Identification of where evacuation routes terminate.

Even though most literature studies each area separately, they are all inter-related.

Since the study conducted as part of this research studied at strategies within each of these three categories, the literature review has been separated based on research relevant to Evacuation behavior, Cell Transmission Model, Scheduling of evacuation order and Contraflow and Macroscopic models. 


\subsection{Evacuation Behavior}

There are two aspects of evacuation behavior, the first is the rate at which people evacuate and the second are the driving characteristics.

Understanding the evacuation demand behavior of the population is critical for devising traffic management strategies to safely evacuate people from the path of a major hurricane. Literature on evacuation behavior suggests that the common perception of irrational evacuation behavior during hurricanes (possibly due to panic) is not accurate (Quarantelli (1985), Tierney et. al. (2006)). In fact, people collectively act rationally during evacuation and their decision to evacuate depends on factors such as direct perception of threat (Mikami et. al. (1985)) and issuance of evacuation notice (Mikami et. al. (1985), Fitzpatrick et. al. (1991), Sorenson et. al. (1988)). Baker (1991) found that housing and storm specific threat factors also affected the evacuation behavior. Hultaker (1983) noted that families tend to make decisions about evacuation collectively and not on an individual basis. In a study of parishes in Southeastern Louisiana, it was found that people, whose homes were damaged by an earlier hurricane, were more likely to heed the official recommendation to evacuate (Howell et. al. (2005)).

If the premise of rational evacuation behavior is accepted then one should be able to model the behavior based on certain environmental and demographic factors. A study conducted by U.S. Army Corps of Engineers (USACE) (2000) showed that the evacuation response rates follows an S-curve and that $10 \%$ of all evacuees had left by the time evacuation orders were delivered. Alsnih and Stopher (2004) summarized the 
research on evacuation demand, illustrating both a general model of evacuation behavior, as well as the response curves. Fu and Wilmot (2004) developed a sequential logit model to estimate evacuation response. Later $\mathrm{Fu}$ and Wilmot (2006) suggested a survival analysis based evacuation response models. Continuing this work Fu et al. (2007) calibrated an evacuation response curve model for Hurricane Floyd (1999) in South Carolina and used the model to predict evacuation behavior for Hurricane Andrew (1992) in Southeastern Louisiana. In both regions these were the first hurricanes of the corresponding seasons and the populations in these regions were not affected by recent prior hurricanes. Their study did not find any statistically significant difference between the predicted response curve and the actual response curve for hurricane Andrew. This is an interesting finding for understanding the effect of "long memory" on evacuation behavior. South Carolina and Southeastern Louisiana have very different storm histories and even though the calibrated model did not include any variable incorporating the effect of previous hurricanes on that region, the model performed well in predicting response curves for a hurricane seven years before Floyd and a different region. This indicates that "long memory" may not have a significant impact on impact on evacuation behavior during hurricanes

The studies mentioned so far can be categorized based on the questions they attempt to answer. Drabek (1983) referred to research problem of trying to understand why some subjects evacuate while others do not, as the "Shall we leave?" question. Another critical group of questions categorized by Sorensen (1991), was the "When shall we leave?" question. This question relates to the variations in departure times during a single 
hurricane or any short-notice disaster for that matter. An important component of these variations, in the context of a short-notice disaster, is the time spent in preparing for the evacuation after making the decision to evacuate. This duration is referred to as mobilization time in this study, and relates to "Why do we leave when we do?" question (Sorenson (1991)). Understanding these variations can be used to generate empirical data based traffic loading rates that can in turn be used for evacuation planning. According to Sorensen (1991) the relationships between mobilization time and characteristics of the evacuees is very critical for developing improved evacuation plans. One of the studies attempting to understand the mobilization time, sometimes also referred to as "evacuation delay", have found that households with older members and pets have higher mobilization time due to the need for appropriate transportation (Alsnih et. al. (2004), Vogt (1991), Heath et. al. (2001)). These results on participation rates and factors affecting delays were examined only for evacuations due to isolated hurricanes. However, they do not explicitly address the effects of a major preceding hurricane on the evacuation behavior during a subsequent hurricane.

Another aspect of evacuation behavior is driving behavior during evacuation. Petruccelli (2003) found that drivers tend to be more aggressive during an evacuation (after an earthquake). Studies on perception reaction time have been conducted for congested conditions and have been well documented in chapter 2 of the Traffic Flow Theory Monograph.(2006) Human factors have been found to significantly affect traffic stream characteristics. The effects are basically seen on free-flow speeds and backward speed propagation. It has also been observed that flows on contraflow lanes are $67 \%$ of that on 
normal lanes. This is attributed to the unfamiliarity of driving in the reverse conditions (Wolshon et. al. (2003)). With whatever little is known about driving behavior under evacuation, these aspects need to be explicitly modeled as part of the traffic stream characteristics.

\subsection{Cell Transmission Model}

Cell Transmission Model proposed by Daganzo (1994a, 1994b) is an interesting way to model traffic flow in a network and in a freeway corridor. CTM is a deterministic mesoscopic model that predicts flow, occupancy and density with accuracy. CTM unlike macroscopic models is able to account for backward wave propagation due to congestions downstream and is also able to predict merge and diverge behavior of traffic at junctions. Unlike microscopic simulations, the CTM consumes far less time and space on the computer and is much easier to code. This makes the CTM an ideal tool to use as an underlying basis for a Decision Support System that will help decision makers determine the best possible strategies during evacuation quickly and accurately.

In the CTM, the road section is divided into homogenous cells, such that the length of each cell is such that a vehicle at free flow speed will traverse the length of that section in one clock tick (Time unit). The state of the system at any time $t$ is determined by the number of vehicles in cell $i$ and is expressed as $n_{i}(t)$. Parameter $N_{i}(t)$ defines the maximum number of vehicle allowed in cell $i$ during time interval $t$. Parameter $Q_{i}(t)$ defines the maximum number of vehicles that can flow into cell $i$ when the clock 
advances from $t$ to $t+1$. If cells are numbered consecutively starting with the upstream end of the road from $i=1$ to $I$, the recursive relationship of the CTM can be expressed as $n_{i}(t+1)=n_{i}(t)+y_{i}(t)-y_{i+1}(t)$

Where, $y_{i}(t)$ is the inflow to cell $i$ in the time interval $(\mathrm{t}, \mathrm{t}+1)$, given by

$y_{i}(t)=\min \left\{n_{i-1}(t), Q_{i}(t), \delta\left[N_{i}(t)-n_{i}(t)\right]\right\}$

Where $\delta=\frac{w}{v}, w$ is the speed with which disturbances propagate backward when traffic is congested and $v$ is the free flow speed. It was seen by Daganzo (1994a, 1994b) the accuracy of the model is enhanced if $\delta$ is redefined such that

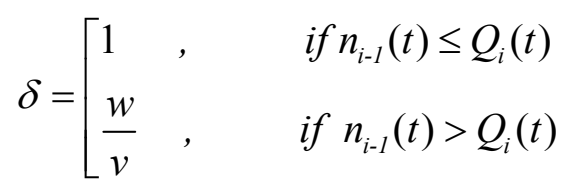

The Cell transmission model can be formulated as a Linear programming problem (Zilliaskospoulos (2000), Tuydes et. al. (2004), Chiu et. al. (2006)) that can provide guidelines for traffic assignment and signal timings.

\subsection{Scheduling Evacuation Orders}

$\mathrm{Fu}$ (2004), as part of his dissertation, modeled evacuation response curves for hurricane Andrew and Floyd. The study found that time of day and the time of order significantly influenced the shape of response curve. 
During hurricane Rita, evacuees from Galveston were stranded for hours on the evacuation routes due to evacuating traffic from downstream Houston. This brings to light how downstream evacuating traffic might adversely affect evacuating traffic from a greater at risk region.

It has been found that there is a definitely a need to co-ordinate the issuance of evacuation order (Wolshon et. al. (2003)) for efficient evacuation operations.

Ozbay et. al. (2006) conducted a critical analysis on demand generation and network loading models, for determining optimal evacuation staging (scheduling) schemes. They reviewed three widely used models, S-curves, Twedie's and Sequential Logit Models. They concluded that using the system optimal traffic assignment the S-curve and Tweedie's demand generation resulted in unrealistic delays and The sequential logit model provided more realistic results.

Liu et. al. (2006) proposed a cell based network model in order to determine optimal staging schemes. The model used Tweedie's demand generation model. In the light of research conducted by Ozbay et. al. (2006), there is a need to incorporate Sequential Logit Models as demand generation model for determining optimal staging schemes during hurricane evacuation. 
Mitchell, et. al., (2006) evaluated various heuristic strategies to improve evacuation clearance time of people evacuating from Ormond Beach. This research showed the advantages of staging demand during evacuation.

Sbayti, et. al., (2006) realized that by staggering the evacuating load onto the network, the onset of congestion may be delayed, and people can be evacuated faster. In this paper, they considered the problem of scheduling evacuation trips between a selected set of origin nodes and (safety) destinations, with the objective of minimizing the network clearance time.

One of the aspects about all the research reviewed so far, it was assumed that evacuation began after the evacuation order was given. Based on Fu's study this would be a wrong assumption, and would provide very wrong guidelines for staging evacuation.

\subsection{Contraflow}

Contraflow operations are being widely used to improve evacuation operations. Contraflow operation is the reversal of inbound lanes to outbound lanes so as to increase capacity of evacuation routes. One of the main issues related to contraflow operations is access to contraflow lanes. These accesses are also referred to as crossovers. Inappropriate locations of these crossovers might result in bottlenecks, which adversely affect the evacuation operations. Therefore it is of utmost importance to determine locations for crossovers that will help improve evacuation operations. The number of crossovers is also constrained by the amount of manpower required, logistics and cost to 
implement them. Hence it is crucial to determine locations and number of crossovers under constraints that will provide the best benefit to the evacuation operation.

The work done by Wolshon (2001) helped understand contraflow operations during an evacuation. The paper discussed the safety, operational, accessibility and cost issues with respect to contraflow lanes. The work also tabulated the gains in capacity for conversion of each lane being reversed. The paper pointed out that when all the lanes were reversed the total increase in capacity was only $67 \%$, though a $100 \%$ increase in capacity should have been expected, due to reversal of all lanes. This was attributed to the unfamiliarity and discomfort of drivers driving on the contraflow lane, therefore resulting in lower speeds.

Tuydes et. al. (2004) proposed an optimization model to determine sections of roads where contraflow plans need to be implemented. One of the drawbacks was that the results generated by this model did not incorporate merge and diverge congestions, which might be crucial in determining the location of crossovers.

Theodoulou $(2003,2004)$ modeled and analyzed certain freeway contraflow operations in the New Orleans area. This was one of the first efforts to discuss design issues with respect to entry-exit and termination strategies. The basic idea used by them was to manage congestion caused by merge and diverge and improve utilization of capacity created due to contraflow operations. Theodoulou in his study had assumed $15 \%$ of heavy vehicles. As stated in his research, he assumed a high percentage in heavy vehicles, 
because it has been observed in previous literature (Baker, (1991)), that evacuees instinctively tend to carry as much of their belongings as possible. Theodoulou in his study also observed that $60 \%$ evacuees tend to use normal lanes, while the rest $40 \%$ use the contraflow lanes.

\subsection{Macroscopic Models}

Initial attempts to understand relationships between network level variables consisted of Zahavi's (1972a, 1972b) work on the $\alpha$-relationship between network level parameters of traffic intensity ( $I$, the distance traveled per unit area), road density (R, length of road per unit area) and the weighted space mean speed (v). Using data from England and the U.S. he arrived at the relationship in equation 1.

$I=\alpha R / v$

Buckley and Wardrop (1980) later showed that $\alpha$ was strongly correlated to the space mean speed. In a later field study, Ardekani (1984) proved that the $\alpha$ parameter had a positive correlation to network concentration. This made the $\alpha$ parameter model highly inaccurate. Chapter 6 of the Traffic Flow Theory monograph revised 1997 contains a comprehensive review of these macroscopic flow models.

In order to characterize flow of vehicles in urban network Prirgogine and Herman (1971) proposed the two-fluid theory. The two-fluid model assumes that vehicular traffic in an urban network can be differentiated as stopped vehicles and running vehicles. These models were constructed between the average travel time per mile $(T)$ versus the average 
running time per mile $\left(T_{r}\right)$ using regression (Equation 1-5). The parameters $\left(k, T_{m}\right)$ involved in this two-fluid model were indicative of the quality of service of the networks. $T_{r}=T_{m}^{\frac{1}{k+1}} T^{\frac{k}{k+1}}$

Mahmassani et al. (1984) and Williams et al. (1985) during their study of two fluid models using computer simulation showed that relationships between the three fundamental traffic variables speed/flow/concentration (Equation 1-6) at a network level were similar to those on individual road facilities.

$Q=K V$

In a later simulation study Mahmassani et al. (1987) found that both the linear V-K model proposed by Greenshield, and the non-linear 'bell-shaped' function proposed by Drake et al. (1967) were able to describe the relationship between $V$ and $K$ fairly well. In their paper they also studied the effect of length and width of links as well as various traffic controls (perfectly coordinated, isolated and simultaneous signal operation) on the speedconcentration relationships and the flow-concentration relationships.

Even though these studies showed interesting results, due to the very few (six) data points used for the analysis, the conclusions in the paper are prone to major skepticism. Also each simulation run was done for constant concentration conditions, in which constant concentration was maintained by allowing vehicles to circulate in the network. Such concentration conditions generally do not prevail in real urban networks, where vehicles enter and leave, and concentrations in the network vary more dynamically. 
Mahmassani et al. (1990) conducted microscopic simulation experiments on larger urban networks than the ones studied in Mahmassani et al. $(1984,1987)$ and Williams et al. (1985, 1987). The experiments concluded that the relationship between speed and concentration remained significantly identical for various network sizes. This indicated that these relationships between various network level variables were independent of network size and consistent. During their analysis they observed that the average network speed at a given concentration was lower when the intersections were operated as an unsignalized (stop-sign control) as compared to signalized intersections.

Ardekani (1984) studied the two fluid characterizations urban road networks and proved the validity of these models on real urban road networks. Ardekani through field studies also concluded that the fundamental equation 3 holds true.

Recently Daganzo (2007) using average network flow and accumulation suggested various recipes for improving city mobility through gridlock control. The paper proposed a relationship between the outflow (exit function $(G(n))$ ) and the number of vehicles in the network. The paper derived a differential equation (equation 4) describing the number of vehicles in the network, based on the inflow $(f(t))$ and outflow $(G(n))$.

$\frac{d n}{d t}=f(t)-G(n(t)), \quad$ for $t \geq 0$

These relationships are used in the paper to determine an optimal control strategy (A-B strategy) to control inflows so as to maximize outflow. One of the practical drawbacks of 
this approach is that due to the stochastic nature of traffic flow there are periods where inflow is greater than the outflow, leading to eventual jam conditions, hence in the strategy proposed for efficient operations real monitoring and control of the network is required. In this paper the proposed strategy overcomes this drawback.

Geroliminis and Daganzo (2007) as a continuation of Daganzo's (2007) theoretical work conducted simulation experiments with the San-Francisco network. They showed a linear dependence between the travel production in the network and the outflow from the network, and an inverted U-shaped relationship between the travel production and accumulation. In addition the paper also describes the behavior of inflow with respect to accumulation. They showed that inflow remained constant till a certain degree of accumulation and then started decreasing. The paper also proposed control strategies based on real time observation of accumulation and were tested using simulation 


\section{CHAPTER 3 \\ EFFECT OF A RECENT HURICANE ON EVACUATION BEHAVIOR \\ DURING A SUBSEQUENT HURRICANE}

\subsection{Overview}

A region being affected by multiple hurricanes in a span of few weeks is not uncommon. The behavior of the evacuees during the subsequent hurricane(s) in the same season is affected by the damage to infrastructure and vehicles/assets belonging to evacuees, as well as by the psychological impact made by the preceding hurricane. This phenomenon has been termed as the 'Katrina' effect.

A behavioral aspect which impacts the traffic loading rates during a hurricane is the evacuation delay or mobilization time. In this study, mobilization time for an evacuee is defined as the difference between the times at which decision to leave was made and the actual time of departure.

This chapter proposes a methodology to better understand the factors associated with the mobilization time during a subsequent hurricane, while accounting for the effects of the preceding hurricane. The effect of preceding hurricane is accounted for by modeling levels of mobilization time simultaneously with an ordinal variable representing evacuation participation levels during hurricane Charley. The data for survey conducted on the evacuees of hurricane Frances, which made landfall three weeks after hurricane 
Charley, are used in this study. The implications of these findings for the demand S-curve are also briefly discussed in this chapter.

\subsection{Study Area and Variable Description}

Data used in this study were collected through a phone survey during May and June of 2005, conducted by representatives of Federal Emergency Management Agency (FEMA), USACE, and the state of Florida. Data were collected from counties that were known to have had a recommended evacuation for at least a portion of their residents (Figure 3-1). For the purpose of sample allocation, the counties were aggregated into groups. The aggregations of coastal counties were based on groupings used for hurricane evacuation planning studies in Florida. There were five aggregations of coastal counties (Northeast/East Central, Treasure Coast, Southeast Tampa Bay, and southwest Florida) and two aggregations of inland or non-coastal counties (Central, and Southern). The aggregation of the counties is shown in Figure 3-1. The survey encompassed 1700 respondents and included a screening question for collecting the responses only from evacuees of hurricane Frances. The data consisted of information on delays in start of evacuation (i.e., mobilization time) and other information for 454 respondents who evacuated during hurricane Frances. Details of the survey data along with the distributions of responses are available on the USACE (United States Army Corps of Engineers) website (2000). 


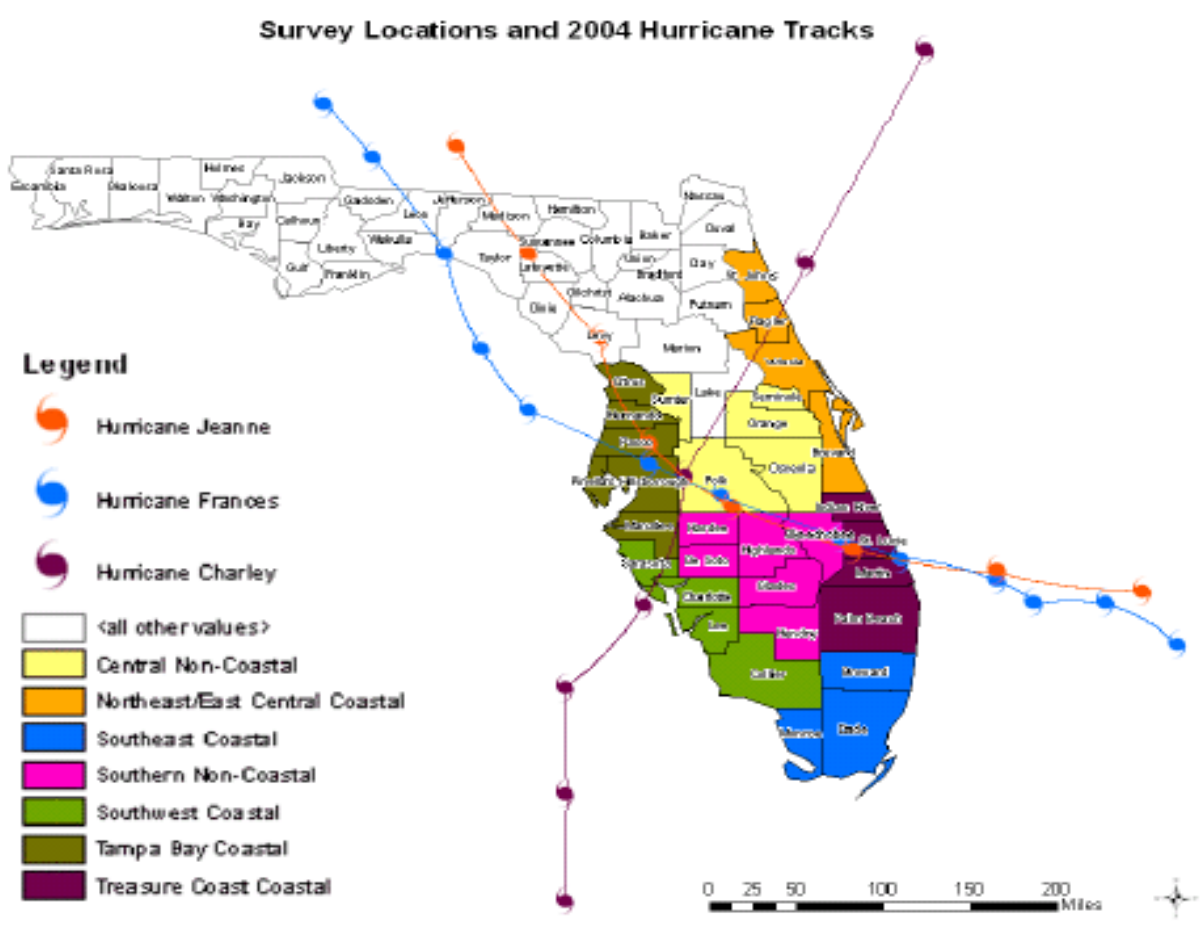

Figure 3-1: Areas affected by Hurricane Frances [USACE, 2000]

The dependent and independent variables from the survey used for analysis in this study are listed in Table 3-1. Table 3-1 also lists the percentages of respondents belonging to individual categories of nominal and ordinal variables in the dataset. While most of the variables listed in the table are self-explanatory; few that are in need of clarification are explained in the remainder of this section. In the original dataset evacuation delay or mobilization times were categorized into six levels. These times were reclassified into five categories represented by the variable "delay" such that the resulting categories contained roughly equal number of respondents. Delays between 7-12 hours and 12-24 hours were combined into one level to reclassify the variable (See Table 3-1). The variable "surge_coast" essentially defines the type of risk presented by hurricane Frances. Since hurricane Frances moved from the east coast of Florida to the west coast, the surge was more severe on the east coast compared to the west coast. The variable "surge_coast" 
was valued 1 for the east coast of the state where the impact of surge was most intense, 2 for surge affected regions on the west coast of the state, and 3 for all regions that were not affected by surge (i.e., Central non-coastal region). It is worth mentioning that this variable was measured on a nominal scale rather than on an ordinal scale. The variable "MHstrength" essentially signifies the strengths of mobile homes. If the mobile homes were built pre-1993, "MHstrength" was assigned 1, and if it was manufactured post-1993 the value of "MHstrength" were 2. This was because, mobile homes built after 1993 were made to adhere to certain hurricane safety guidelines. For homes that were not mobile homes "MHstrangth" was assigned 3. An ordinal scale was used for this variable. Also, since a sizeable proportion of respondents refused to disclose their household earnings; their place in the ordinal scale would be unknown. Therefore, the variable "income" was measured on a nominal scale and not on an ordinal scale which is generally the case for the categorical variables representing household incomes. 
Table 3-1: Description of Variables

\begin{tabular}{|c|c|c|}
\hline Variables & Values & Description \\
\hline \multicolumn{3}{|l|}{ Binary } \\
\hline \multirow[t]{2}{*}{ own_rent } & 1 & Respondent owns home $(88.56 \%)$ \\
\hline & 2 & Respondent rents home (11.44\%) \\
\hline \multirow[t]{2}{*}{ Pets } & 1 & Respondent has pets $(50.63 \%)$ \\
\hline & 2 & Respondent has no pets $(49.37 \%)$ \\
\hline \multirow[t]{2}{*}{ Eighty_plus } & 0 & $\begin{array}{l}\text { If household has no individual of more than } 80 \text { years } \\
\text { of age in the household }(91.61 \%)\end{array}$ \\
\hline & 1 & $\begin{array}{l}\text { If household has individual(s) of more than } 80 \text { years } \\
\text { old in the household }(8.39 \%)\end{array}$ \\
\hline \multirow[t]{2}{*}{ Assist } & 0 & $\begin{array}{l}\text { If transportation, shelter care or any other assistance } \\
\text { was not required }(95.76 \%)\end{array}$ \\
\hline & 1 & $\begin{array}{l}\text { If transportation, shelter care or any other assistance } \\
\text { was not required }(4.24 \%)\end{array}$ \\
\hline \multicolumn{3}{|c|}{ Multinomial Nominal } \\
\hline \multirow[t]{6}{*}{ Income } & 1 & $\leq \$ 15000(6.90 \%)$ \\
\hline & 2 & $\$ 15000-\$ 24999(9.83 \%)$ \\
\hline & 3 & $\$ 25000-\$ 39999(15.48 \%)$ \\
\hline & 4 & $\$ 40000-\$ 79999(21.34 \%)$ \\
\hline & 5 & $\geq \$ 80000(18.62 \%)$ \\
\hline & 6 & $\begin{array}{l}\text { Respondents who refused to divulge information about } \\
\text { their income }(27.82 \%)\end{array}$ \\
\hline \multirow[t]{5}{*}{ type_struct } & 1 & Detached single family home $(58.93 \%)$ \\
\hline & 2 & Duplex/triplex/quadruple home (4.04\%) \\
\hline & 3 & Multi-family home with 4 stories or less $(14.47 \%)$ \\
\hline & 4 & Multifamily building more than 4 stories $(5.11 \%)$ \\
\hline & 5 & Mobile homes and manufactured homes (17.44\%) \\
\hline \multirow[t]{3}{*}{ surge_coast } & 1 & $\begin{array}{l}\text { If the region affected by surge is on east coast } \\
(60.67 \%)\end{array}$ \\
\hline & 2 & $\begin{array}{l}\text { If the region affected by surge is on west coast } \\
(5.44 \%)\end{array}$ \\
\hline & 3 & Regions not affected by the surge $(33.89 \%)$ \\
\hline \multicolumn{3}{|c|}{ Ordinal/Interval variables } \\
\hline Num_kids & & Number of Kids in the household \\
\hline Num_hh & & Number of individuals in the household \\
\hline fla_years & & Number of years spent in Florida \\
\hline MHstrength & & The strength of homes \\
\hline \multirow[t]{5}{*}{ Delay* } & 1 & $<1$ hour $(23.64 \%)$ \\
\hline & 2 & Between 2-3 hours (17.99\%) \\
\hline & 3 & Between $4-6$ hours $(19.25 \%)$ \\
\hline & 4 & Between 7-24 hours (18.62\%) \\
\hline & 5 & $>24$ hours $(20.50 \%)$ \\
\hline
\end{tabular}

"The dependent variable representing mobilization time in the analysis 
Note that geographical region belonging to the respondents was also available in the database. Even though it was not part of the variables that were directly used in the modeling process; the information was instrumental in quantifying the relative impact of hurricane Charley. The five levels of Evacuation participation during hurricane Charley are referred to as severity of hurricane Charley in this study. An ordinal variable "charley" was created to quantify the impact of hurricane Charley for the respondents based on their geographical location. For this purpose, post-Charley assessments made by the Army Corp of Engineers for different regions of Florida were used. The regions affected by hurricane Charley are shown in Figure 3-2, while the regions affected by hurricane Frances are shown in Figure 3-1. The effect of Charley on a region was measured as the evacuation participation from that geographical region. Table 3-2 provides the levels of evacuation participation during hurricane Charley along with the rankings that constitute the categories of the ordinal variable "charley". The ordinal variable essentially provides the relative effect (or severity) of hurricane Charley on the evacuees of hurricane Frances depending on their respective geographical location. It should be noted that the paths of hurricane Charley and Frances were not identical but some regions of the state were impacted by both. 


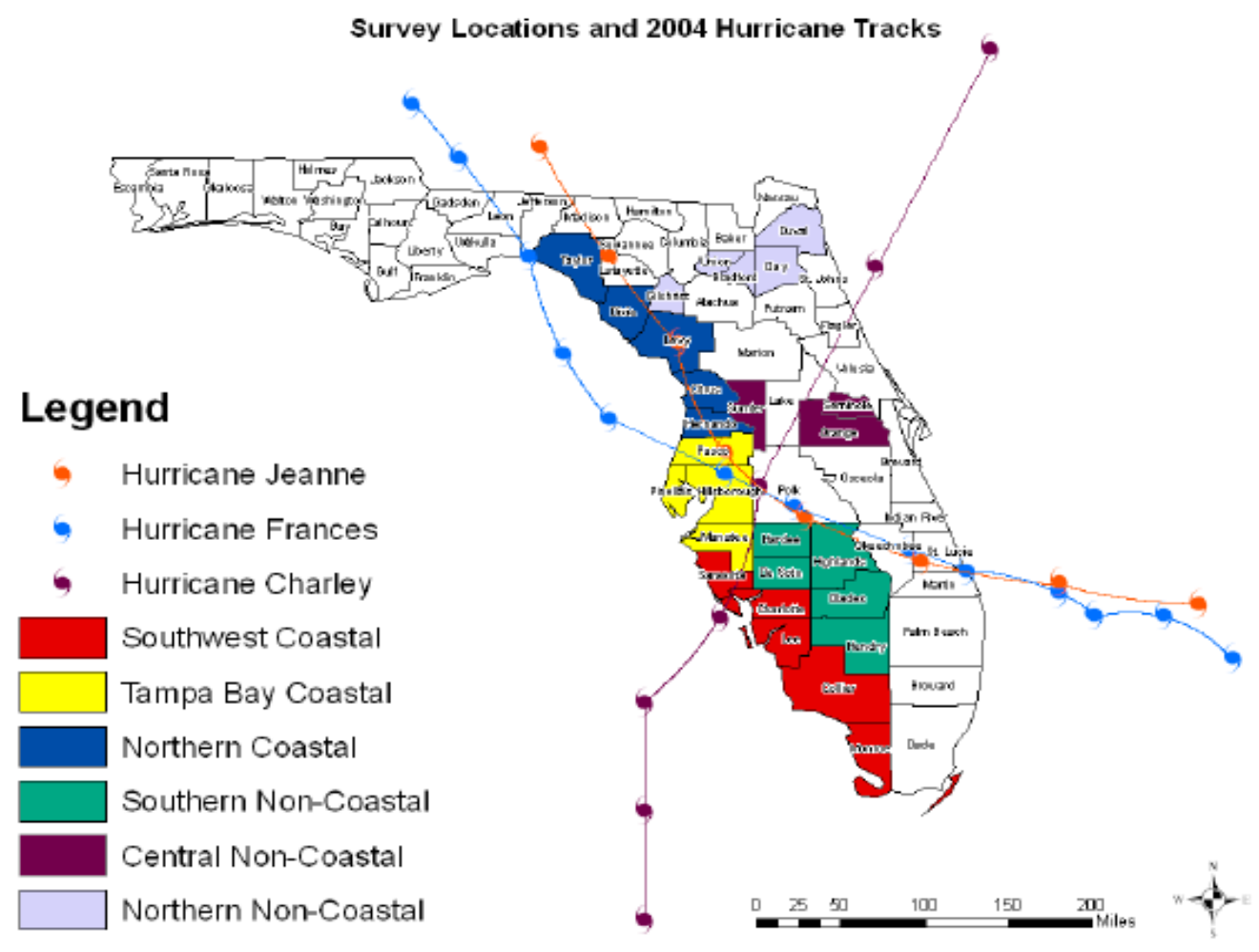

Figure 3-2: Areas affected by Hurricane Charley [USACE, 2000]

Table 3-2: Evacuation participation during hurricane Charley

\begin{tabular}{|l|c|c|c|}
\hline \multicolumn{1}{|c|}{ Region } & $\begin{array}{c}\text { Evacuation Participation } \\
\text { during Charley } \\
\text { (Severity of hurricane } \\
\text { Charley) }\end{array}$ & $\begin{array}{c}\text { Ranking } \\
\text { (Value of } \\
\text { variable } \\
\text { "charley") }\end{array}$ & $\begin{array}{c}\text { Percentage of } \\
\text { Respondents }\end{array}$ \\
\hline Treasure Coast & $0 \%$ & 0 & \multirow{2}{*}{75.10} \\
\cline { 1 - 2 } South East Coastal & $0 \%$ & 0 & 8.16 \\
\hline Central Non-Coastal & $13 \%$ & 1 & 3.56 \\
\hline South West Coastal & $24 \%$ & 2 & 7.95 \\
\hline Southern Non-Coastal & $33 \%$ & 3 & 5.23 \\
\hline Tampa Bay Coastal & $40 \%$ & 4 & \\
\hline
\end{tabular}




\subsection{Solution Approach}

The objective of this study is to understand the impact of a recent hurricane on the individual mobilization times for the evacuees during the subsequent hurricane. It is not a trivial issue because the evacuation delays might be affected by psychological factors as well as by damage caused by the preceding hurricanes to the regional infrastructure along with vehicles/assets belonging to the evacuees. Moreover, the effects of the preceding hurricane may also be confounded by differences in demographics of the regions affected by it. It is crucial to address these issues while modeling the mobilization times for individual evacuees based on their demographics. The straight forward way to assess the impact of the severity of hurricane Charley on mobilization times would be to use "charley" as an independent variable in the ordered probit model for mobilization times characterized by the variable "delay". However, since "charley" is essentially based on different regions of Florida (Table 3-2) it would confound with the differences in regional demographics.

If we model the variable "charley" (dependent variable) based on the demographics of the respondents (independent variables); the error term would include the random error as well as the information on additional characteristics of the respondents that are not included in the model but may relate to the severity of hurricane Charley. Similarly, the error term in the model for mobilization time (with "delay" as the dependent variable and demographic characteristics as independent variables) would contain information about the effects of variables not included in the model. Simultaneous estimation of the two 
models would account for the correlation in the two error terms resulting from common unknown variables affecting both "charley" and mobilization times.

The significant variables in the model for 'charley' contains information about the socioeconomic characteristics of survey respondents (i.e., evacuees of Hurricane Frances) living in different regions of state (with regions categorized by severity of hurricane Charley). The only real conclusion that can be made from this model is about how evacuees of different demographics were distributed between the regions affected differently by hurricane Charley.

Therefore, in this study the variables "charley" and "delay" are simultaneously modeled as a system of equations. It essentially means that the correlation in error terms of the two models is not assumed to be zero as would be the case if the two variables were modeled independently. The modeling procedure provides estimated coefficients for both models. These coefficients, for either model, account for the correlation between the errors. For the evacuees of hurricane Frances sampled in this survey the model for the variable "charley" would identify which of the factors associated with the evacuees can explain the extent to which they were affected by hurricane Charley. The error term, representing the unexplained variance for the model, might contain 'useful' information on psychological effects and variables not reported in the survey. If a similar set of unaccounted variables impacts the mobilization time, i.e., the variable "delay", then the errors might be correlated. Simultaneous estimation of the two variables would improve the coefficient estimates by accounting for the correlations between the unmeasured 
factors. The modeling procedure provides the $p$-value of the statistical test on correlation with the null hypothesis being that the correlation coefficient $\rho=0$. If the correlation in the error terms for the two models is found significant, then the coefficients estimated by the simultaneous estimation would indeed be more efficient than the coefficients resulting from independent estimation of the mobilization time, i.e., the variable "delay".

\subsection{Methodology: Simultaneous Estimation}

Simultaneous estimation of the two equations allows one to account for factors that can not be measured or were accidentally not included in the models. As explained in the previous section, the models for "charley" and "delay" were estimated simultaneously as ordered probit models of the following form using the SAS system (APPENDIX A):

$$
\begin{aligned}
& \text { charley }=\beta_{1} X_{1}+u_{1}+\varepsilon_{1} \\
& \text { delay }=\beta_{2} X_{2}+u_{2}+\varepsilon_{2}
\end{aligned}
$$

Where $\mathrm{u}_{1}$ and $\mathrm{u}_{2}$ are the effects of non-measurable and unaccounted variables (some of them may be common for both models) in the two models, while $\varepsilon_{1}$ and $\varepsilon_{2}$ are the randomly distributed errors in the two models. Equation 3-1 relates "charley" with the demographics of the evacuees of hurricane Frances; while Equation 3-2 relates mobilization time for the evacuees with the independent variables. This formulation allows us to relate the severity of hurricane Charley with the mobilization time of hurricane Frances without confounding the effects of demographical differences between the regions constituting categories of the variable "charley". Equations 3-1 and 3-2 can be 
reduced to equations 3-3 and 3-4 where $k_{1}\left(=\mathrm{u}_{1}+\varepsilon_{1}\right)$ and $k_{2}\left(=\mathrm{u}_{2}+\varepsilon_{2}\right)$ are correlated with correlation coefficient $\rho$ :

charley $^{*}=\beta_{1} X_{1}+k_{1}$

delay $^{*}=\beta_{2} X_{2}+k_{2}$

It should be noted that charley* and delay* are unobserved continuous variables. The ordinal scale dependent variables charley and delay are observed when the respective latent variables charley $^{*}$ and delay ${ }^{*}$ fall in certain ranges. The two independent variables observed as discrete categories (i.e., charley and delay) are specified below:

charley $=\left\{\begin{array}{lll}0 & \text { if } & \text { charley }{ }^{*} \leq 0 \\ 1 & \text { if } & 0<\text { charley }^{*}<\mu_{1} \\ 2 & \text { if } & \mu_{1}<\text { charley }^{*}<\mu_{2} \\ 3 & \text { if } & \mu_{2}<\text { charley }^{*}<\mu_{3} \\ 4 & \text { if } & \mu_{3}<\text { charley }^{*}<\mu_{4}\end{array}\right.$

delay $=\left\{\begin{array}{lll}1 & \text { if } & \text { delay }^{*} \leq 0 \\ 2 & \text { if } & 0<\text { delay }^{*}<\lambda_{1} \\ 3 & \text { if } & \lambda_{1}<\text { delay }^{*}<\lambda_{2} \\ 4 & \text { if } & \lambda_{2}<\text { delay }^{*}<\lambda_{3} \\ 5 & \text { if } & \lambda_{3}<\text { delay }^{*}<\lambda_{4}\end{array}\right.$ 
The likelihood function which is maximized to obtain the model coefficients incorporates the effect of correlation between the error terms. The procedure for estimating the maximum likelihood estimates for parameter coefficients (vectors $\boldsymbol{\beta}_{1}$ and $\boldsymbol{\beta}_{2}$ ) as well as the correlation coefficient $\left(\rho\left(k_{1}, k_{2}\right)\right)$ may be found in Greene (2003). This estimation procedure also estimates the $\lambda$ and $\mu$.

\subsection{Modeling Results}

As explained in the previous section the equations with "charley" and "delay" as the dependent variables are estimated simultaneously in order to incorporate the effects of immeasurable quantities and unaccounted variables. The model coefficients are shown in Table 3-3 with the significant variables highlighted. The most important result shown in the table is the correlation coefficient between errors terms for the two equations. The correlation coefficient was estimated to be -0.32 and was found to be significant with $p$ value $=0.0002$. This indicates that certain common factors that are not included are indeed related to the set of dependent variables. It also validates the proposed approach of modeling the two equations simultaneously.

In Table 3-3 the coefficients for the models for "charley" and "delay" are shown in the form of "charley.X" and delay.X", respectively. The model for variable "charley" enumerates the demographics of evacuees of hurricane Frances as it relates to the severity of hurricane Charley in their region. The variables significant for separating the evacuation levels during hurricane Charley for the evacuees of hurricane Frances were 
"own_rent", "Pets" and "type_struct". These variables explained the impact of hurricane Charley on the evacuees of hurricane Frances.

The coefficient for variable "own_rent" was positive. It indicates that among evacuees of hurricane Frances the people who rented their homes were more likely to be from an area that had a higher evacuation participation rate during hurricane Charley. The variable "Pets" also has a positive coefficient indicating that evacuees of Frances with pets were more likely to be from an area that had a higher evacuation participation rate during hurricane Charley. The levels of variable "type_struct", describing the type of structure in which any respondent was living, were found to be significant compared to people living in manufactured homes and mobile homes and the coefficients associated with every level were negative. This suggested that survey respondents (i.e., evacuees of hurricane Frances) residing in manufactured and/or mobile homes were more likely to belong to areas where the severity of hurricane Charley was higher.

In the model for dependent variable of primary interest, i.e., mobilization time, the independent variables "own_rent", "Num_hh" (Number of people in the household), "Income" and "surge_coast" (defining the intensity of hurricane Frances relative to the risk of surge) were found to be significant.

The binary variable "own_rent" had a negative coefficient in the "delay" model was marginally significant $(\mathrm{p}$-value $=0.1121)$. This indicates that people renting their home have lower mobilization time compared to the home owners. It essentially means that the 
home owners need time to better prepare their houses for potential damages. The renters on the other hand could just secure their belongings without worrying too much about minor damages to the houses.

Households with more people were also found to have higher delays. This was inferred from the positive coefficient associated to the variable "Num_hh". It leads to the inference that with more people in the households the time to prepare for evacuation also increases.

The evacuees with household incomes between $\$ 40000$ and $\$ 79999$ and those with income greater than $\$ 80000$ were found to have significantly different mobilization times compared to evacuees in other income brackets. The coefficients associated to these two income classes were positive, indicating that people in these brackets of income have higher delays for evacuation. It likely relates to the fact that the higher income households are more likely to possess material goods that might need to be protected before evacuation.

The category of nominal variable "surge_coast" representing east coast of Florida had a significant and positive coefficient for the model in delay. It indicated that the evacuees from this region had higher mobilization time. It relates to the higher risk of surge and the necessary preparation that is required because of it. The other two regions of the state (west coast and the central non-coastal region) were not significantly different from each 
other. It indicated that by the time storm reached the west coast of the state it had weakened enough to eliminate the need for the evacuees to prepare for the surge. 
Table 3-3: Parameter Estimates for simultaneous estimation of "charley" and "delay"

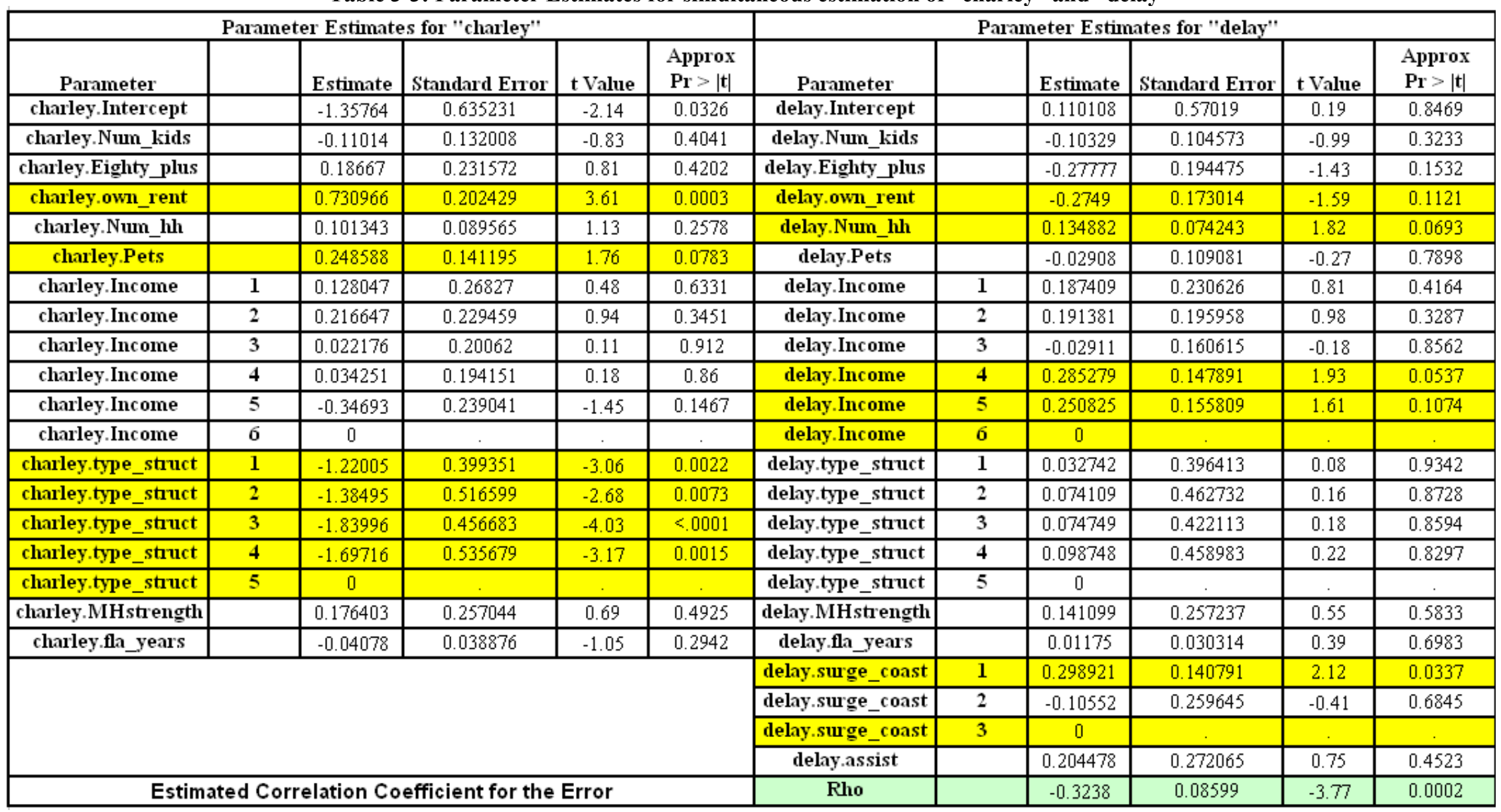


It is interesting to note is that pet ownership and number of kids were not significant in the model for "delay". On surface it seems to contradict the findings from (Vogt (1991) and Heath et. al. (2001)). However, it should be noted that the analysis in (Vogt (1991) and Heath et. al. (2001)) was conducted for an isolated hurricane. In this study we are examining the behavior of evacuees during hurricane Frances which followed hurricane Charley after three weeks. This unexpected result is believed to be due to the special preparations required before evacuation for households with pets and children (such as stocking up on pet and child essentials). During the first hurricane of a season these material need to be stocked up which in turn adds to the mobilization time. During a subsequent hurricane of the season, however, population is generally well stocked with such essentials gathered during previous evacuation. Therefore, presence of pets/children may not significantly affect the mobilization time on evacuation during a subsequent hurricane.

For Home owners on the other hand (compared to renters) most of the preparations need to be re-done during subsequent hurricanes. These preparations include packing, putting wood protection on the windows etc. Once families return home they unpack and settle down to normal household operations. During the subsequent hurricane they once again need to pack up and secure their homes irrespective of the previous hurricane. Hence, their mobilization time during a subsequent hurricane is not significantly different than the first hurricane of the season. It in turn leads to higher mobilization times for home owners remain higher compared to people renting (Hence, an "expected conclusion"). Similarly, for households with more people, people still need to pack irrespective of the previous hurricane of the season. Therefore, the expected conclusion of "more the number of people the higher the 
mobilization time" holds true during despite accounting for effect of hurricane Charley in this study.

This result underscores the need to carefully analyze the differences between evacuee behavior during isolated and subsequent hurricanes.

\subsection{Qualitative Comparison of Response Curve}

To understand the implications of the results of this study on evacuation response lets compare the corresponding cumulative response curves for hurricane Charley (Figure 3-3) and hurricane Frances (Figure 3-4) (USACE, 2000). It should be noted that hurricane Charley made landfall as a Category-4 hurricane while hurricane Frances made landfall as a Category-2 hurricane.

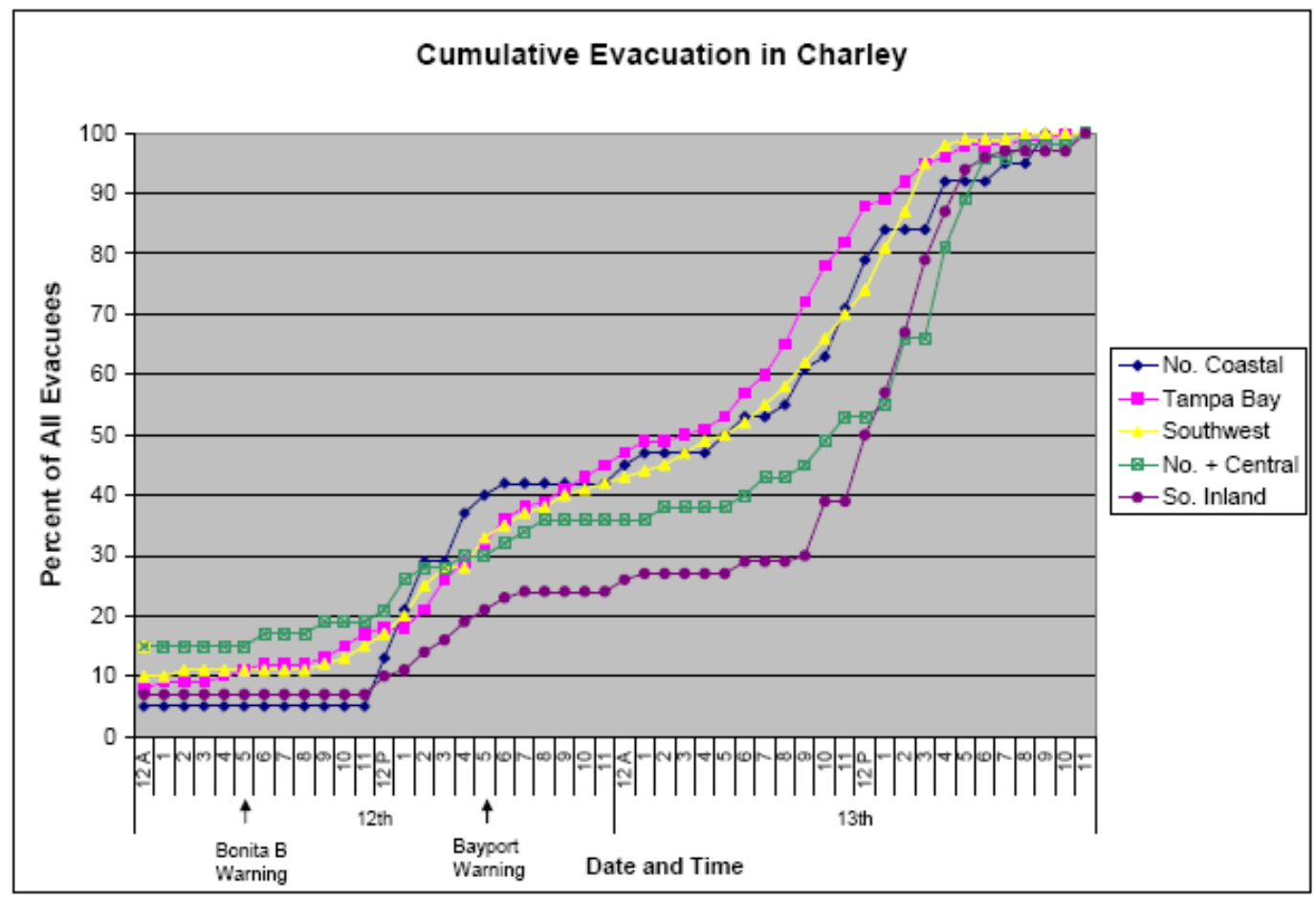

Figure 3-3: Response curve for evacuees belonging to different regions during hurricane Charley (USACE, 2000) 


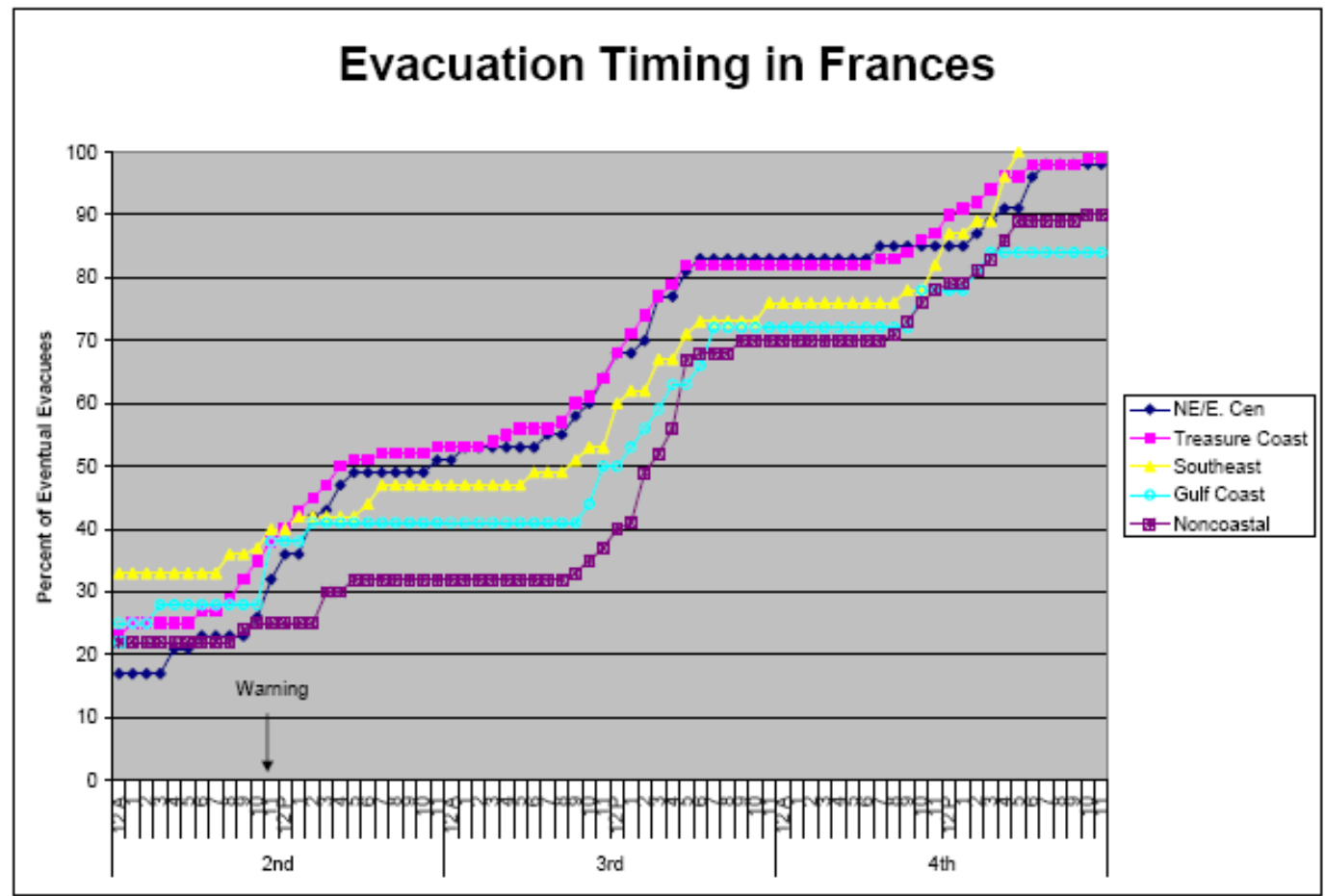

Figure 3-4: Response curve for evacuees belonging to different regions during hurricane Frances (USACE, 2000)

It may be inferred from the response curves that despite being a stronger storm (compared to hurricane Frances) the initial rate of evacuation prior to hurricane Charley was lower compared to hurricane Frances. At the end of the first day the proportion of evacuees who had left before hurricane Charley ranged between $25 \%$ through $45 \%$ (depending upon the region) compared to $32 \%$ through $55 \%$ during hurricane Frances.

One of the factors that explain this increase in the initial evacuation response rate is that with fresh memory of damage done by hurricane Charley more evacuees would try to evacuate in-time. Also, according to the results from this study, the households (with pets, higher number of kids, older people) that would generally (in case of an isolated hurricane) belong to far right of the evacuation response curve due to higher mobilization time would be better prepared during a subsequent hurricane. Hence, 
these households might also evacuate early due to reduced mobilization time. What proportion of the increase in early evacuation response rate is due to reduced mobilization time would be an interesting avenue for future research.

It would also be interesting to examine the effects, if any, related to the change(s) in path(s) of either preceding or subsequent hurricane. For example, present approach does not explicitly account for the change in path of the preceding hurricane (i.e., Charley). Hurricane Charley was expected to make landfall close to Tampa, but eventually moved towards south of Tampa. Hence, population initially believed to be safe was suddenly required to evacuate and vice-versa. It can not be ascertained if this change could have caused a change in the order of the categories of variable "charley".

\subsection{Conclusion}

This analysis evaluated the impact of a preceding hurricane on the mobilization time of the evacuees in a unique way. The mobilization time, sometimes referred to as evacuation delay, is defined as time taken to actually evacuate from the point of time at which the decision to evacuate was made. Mobilization time is an important component of the time of departure for the evacuees which in turn relates to the demand S-curve for a short-notice disaster such as hurricane.

The known and unknown factors associated with evacuation participation during the preceding hurricane (i.e., hurricane Charley) were incorporated into the coefficients of the model estimating mobilization time (during hurricane Frances) by estimating the two models simultaneously. The estimated correlation coefficient between the error 
terms (representing the unexplained variances) for the two constituent models was found to be statistically significant, which validates the approach used in this study.

The most interesting finding in the model for mobilization time (i.e., variable "delay") related to the variables that were found to be insignificant. These variables include pet ownership ("pets"), number of kids ("num_kids"), presence of very old individuals (age > 80 years; variable "eighty_plus") in the household, and need for special assistance ("assist"). Some of these variables have been found to significantly increase mobilization times for the evacuees during an isolated hurricane (Vogt (1991) and Heath et. al. (2001)). It indicates that following a major hurricane the households, which generally take more time to evacuate, make arrangements to better prepare themselves. It likely reduces their mobilization times during a subsequent hurricane.

It would be interesting to find out how the reduced mobilization times relate to the evacuation demand (generally represented by an S-curve) during a subsequent storm. It was observed that initial portion of the S-curve(s) representing cumulative evacuation response was indeed higher for hurricane Frances compared to hurricane Charley. What proportion of this increased evacuation response rate may be attributed to the households with reduced mobilization times remains to be studied. Furthermore, the increase in overall evacuation participation that might result from a preceding hurricane also needs to be considered in planning for subsequent hurricanes. Survey data that combines information on characteristics of evacuees and non-evacuees from a storm affected region would have to be used for these future investigations. 


\section{CHAPTER 4 \\ MICROSCOPIC vs. MESOSCOPIC SIMULATION}

\subsection{Overview}

The time required to run the microscopic simulation to arrive at valid results that can be used with reasonable level of confidence is extremely large. To overcome this drawback, the Cell Transmission Model (CTM) is tested. It is observed that the results were extremely close to the results from the microscopic simulation. The robustness and speed of the CTM are compared with VISSIM.

\subsection{Study Area}

This section studies the contraflow plans for Interstate-4, which is a major evacuation route from Tampa to Orlando. The PBS\&J report (2000) on contraflow operation for Interstate- 4 stated that the contraflow operation is to operate from Tampa to Orange County line. This was used as the guideline for the contraflow operations on I-4. Under free flow conditions, it takes $1.5 \mathrm{hrs}$ to travel from Tampa (I-4 Milepost 1) to the start of Orange County line in Orlando.

Plant City and Lakeland were identified as the other two major demand origins along I-4. I-4 has three lanes in each direction with a free flow speed of $60 \mathrm{mph}$. All lanes were reversed on the opposite directions during contraflow operations. As discussed earlier the free flow speed on the contraflow lanes was assumed to be $55 \mathrm{mph}$. The demands for the regions were estimated based on the number of households from the U.S. census data (2000). It was assumed that each household would evacuate with only one vehicle. It was also assumed that $50 \%$ of evacuees from Tampa and $100 \%$ 
from Plant City and Lakeland would evacuate towards Orlando. The demand from each region is shown in Table 4-1. Vehicles were loaded from the three locations based on fixed input flow rate for a predetermined time. Time period is defined as the demand input period for all the vehicles to be evacuated. The input flow rates and time for the simulation model are also shown in Table 4-1.

Table 4-1: Demand from each location to Orlando on I-4

\begin{tabular}{|l|c|c|c|}
\hline \multicolumn{1}{|c|}{ City } & $\begin{array}{c}\text { Total } \\
\text { Vehicles }\end{array}$ & $\begin{array}{c}\text { Entry Flow } \\
\text { Rate (veh/hr) }\end{array}$ & $\begin{array}{c}\text { Time } \\
\text { period } \\
\text { (Hrs) }\end{array}$ \\
\hline Tampa & 67000 & 3600 & 18.61 \\
\hline Plant City & 12000 & 1000 & 12 \\
\hline Lakeland & 33000 & 2400 & 13.75 \\
\hline
\end{tabular}

The analysis for determining the location of crossovers was conducted using two distinct simulation approaches. The first analysis was done using microscopic simulation software called VISSIM .The second analysis was done using the Cell Transmission Model proposed by Daganzo (1994a, 1994b). The results from both analyses are compared to determine the appropriate locations for the crossover point.

\subsection{Microscopic Simulation Approach}

The traffic network (Figure 4-1) was coded in VISSIM as links and connectors using the aerial photographs as overlay. Three possible crossover locations were available for this study area. The first feasible crossover location was at 4 miles from the start of I-4, the second crossover location (Plant City) was at 46 miles from the first feasible crossover location and the last feasible crossover location (Lakeland) was at 16 miles from the crossover at Plant City. Under free flow conditions, it takes 30 
minutes to travel from crossover at Tampa to Crossover at Plant City and it takes 15 minutes to travel from crossover at Plant City to crossover at Lakeland.

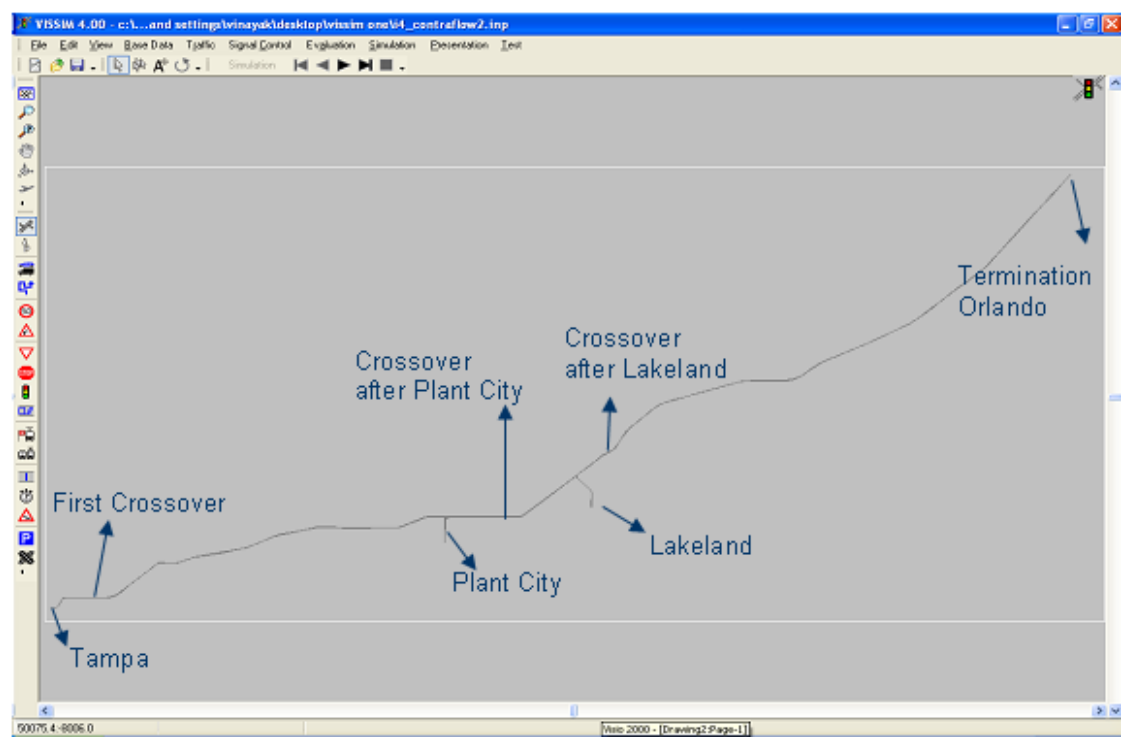

Figure 4-1: The map of Interstate-4 extending from Tampa to Orlando

To determine best crossover locations, four strategies were compared between each other and the Base case. The base case is normal operations with no contraflow lanes. The four strategies are as follows:

- Strategy 1: One crossover after Tampa.

- Strategy 2: Two crossovers - one after Tampa and the other after Plant City.

- Strategy 3: Two crossovers - one after Plant City and the other after Lakeland.

- Strategy 4: Two crossovers - one after Tampa and the other after Lakeland.

The crossover locations are shown in Figure 4-1. For all of the above strategies having contraflow operations, the contraflow lanes were terminated by making the normal lanes exit and then transferring vehicles from the contraflow lanes to the normal lanes. Also all the crossover discussed in the strategies provide access for vehicles on the normal lanes to use the contraflow lanes. This was done in order to 
ensure that there was no congestion due to merging of vehicles at the termination of contraflow lanes. Merging at the termination of contraflow could result in huge backups and reduce the benefits of contraflow operations.

Vehicles were loaded from the three locations based on fixed input flow rate for a predetermined time. The input flow rates and time for the simulation model are shown in Table 4-1. Due to congestion at Lakeland on-ramp, the simulation software was unable to load the vehicles on the on-ramp according to the pre-specified flow during the pre-specified time. This resulted in some vehicles unable to enter the network. Therefore, the number of vehicles unable to enter the network is used a measure of performance of congestion.

Multiple Measures of Effectiveness (MOE) were considered for comparing the base case and the four strategies. The total travel time of all the vehicles, number of vehicles unable to enter the network and the $80 \%, 85 \%, 90 \%$ and $95 \%$ evacuation clearance time were used as MOEs. Loop detectors were placed at the destination link to count the $80 \%, 85 \%, 90 \%$ and $95 \%$ of vehicles exiting the network. VISSIM results for all the scenarios are shown in Table 4-2.

Table 4-2: VISSIM results for base case and four strategies

\begin{tabular}{|c|c|c|c|c|c|c|}
\hline \multirow{2}{*}{$\begin{array}{c}\text { Microscopic } \\
\text { Simulation }\end{array}$} & \multirow{2}{*}{$\begin{array}{c}\text { Total } \\
\text { VehicleTravel } \\
\text { Time } \\
\text { (vehicle-hrs) }\end{array}$} & \multicolumn{4}{|c|}{ Evacuation Clearance Time (hrs) } & \multirow{2}{*}{$\begin{array}{l}\text { Excess } \\
\text { Vehicles at } \\
\text { Lakeland }\end{array}$} \\
\hline & & t80 & t85 & t90 & t95 & \\
\hline Base Case & 134012.9 & 14.77 & 15.65 & 16.99 & 18.39 & 13014 \\
\hline Strategy 1 & 113179.7 & 13.76 & 14.91 & 16.53 & 18.16 & 0 \\
\hline Strategy 2 & 112056.1 & 13.73 & 14.86 & 16.53 & 18.19 & 0 \\
\hline Strategy 3 & 119408.3 & 14.18 & 15.28 & 16.78 & 18.26 & 8840 \\
\hline Strategy 4 & 114301 & 14.1 & 15.22 & 16.74 & 18.27 & 11135 \\
\hline
\end{tabular}


As can be seen in Figure 4-2a, Strategy 1 and Strategy 2 performed the best with all the vehicles being loaded onto the network from all three regions. The base case performed the worst with an average of approximately 13,000 vehicles being unable to enter the network at Lakeland. And also approximately 11,134 and 8,840 vehicles were unable to enter the network for Strategies 4 and 3 respectively. It should be noted that having one crossover (Strategy 1) performed better than Strategies 3 and 4, which had two crossovers.

It is observed that in Strategy 4 more numbers of vehicles were unable to enter the network at Lakeland as compared to Strategy 3. This is because the crossovers provide relief to merge congestion where on-ramps merge with normal lanes. In Strategy 3 there is an upstream crossover at Plant City while in Strategy 4 the upstream crossover is located at Tampa. In Strategy 4 the vehicles entering at Plant City do not get an opportunity to access the contraflow lanes and adds to the flow on the normal lanes as compared to Strategy 3 in which vehicles get distributed to the contraflow lanes. Therefore due to the higher flows on the normal lanes in Strategy 4 the congestion at the merge of the normal lane with the on-ramp at Lakeland is higher, resulting in higher number of vehicles not being able to enter the network at Lakeland.

Another interesting aspect observed was the shockwave effect due to the lower speeds and flow rates at the crossover. This case occurred at the crossover after Lakeland and could be attributed to the shockwave effect of vehicles at the crossover, because a large number of vehicles that could not enter the network at Lakeland in Strategy 3, as compared to Strategy 1 where all vehicles were able to enter the network at Lakeland. 
This difference can not be attributed to the merge congestion since the flows on the normal lanes after Plant City in Strategy 1 and Strategy 3 are the same, and can be only attributed to the shockwave effects due to the downstream crossover at Lakeland. The reason the downstream crossover after Plant City does not result in excess vehicles left at Plant City is due to the low flows entering at Plant City.

Total vehicle travel time is an important measure of effectiveness for an evacuation plan. Lower total vehicle travel time indicates the reduction in time spent by vehicles in the network. Figure $4-2 b$ shows the total vehicle travel time for base case and four strategies. Despite the fact the all the demand was not loaded onto the network, Strategy 2 had the least total vehicle travel time and performed only marginally better than Strategy 1.

Evacuation clearance time is an important measure of effectiveness for evacuation strategies. It is a measure of how quickly people got out of the threat zone. Four different measures of evacuation clearance time were considered, the time required to clear $80 \%, 85 \%, 90 \%$ and $95 \%$ of evacuees that reached the destination. From Figure 4-2c, it can be concluded that Strategy 2 performed the best, but was only marginally better than Strategy 1. Figure 4-2c also shows that as the percentage of evacuees reaching the destination increases from $80 \%$ to $95 \%$, the difference between the clearance times between the strategies decreases. This is observed that as the percentage of evacuees reaching the destination increases the flattening of the dip at Strategy 1 and Strategy 2 increases. This was because as the percentage of evacuees reaching their destination increased there were origins that were totally evacuated, and there were no vehicles entering from these origins that could affect operations. Hence 
the strategies that were helping reduce the congestion were not being effective, since there was no congestion to alleviate in the later stages (where percentage of evacuees reaching their destination increased). For example after $13.75 \mathrm{hrs}$ all vehicles from both Plant City and Lakeland had left their respective origins, after which there were no merge congestions at these two on-ramps. A total of around $86 \%$ vehicles had left their respective origins after $13.75 \mathrm{hrs}$ after which there would be no congestion at these on-ramps, therefore it is no coincidence that significant flattening of the dip was observed from $85 \%$ to $90 \%$. The minute differences still observed in the strategies for evacuation clearance time for $90 \%$ and $95 \%$ evacuees reaching the destination was due to the shockwave effect. 


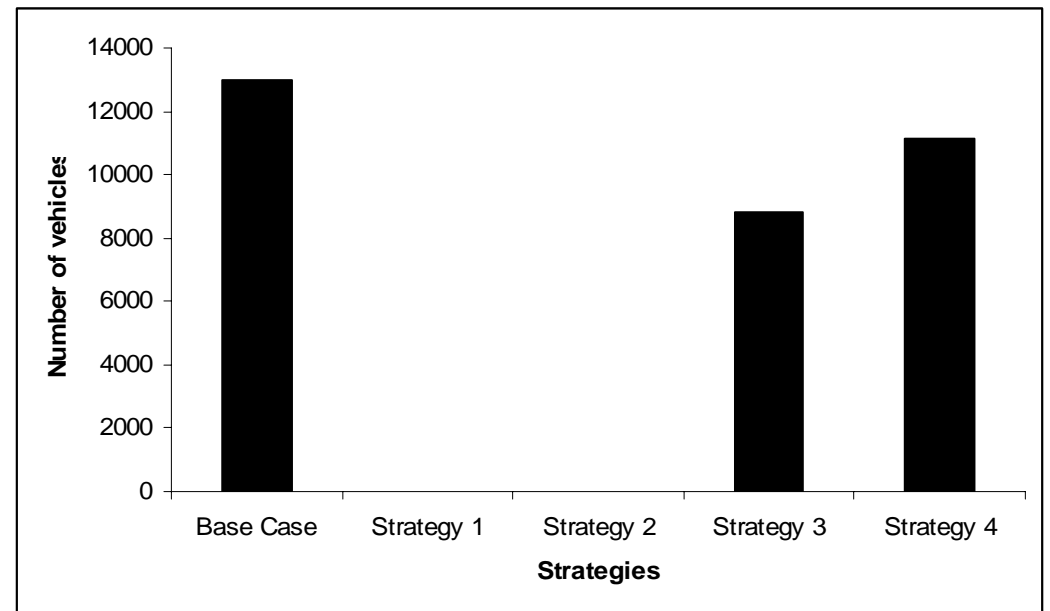

Figure 4-2a: Number of vehicles not dissipated into the network for various strategies

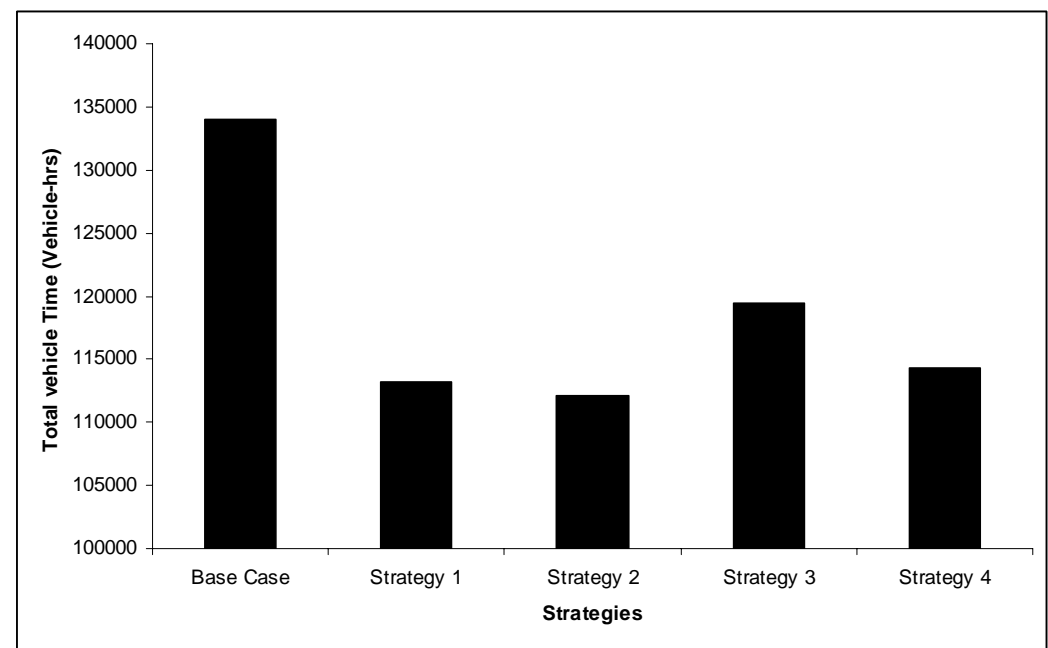

Figure 4-2b: Total vehicle travel time for various strategies

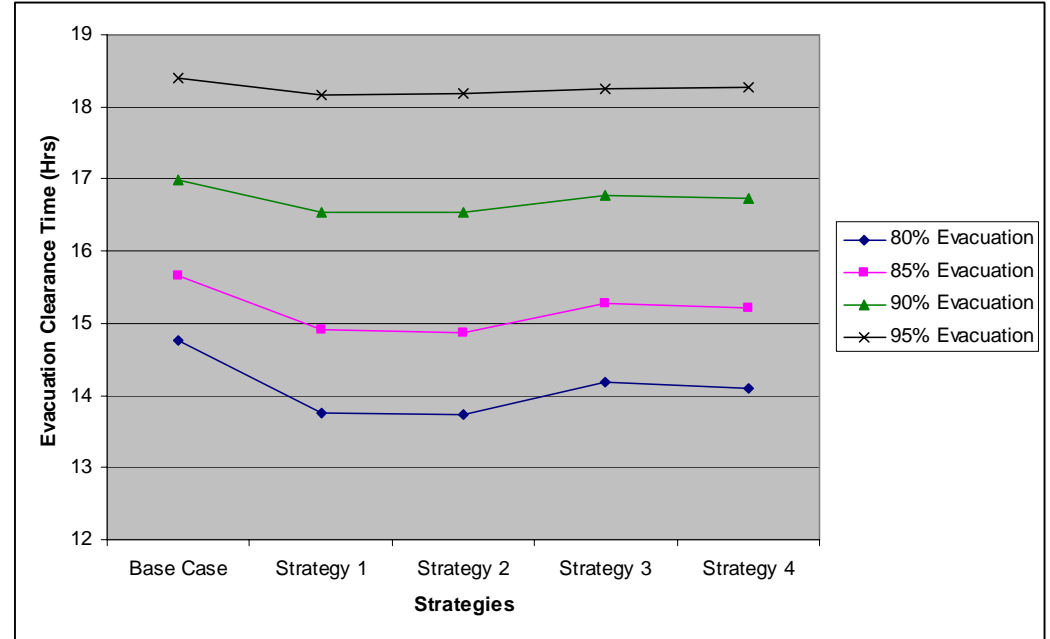

Figure 4-2c: $80 \%, 85 \%, 90 \%$ and $95 \%$ evacuation clearance time for various strategies

Figure 4-2: Plots of measure of effectiveness for various strategies using microscopic simulation (VISSIM) 
Results show that providing one crossover after Tampa and another after Plant City provided for the best evacuation operations, but was only marginally better than having one crossover at Tampa. It was also observed that one crossover after Tampa was better than having 2 crossovers corresponding to strategy 4 and strategy 5 , due to merge and diverge congestion.

It was observed that microscopic simulation analysis for such a simple network structure took extremely large amount of time (4 hours) for a single run on a Pentium 4 with 2 GB RAM, WINDOWS XP machine. This was a huge drawback in using this approach. In case of bottlenecks created by unforeseen events leading to drop in capacity (such as incidents and breakdown of vehicles), it is crucial to make real time decisions to ensure smooth flow of traffic. These decisions might include having to have a new location for a crossover. With approximately 4 hours of time taken to execute one run for a scenario, and at least five runs are required to come to some kind of statistical confidence, and five scenarios to test, a simple number crunching gets us to a conclusion that approximately 100 computer hours is required to decide on a strategy. Real time decisions can not be made with such high computing time. This problem created a need to explore other simulation models. The Cell Transmission Model, a mesoscopic model seemed to hold the solution to this problem. The nice linear relationships between flows and occupancies made it seem to be an ideal candidate for real time simulation. The deterministic nature of this simulation also resulted in doing away with the need for multiple runs to evaluate a strategy. Cell Transmission Model was coded in MATLAB (APPENDIX B). 


\subsection{Calibration of Cell Transmission Model}

The first step was to determine the size of the smallest 'tick' of clock in the CTM. To maintain an acceptable amount of resolution, each tick was chosen to be 30 seconds. Since the free flow speed on the normal lane was $60 \mathrm{mph}$ and on the contraflow lanes was $55 \mathrm{mph}$, the cell length was determined by multiplying the number of seconds in a tick with the free flow speed of the type of lanes. Therefore the cell length of normal lanes is 0.5 miles while that of the contraflow lanes is 0.46 miles.

Since it was assumed that percentage of heavy vehicles was $15 \%$ during the simulation, the average length of vehicles would be greater than the length of a normal vehicle. The length of a normal vehicle is assumed to be $22 \mathrm{ft}$, while that of a heavy vehicle is assumed to be $40 \mathrm{ft}$. To determine the average length of vehicles, a weighted average of the lengths of the two types of vehicles were taken depending upon the percentage of each kind of vehicle on the road. This implies that $0.15 * 40+0.85 * 22=24.7 \mathrm{ft}$ is the average length of vehicles.

The average length of vehicles, length of a cell and number of lanes in a cell were considered to determine the maximum number of vehicles a cell can hold. It was found that a normal cell could hold a maximum of 320 vehicles and the contraflow cell could hold a maximum of 293 vehicles.

The maximum flows in each cell were determined by the number of lanes in each cell. Considering that the maximum flow per lane is 1800 vehicles $/ \mathrm{hr}$, it was calculated that 15 vehicles/tick/lane was the maximum flow through a lane in a cell. The cells at 
the on-ramp from Plant City had 4 lanes and at Lakeland had 5 lanes, which were in agreement to the network designed in VISSIM simulation.

For the crossovers the free flow speeds were lower than the normal lanes and contraflow lanes. Therefore the lengths of the cells for crossover were smaller than the other cells.

The parameter $\delta$ is used to enhance the modeling realism on freeways was assumed to be 1. The reason for this was inspired by the work done by Kalfatas and Peeta (2007), in not requiring to incorporate the value of $\delta$, since for freeway cells $Q_{\max } /\left(N_{\max }-\right.$ $\left.Q_{\max }\right)$ is approximately equal to $1 / 5$ which is close to the accepted value ranging from $1 / 4$ to $1 / 6$. For this modeling $Q_{\max }\left(N_{\max }-Q_{\max }\right)$ is $1 / 6$ for both normal and contraflow lanes.

In order to mimic the same conditions as VISSIM network, excess vehicles at Lakeland were not loaded on the network after the predetermined time period. The number of vehicles left in the source cell at Lakeland was recorded but not loaded onto the network

\subsection{Results of Cell Transmission Model for Interstate-4}

The results of the simulation executed using the cell transmission models are shown in Table 4-3. 
Table 4-3: Cell transmission Model results for each of the five strategies

\begin{tabular}{|c|c|c|c|c|c|c|}
\hline \multirow[b]{2}{*}{ CTM } & \multirow{2}{*}{$\begin{array}{c}\text { Total Travel } \\
\text { Time (hrs) }\end{array}$} & \multicolumn{4}{|c|}{ Evacuation Clearance Time (hrs) } & \multirow{2}{*}{$\begin{array}{c}\text { Excess } \\
\text { Vehicles } \\
\text { at } \\
\text { Lakeland }\end{array}$} \\
\hline & & t80 & t85 & t90 & t95 & \\
\hline Base Case & 129375 & 14.73 & 15.65 & 17.03 & 18.42 & 12440 \\
\hline Strategy 1 & 109583.3 & 13.91 & 15.13 & 16.68 & 18.24 & 0 \\
\hline Strategy 2 & 109466.7 & 13.91 & 15.13 & 16.68 & 18.24 & 0 \\
\hline Strategy 3 & 114191.7 & 14.32 & 15.48 & 16.91 & 18.35 & 8386 \\
\hline Strategy 4 & 113050 & 14.41 & 15.58 & 16.98 & 18.39 & 10819 \\
\hline
\end{tabular}

Graphs are plotted for the various strategies with measures of effectiveness as the number of vehicles that were unable to be loaded onto the network (Figure 4-3a), total vehicle travel time (Figure 4-3b) and the evacuation clearance time for $80 \%, 85 \%$, 90\% and 95\% evacuees (Figure 4-3c). Results from CTM are similar to the results observed in VISSIM simulation. Strategy 2 was found to have the least total vehicle travel time, but was only marginally better than Strategy 1. It was also found that the evacuation clearance time for $80 \%, 85 \%, 90 \%$ and $95 \%$ evacuees was same for Strategy 1 and Strategy 2. This was because the difference between the clearance times for Strategy 1 and Strategy 2 from the VISSIM simulation results is less than 1\%. Therefore CTM could not predict the slight difference in clearance times. 


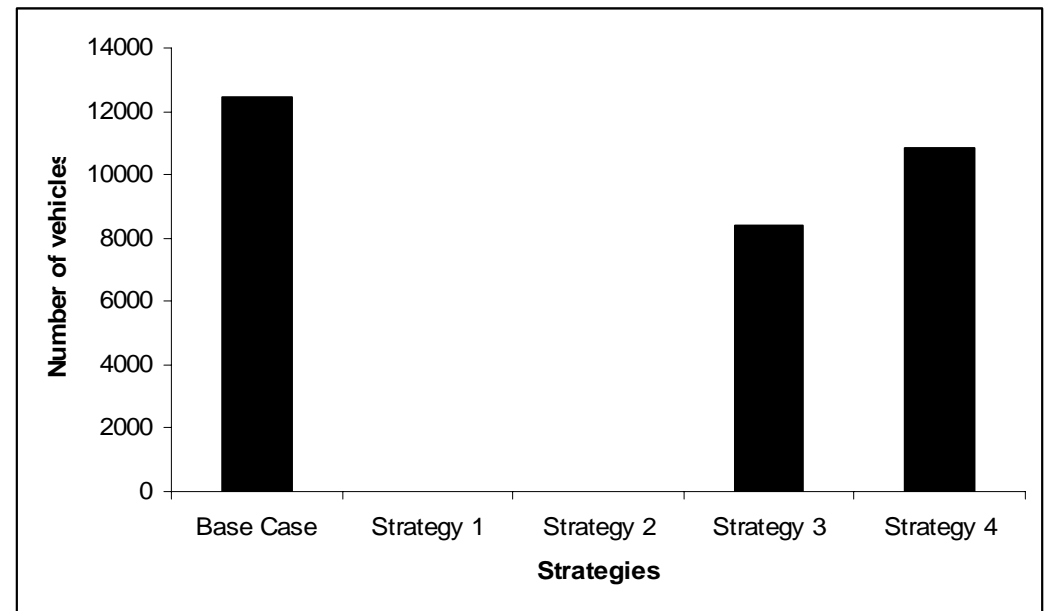

Figure 4-3a: Number of vehicles not dissipated into the network for various strategies

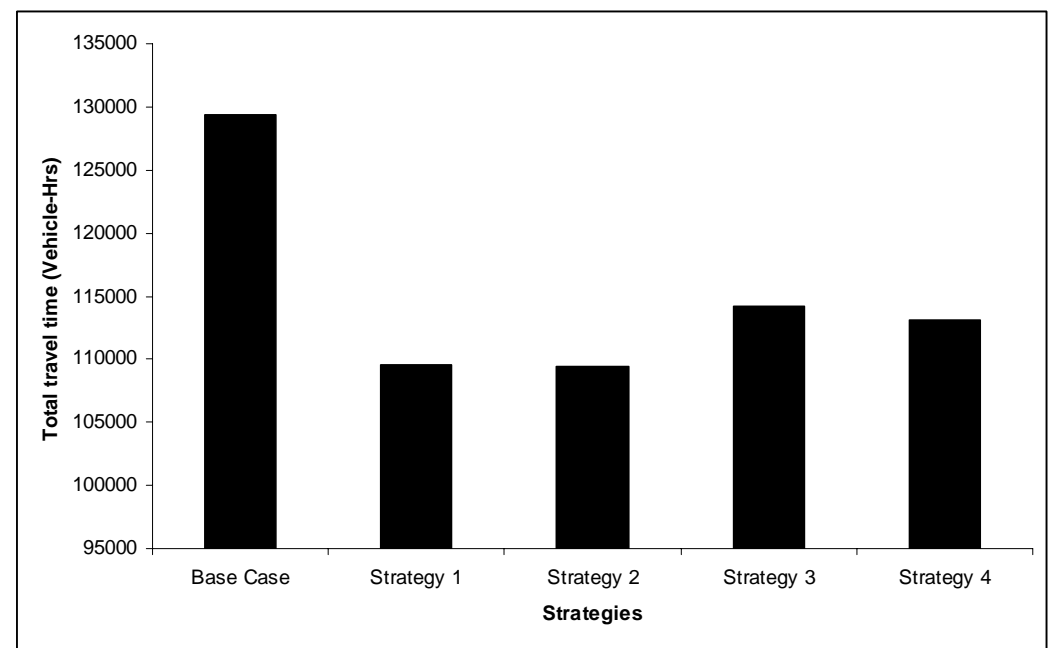

Figure 4-3b: Total vehicle travel time for various strategies

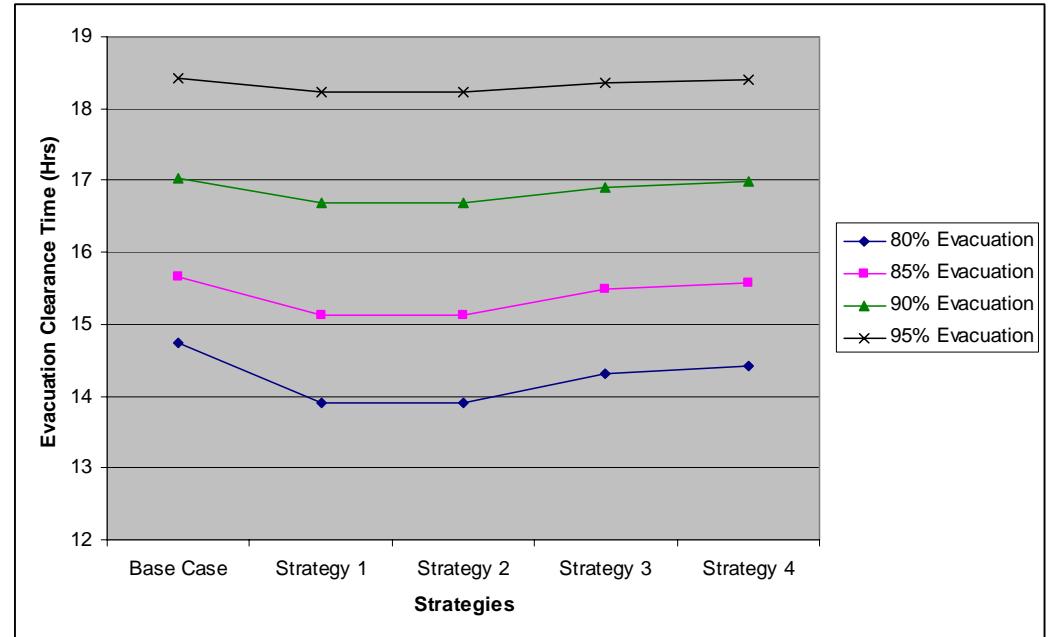

Figure 4-3c: $80 \%, 85 \%, 90 \%$ and $95 \%$ evacuation clearance time for various strategies Figure 4-3: Plots of measure of effectiveness for various strategies using mesoscopic simulation (Cell Transmission Model) 


\subsection{Comparison of Cell Transmission Model with VISSIM}

A comparison of the Cell Transmission Model with VISSIM shows that the errors in estimation of the measure of effectiveness using CTM and VISSIM are much less than or close to $5 \%$ (Table4-4). This indicates that results from CTM are comparable to VISSIM results.

Table 4-4: Percentage errors between estimates of Microscopic Simulation (VISSIM) and Mesoscopic simulation (Cell Transmission Model)

\begin{tabular}{|c|c|c|c|c|c|c|}
\hline Errors & $\begin{array}{c}\text { Total Travel } \\
\text { Time }\end{array}$ & $\mathbf{t 8 0}$ & $\mathbf{t 8 5}$ & $\mathbf{t 9 0}$ & $\mathbf{t 9 5}$ & $\begin{array}{c}\text { Excess } \\
\text { Vehicles at } \\
\text { Lakeland }\end{array}$ \\
\hline Base Case & -3.46 & -0.26 & 0.03 & 0.23 & 0.16 & -4.41 \\
\hline Strategy 1 & -3.18 & 1.05 & 1.49 & 0.93 & 0.47 & 0 \\
\hline Strategy 2 & -2.31 & 1.27 & 1.81 & 0.96 & 0.3 & 0 \\
\hline Strategy 3 & -4.37 & 0.99 & 1.27 & 0.78 & 0.48 & -5.14 \\
\hline Strategy 4 & -1.09 & 2.19 & 2.41 & 1.48 & 0.68 & -2.83 \\
\hline
\end{tabular}

It was observed that the computing time taken to run the 5 scenarios in CTM took 7.5 minutes as compared to 100 hours in VISSIM. This indicates that CTM is an ideal tool that can be used for a real time decision support system to determine dynamic crossovers due to an unforeseen incident.

It was also observed that VISSIM did not load the vehicles if they could not enter the network during a given time frame. This drawback can be easily handled in CTM, so that a more reliable estimate of the evacuation clearance time and total vehicle travel time can be estimated. The results for which all the vehicles are loaded onto the network are shown in Table 4-5. It is clearly seen that the 2.6 hours are saved in clearing $80 \%$ of the evacuees by using strategy 1 . It was also observed that the total vehicle travel time for Strategy 1 was reduced significantly by $16 \%$ from the base case. The plots for measure of effectiveness for various strategies using CTM are shown in Figure 4-4. 
Table 4-5: Cell transmission Model results for each of the five strategies with dissipation of all vehicles into the network

\begin{tabular}{|c|c|c|c|c|c|c|}
\hline \multirow[b]{2}{*}{ CTM } & \multirow{2}{*}{$\begin{array}{c}\text { Total Travel } \\
\text { Time (hrs) }\end{array}$} & \multicolumn{4}{|c|}{ Evacuation Clearance Time (Hrs) } & \multirow{2}{*}{$\begin{array}{c}\text { Excess } \\
\text { Vehicles } \\
\text { at } \\
\text { Lakeland } \\
\end{array}$} \\
\hline & & $\mathbf{t 8 0}$ & t85 & t90 & t95 & \\
\hline Base Case & 140825.00 & 16.46 & 17.43 & 18.4 & 19.38 & 0 \\
\hline Strategy 1 & 109583.33 & 13.91 & 15.13 & 16.68 & 18.24 & 0 \\
\hline Strategy 2 & 109466.67 & 13.91 & 15.13 & 16.68 & 18.24 & 0 \\
\hline Strategy 3 & 122775.00 & 15.47 & 16.43 & 17.39 & 18.35 & 0 \\
\hline Strategy 4 & 123816.67 & 15.85 & 16.78 & 17.72 & 18.65 & 0 \\
\hline
\end{tabular}

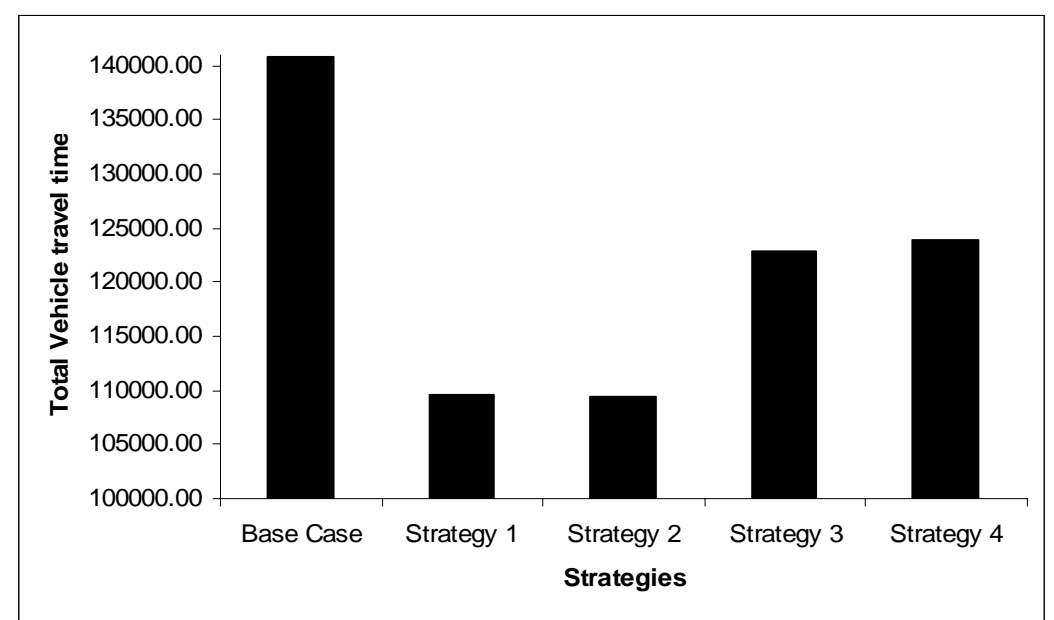

Figure 4-4a: Total vehicle travel time for various strategies

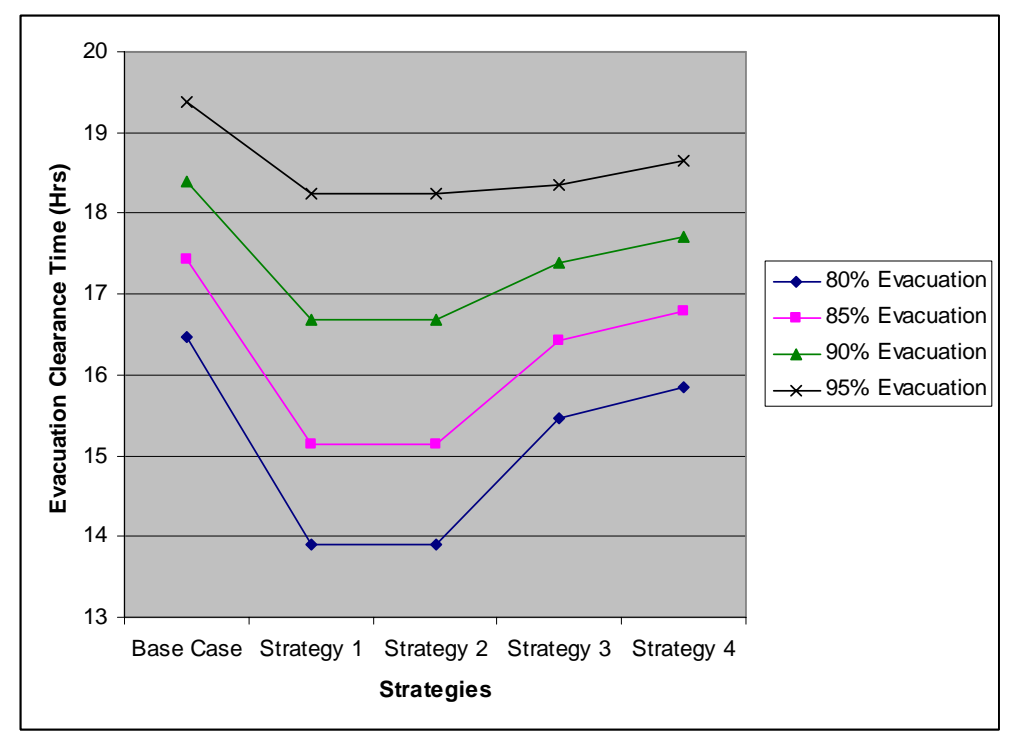

Figure 4-4b: $80 \%, 85 \%, 90 \%$ and $95 \%$ evacuation clearance time for various strategies

Figure 4-4: Plots of measure of effectiveness for various strategies using mesoscopic simulation (Cell Transmission Model) allowing all vehicles to dissipate into the network 


\subsection{Conclusion}

This chapter compares two levels of simulation mesoscopic and microscopic represented by CTM and VISSIM respectively. The two simulations were also used to determine the best crossover locations for the evacuation routes Interstate- 4 between Tampa to Orlando.

It was interesting to find that providing one crossover after Tampa and another after Plant City provided for the best evacuation operations, but was only marginally better than having one crossover at Tampa. So considering the cost and manpower needed for providing a crossover, having one crossover after Tampa was found to be a logical choice than providing two crossovers. It was also observed that having two crossovers, with one of those crossovers after Lakeland performed worse than having just one crossover. This showed that the idea "more the number of crossovers the better!" is wrong and the location and number of crossovers needed should be considered.

From the results observed, there are two main aspects that need to be addressed while contraflow planning for a general corridor. The first is that contraflow operations reduce the number of vehicles flowing on the normal lanes and therefore reducing the merge congestion at downstream locations where vehicles from the on-ramp merge with the normal lanes. This phenomenon was observed in the fact that a higher number of vehicles that were unable to enter the network at Lakeland in Strategy 4 as compared to Strategy 3. The second aspect that should be kept in mind is the shockwave effect due to lower speeds and flow rates at the crossover. This case occurred at the crossover after Lakeland and could be attributed to the shockwave 
effect of vehicles at the crossover, because a large number of vehicles that could not enter the network at Lakeland in Strategy 3, as compared to Strategy 1 where all vehicles were able to enter the network at Lakeland.

It was also found that the CTM predicted the MOEs as well as VISSIM with approximately $5 \%$ error in the results between CTM and VISSIM. With faster computing time, CTM was ideal for real time decision support system, which will be able to determine dynamic crossovers in event of bottlenecks caused by incidents or vehicle breakdowns. The fast computation and realistic representation of traffic flow makes it suitable for modeling evacuation routes and quickly verifying the effectiveness of plans. CTM is also able to dissipate all vehicles into the network allowing for a more holistic comparison between various strategies. With a need for a more flexible evacuation plans, CTM's capability makes it an ideal tool for testing various scenarios. 


\section{CHAPTER 5 \\ SCHEDULING EVACUATION ORDERS}

\subsection{Overview}

Issuing of evacuation orders have been found to accelerate the rate at which people evacuate. Inefficient issuance of orders would result in high rate of loading from all origins at all time, leading to avoidable congestion, and putting people most vulnerable to the disaster at high risk. An example of this was, during hurricane Rita, evacuees from coastal Galveston were stranded for hours on the evacuation routes due to evacuating traffic from downstream inland Houston

Therefore, scheduling of evacuation orders is an important strategy to ensure safe and quick movement of people from harms way. This chapter proposes a new robust optimization model to identify the time at which evacuation orders should be given at different locations.

\subsection{Study Area}

This section describes a network showing Tampa, Plant City Brandon, Lakeland and Orlando and the major evacuation routes to Orlando. Under free flow conditions, it takes $1.5 \mathrm{hrs}$ to travel from Tampa (I-4 Milepost 1) to the start of Orange County line in Orlando. The network is shown in Figure 5-1. The time slices for CTM is taken to be 6 minutes. Since the contraflow lanes and normal lanes terminate at Orlando, one destination (Orlando) is the super destination. 


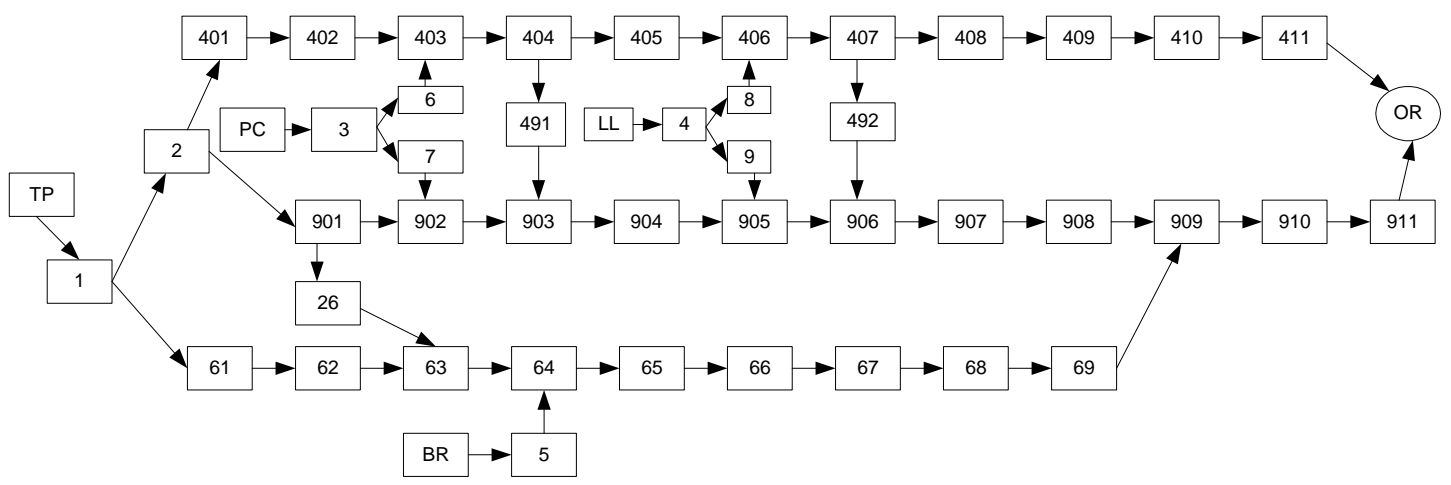

Figure 5-1: Cell transmission Model for the Network.

Plant City, Brandon and Lakeland were identified as the other three major demand origins. The demands from each region are shown in Table 5-1. Vehicles were loaded from the four locations based on ' $S$ ' curves. The demand curves are discussed in the following section.

\subsection{Demand}

To approximate the ' $\mathrm{S}$ ' curve for the demand an exponential demand was assumed with the main variables being Time of Day and time of order. The probability distribution was assumed to be:

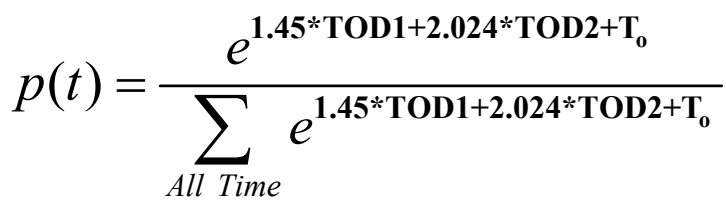

where,

$T_{o}= \begin{cases}0 & \text { for } t<\text { Time of Order } \\ 1 & \text { for } t \geq \text { Time of Order }\end{cases}$

According to $\mathrm{Fu}$ (2004) study the variables time of day is found to be a significant factor in the evacuation response curve. The evacuation rate is higher during the 
afternoon as compared to early morning and night, and early morning evacuation is higher as compared to the night. He also observed that after the evacuation order is given out, the probability of evacuating increases significantly. The model described in equation 5-1 has these properties. The true values for these particular regions were not available, therefore needed to be assumed, but for the purpose of demonstration of the optimization model, this assumption is sufficient.

The actual structure of the demand model is not crucial. The demand profile needs to be available for every possible time an evacuation order would be given. The demand distribution could be generated from any general models.(Sequential Logit Model, Tweedie's model, piecewise exponential models).. It was assumed that the decision to give an order to evacuate will be evaluated every 6 hours.

The cumulative probability curves (Figure 5-2) were generated for orders given at time $\mathrm{t}$ is equal to 0 hours, 6 hours and 12 hours. 


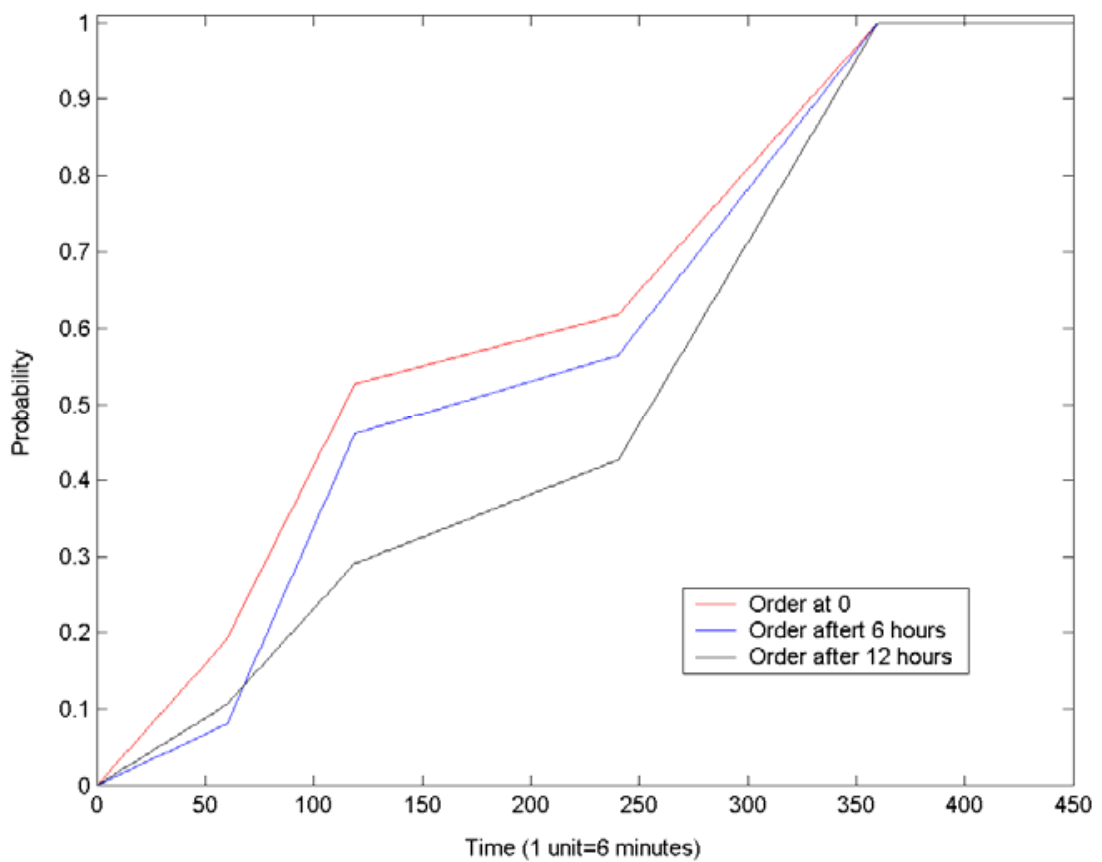

Figure 5-2: Cumulative probability of number of people that have left for orders given at different times

The demand for each of the regions was assumed based on number of households from the census data (Table 5-1)

Table 5-1: Total vehicular demand in each city.

\begin{tabular}{|c|c|}
\hline Cities & $\begin{array}{c}\text { Total Demand } \\
\text { (Vehicles) }\end{array}$ \\
\hline Tampa & 67000 \\
\hline Plant City & 11800 \\
\hline Lakeland & 25000 \\
\hline Brandon & 39000 \\
\hline
\end{tabular}

Utilizing the total demand in Table 5-1 and the probability distribution shown in

Figure 5-2, the demand flow rates were determined and are shown in Figure 5-3. 


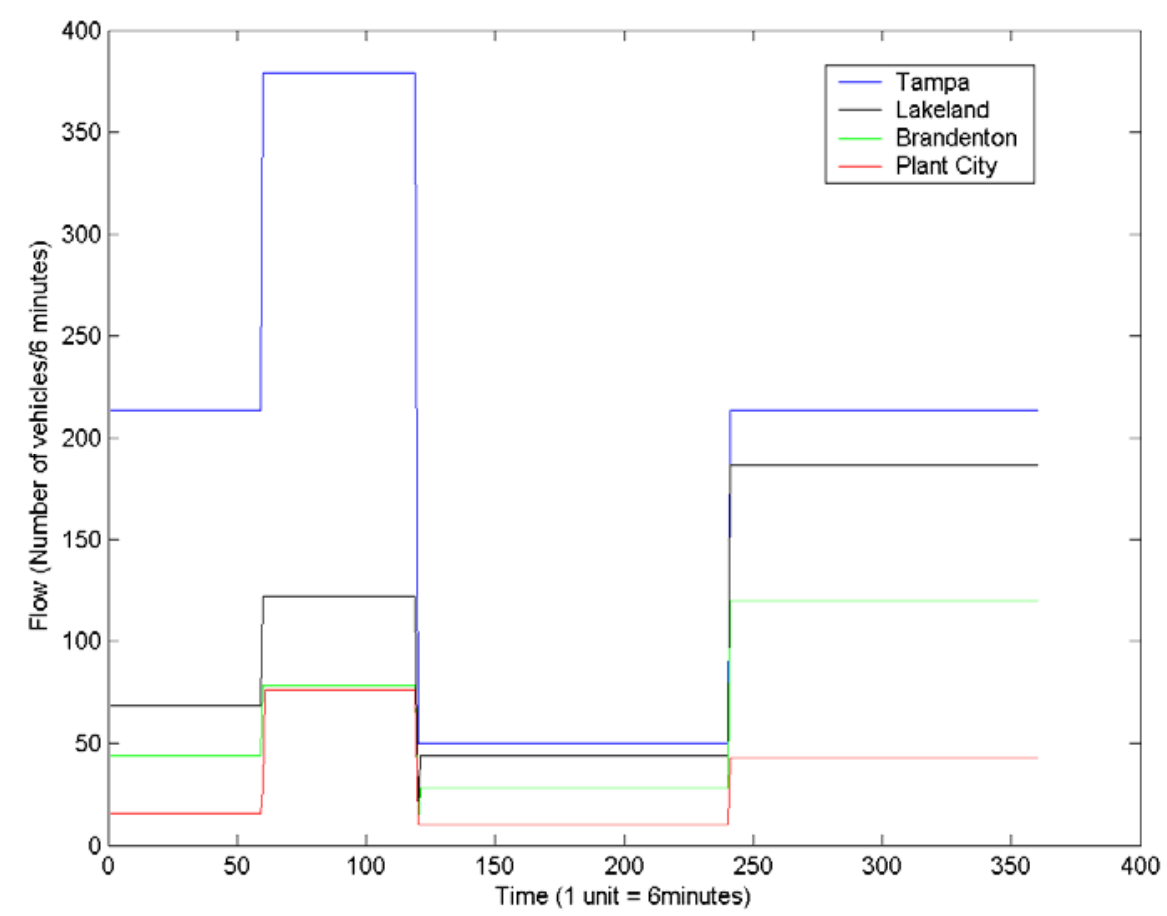

Figure 5-3: Demand Flow profile from each of the cities

\subsection{Optimization Model}

This section describes an optimization model to determine optimal locations of crossover constrained by the maximum number of crossovers allowed (due to constraints of manpower and logistics). This model is dynamic in nature, since the solution could involve having certain crossovers open during certain periods of time, depending on demand and traffic conditions (such as incidents).

The details of the models are as follows:

$C \quad$ is the set of cells. It is the unions of ordinary cells $\left(C_{O}\right)$, merge cells $\left(C_{M}\right)$, diverge cells $\left(C_{D}\right)$, source cell $\left(C_{R}\right)$ and sink cells $\left(C_{S}\right)$.

$H \quad$ is the set of links between cells. It is the union of source links $\left(H_{R}=\{(i, j) \mid j\right.$ $\left.\left.\in C_{R}\right\}\right)$, sink links $\left(H_{S}=\left\{(i, j) \mid j \in C_{S}\right\}\right)$, ordinary links $\left(H_{O}=\left\{(i, j) \mid i \in\left(C_{O} \mathrm{U} C_{M}\right)\right.\right.$, 
$\left.\left.j \in\left(C_{O} \mathrm{U} C_{D}\right)\right\}\right)$, merge links $\left(H_{M}=\left\{(i, j) \mid i \in C_{O}, j \in C_{M}\right\}\right)$, and diverge links $\left(H_{D}=\left\{(i, j) \mid i \in C_{D}, j \in C_{O}\right\}\right)$.

$x_{i}^{t} \quad$ is the number of vehicles in cell $i$ at time $t$.

$Q_{i}^{t} \quad$ is the maximum flow in cell $i$ at time $t$.

$N_{i}^{t} \quad$ the maximum number of vehicles that can be accommodated in cell $i$ at time $t$.

$d_{i}^{t} \quad$ Demand from source $i$ at time $t$.

$D_{i}^{t, o} \quad$ Demand from source $i$ at time $t$, due to an evacuation order $o$.

$y_{i j}^{t} \quad$ is the number of vehicles transferred from cell $i$ to cell $j$ at time $t$

$T \quad$ is the total time of analysis.

$T_{O} \quad$ is the set of all times when order can be given.

$\Gamma(i)$ is the function defining the cells downstream of cell $i$, the inverse of $\Gamma$ defines all the cells upstream of cell $i$.

$\operatorname{Min} \quad Z=\sum_{i \in C \backslash C_{S}} \sum_{t \in T} x_{i}^{t} \Delta t$

Subject to:

$$
\begin{array}{ll}
x_{i}^{t}=x_{i}^{t-1}+\sum_{k \in \Gamma^{-1}(i)} y_{k i}^{t-1}-\sum_{k \in \Gamma(i)} y_{i k}^{t-1} & \forall i \in C \backslash\left(C_{R} \cup C_{S}\right), \forall t \in T \\
x_{i}^{t}=x_{i}^{t-1}+d_{i}^{t}-\sum_{k \in \Gamma(i)} y_{i k}^{t-1} & \forall i \in C_{R}, \forall t \in T \\
x_{i}^{t}=x_{i}^{t-1}+\sum_{k \in \Gamma^{-1}(i)} y_{k i}^{t-1} & \forall i \in C_{S}, \forall t \in T \\
\sum_{k \in \Gamma(i)} y_{i k}^{t} \leq x_{i}^{t} & \forall i \in C \backslash C_{S}, \forall t \in T
\end{array}
$$




$$
\begin{array}{ll}
\sum_{k \in \Gamma^{-1}(i)} y_{k i}^{t} \leq Q_{i}^{t} & \forall i \in C \backslash C_{R}, \forall t \in T \\
\sum_{k \in \Gamma(i)} y_{i k}^{t} \leq Q_{k}^{t} & \forall i \in C \backslash C_{S}, \forall t \in T \\
\sum_{i \in \Gamma^{-1}(k)} y_{i k}^{t} \leq N_{k}^{t}-x_{k}^{t} & \forall i \in C \backslash C_{R}, \forall t \in T \\
d_{i}^{t} \leq \sum_{o \in T_{O}} \delta_{i}^{o} D_{i}^{t, o} & \forall i \in C_{R}, \forall t \in T \\
\sum_{o \in T_{O}} \delta_{i}^{o} \leq 1 & \forall i \in C_{R}, \forall t \in T \\
x_{i}^{t} \geq 0 & \forall i \in C \\
y_{i k}^{t} \geq 0 & \forall(i, j) \in H \\
0 \leq \delta_{i}^{t} \leq 1 & \delta_{i}^{t} \text { is Integer } \\
x_{i}^{0}=\bar{x}_{i} & \forall i \in C \\
y_{i j}^{0}=\bar{x}_{i j} & \forall(i, j) \in H
\end{array}
$$

Equation 5-2 in the model is the total system time. The optimization model's objective is to minimize the total system time.

Equations 5-3 represents the flow conservation constraint for the merge, diverge and ordinary cells. Equation 5-4 and 5-5, represent the flow conservation constraints for the source and sink cells respectively.

Equations 5-6 and 5-7 are constraints defining the sending ability of the cell to the next cell. Equations 5-8 and 5-9 are constraints defining the ability to receive vehicles from earlier cells. Equations 5-6, 5-9, 5-8 and 5-9 ensure that the number of vehicles 
moving from one cell to the next cell needs to be less than the sending ability of cells upstream and the receiving ability of cells downstream.

Equation 5-10 introduces a binary variable $\delta_{i}^{o}$ in the constraint. The variable ensures that the demand would be loaded according to the demand generated with evacuation order given at time ' $O$ '. Equation 5-11 ensure that the order is given only once at an origin. As part of the input data the demand profile for each possible time of evacuation order needs to be provided, the optimization selects the optimal demand profile for a region, which is dependent on the evacuation order (variable to be optimized).

Equations 5-12 and 5-13 are the non negative constraints. Equation 5-14 states that $\delta_{i}$ is a binary variable. Equations 5-15 and 5-16 are the initial conditions.

The model was modeled using MATHPROG and LPSOLVE solver (APPENDIX C)

\subsection{Results}

Based on the demand model proposed, the demand was generated for orders given every 6 hours till 24 hours into the evacuation. The optimization model discussed in the earlier section (Methodology) was utilized to determine the optimal schedule of orders to be given for the different cities.

The results of the model indicated that Tampa should be given an order to evacuate immediately, the after 6 hours Plant City should be asked to evacuate, finally after 12 
hours Lakeland and Brandon should be ordered to evacuate. The time of orders are shown in Table 5-2

Table 5-2: Time of Evacuation Orders
\begin{tabular}{|l|c|}
\hline Cities & $\begin{array}{c}\text { Time of Order } \\
\text { (Hours) }\end{array}$ \\
\hline Tampa & 0 \\
\hline Plant City & 6 \\
\hline Lakeland & 12 \\
\hline Brandon & 12 \\
\hline
\end{tabular}

The optimization model was also run with orders given for all the cities at the same time $(\mathrm{t}=0)$. These results are shown in Table 5-3.

Table 5-3: Comparison of Total vehicle hours between simultaneous loading vs. optimal staging

\begin{tabular}{|c|c|c|c|}
\hline $\begin{array}{c}\text { Do-Nothing } \\
\text { (Veh-hrs) }\end{array}$ & $\begin{array}{c}\text { Optimal Staging } \\
\text { (Veh-hrs) }\end{array}$ & $\begin{array}{c}\text { Benefit } \\
\text { (Veh-hrs) }\end{array}$ & $\begin{array}{c}\text { Percentage Reduction } \\
\text { (Veh-hrs) }\end{array}$ \\
\hline 191,914 & 170,559 & 21,355 & $11 \%$ \\
\hline
\end{tabular}

It was observed that optimally scheduling reduced the total system time by around 21,355 vehicle hours, a reduction of $11 \%$. A comparison is shown in the graph in Figure 5-4. 


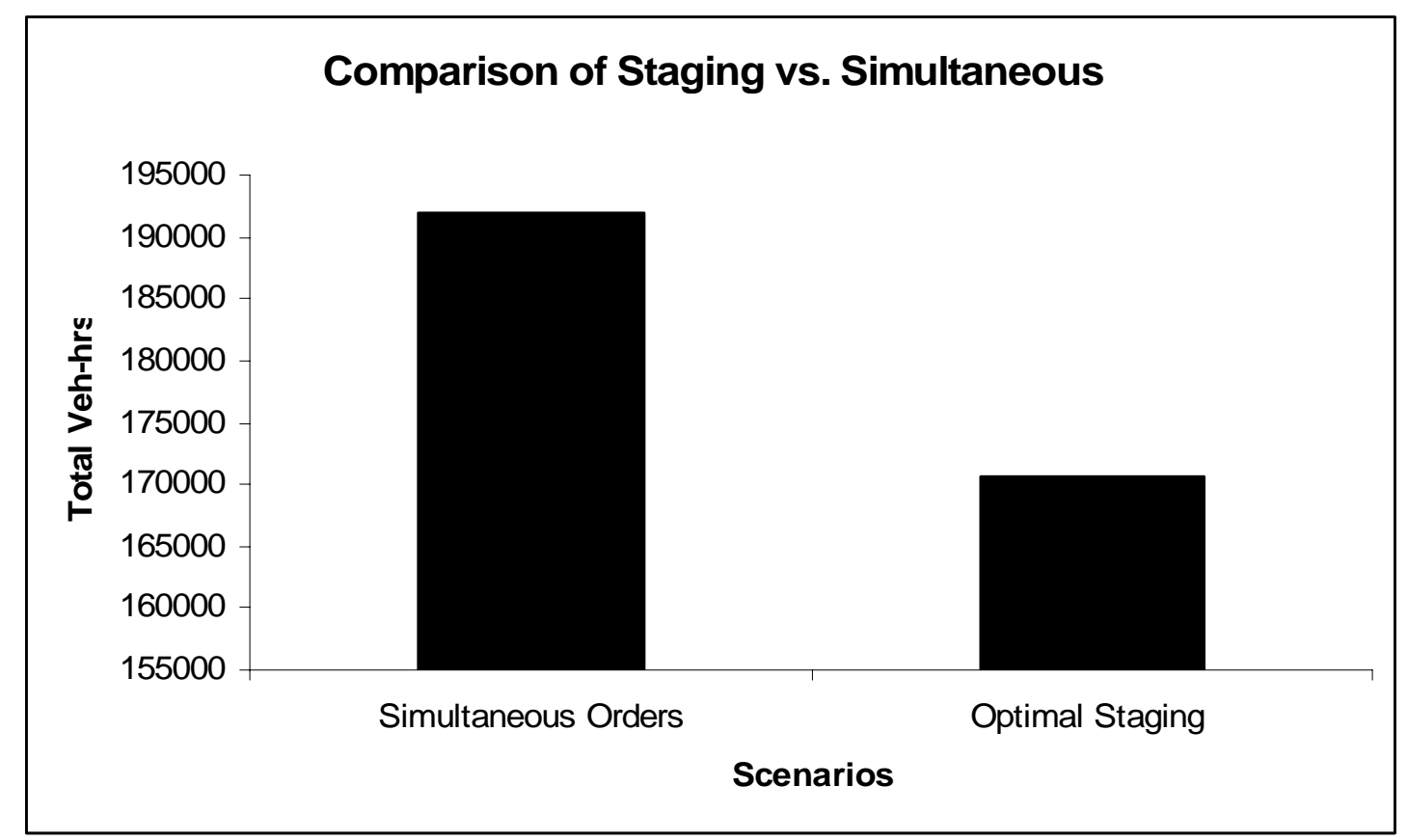

Figure 5-4: Comparison between Staged Evacuation Order and Simultaneous Order

\subsection{Conclusions}

The optimization model proposed can be used to determine optimal schedule of evacuation orders, based on the demand profile of each region. For the numerical problem the scheduled evacuation order provided an improvement of $11 \%$ in total vehicle hours

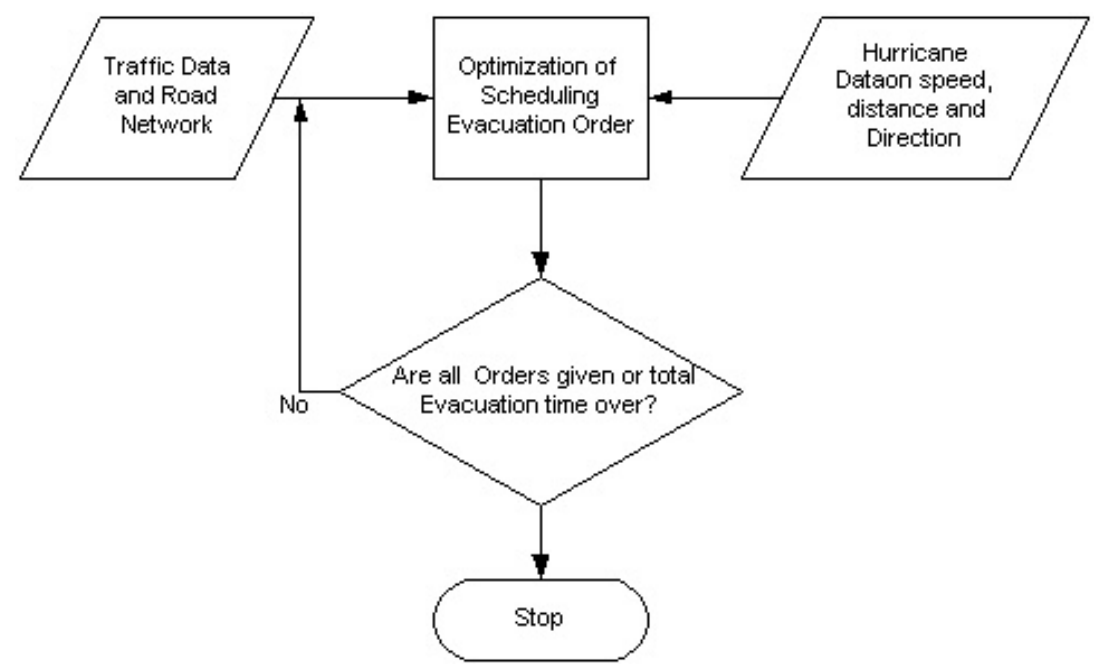

Figure 5-5: Real Time Framework 
These schedules can be reevaluated before every time period in order to incorporate the effect of changes in hurricane path and speed. The frame work is shown in Figure $5-5$.

In the real time framework (Figure 5-5, real time data regarding the traffic state and hurricane characteristics and run the optimization model to determine the optimal schedule for evacuation orders. Before every evacuation order to be given the optimization model is run and time to give the order is re-evaluated.

Such a real time system will prove useful to the evacuation management officers to make decisions regarding, when to order evacuation. It will also help make the evacuation operation efficient. 


\section{CHAPTER 6 \\ CONTRAFLOW CROSSOVER STRATEGIES}

\subsection{Overview}

Better utilization of available road network is critical to improve evacuation operation during a disaster. Contraflow operations help increase capacity of the available network, by reversing the direction of inbound lanes to outbound lanes. This helps improve outflow from a region threatened by disaster. One of the major issues associated with contraflow operations is determining locations for access to contraflow lanes from the normal lanes. These accesses are also referred to as crossovers.

One classical problem associated with contraflow operations is the decision regarding location of crossovers. The cell transmission model is utilized to construct an optimization model that will assist decision makers to determine locations for contraflow crossovers that will optimize the evacuation operation.

In the event of incidents (crash, vehicles running out of fuel) resulting in drop of capacity, a model to determine dynamic crossover locations is also proposed.

\subsection{Study Area}

Interstate-4 is a major evacuation route from Tampa to Orlando. The PBS\&J report (2000) on contraflow operation for Interstate-4 stated that the contraflow operation is to operate from Tampa to Orange County line. This was used as the guideline for the 
contraflow operations on I-4. Under free flow conditions, it takes $1.5 \mathrm{hrs}$ to travel from Tampa (I-4 Milepost 1) to the start of Orange County line in Orlando. The network is shown in Figure 6-1. As seen in Figure6-1 there are three possible crossover locations identified, 'cr1' is the first crossover just after Tampa, 'cr2' is the next one after plant city and the last crossover 'cr3' is after Lakeland. All cell numbered in 200's are the contraflow cells. The time slices for CTM is taken to be 6 minutes. Since the contraflow lanes and normal lanes terminate at Orlando, one destination (Orlando) is the super destination.

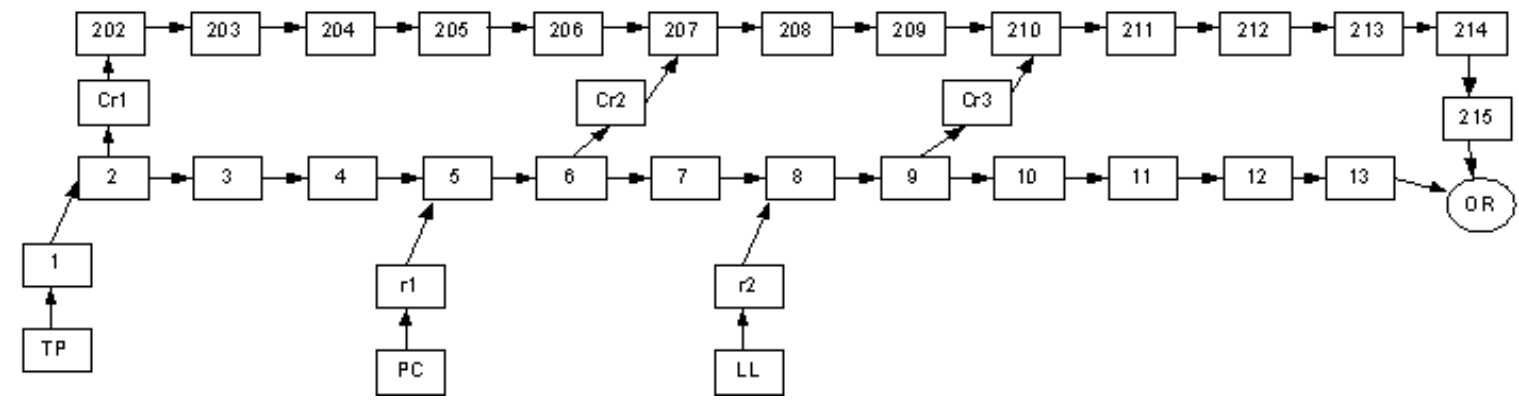

Figure 6-1: Cell transmission Model for Evacuation Route Interstate 4.

Plant City and Lakeland were identified as the other two major demand origins along I-4. I-4 has three lanes in each direction with a free flow speed of $60 \mathrm{mph}$. All lanes were reversed on the opposite directions during contraflow operations. The demands from each region are shown in Table 6-1. Vehicles were loaded from the three locations based on fixed input flow rate for a predetermined time. Time period is defined as the demand input period for all the vehicles to be evacuated. The input flow rates and time period for demand are also shown in Table 6-1. The capacity of the normal lanes were assumed to be $2400 \mathrm{veh} / \mathrm{hr} / \mathrm{ln}$, this value is taken from HCM for a free flow speed of $60 \mathrm{mph}$. 
Table 6-1: Demand from each location to Orlando on I-4

\begin{tabular}{|l|c|c|c|}
\hline \multicolumn{1}{|c|}{ City } & $\begin{array}{c}\text { Total } \\
\text { Vehicles }\end{array}$ & $\begin{array}{c}\text { Entry Flow } \\
\text { Rate (veh/hr) }\end{array}$ & $\begin{array}{c}\text { Time } \\
\text { period } \\
\text { (Hrs) }\end{array}$ \\
\hline Tampa & 84000 & 6000 & 14 \\
\hline Plant City & 42000 & 3000 & 14 \\
\hline Lakeland & 61600 & 4400 & 14 \\
\hline
\end{tabular}

The road signs and markings on the contraflow lanes are created for vehicles traveling in the opposite direction to the evacuating traffic. This results in unfamiliarity of the drivers to the driving conditions, this result in drop of free flow speeds. For the purpose of this study, it was assumed that the free flow speeds on the contraflow lanes dropped to $55 \mathrm{mph}$ from $60 \mathrm{mph}$. There is also discomfort associated to driving on the contraflow lanes due to the limited number of exits on the contraflow lanes, which provide limited opportunities to stop for rest. The unfamiliarity and discomfort associated to traveling on contraflow lanes would result in fewer evacuees preferring to use contraflow lanes as compared to normal lanes. The capacity of the contraflow lanes was assumed to be $2000 \mathrm{vehr} / \mathrm{hr} / \mathrm{ln}$. Due to geometry and unfamiliar conditions the free flow speed at crossovers is assumed to be $30 \mathrm{mph}$.

\subsection{Model Formulation}

This section describes an optimization model to determine optimal locations of crossover constrained by the maximum number of crossovers allowed (due to constraints of manpower and logistics). This model is dynamic in nature, since the solution could involve having certain crossovers open during certain periods of time, depending on demand and traffic conditions (such as incidents).

The details of the models are as follows: 
$C \quad$ is the set of cells. It is the unions of ordinary cells $\left(C_{O}\right)$, merge cells $\left(C_{M}\right)$, diverge cells $\left(C_{D}\right)$, source cell $\left(C_{R}\right)$, sink cells $\left(C_{S}\right)$, and crossover cells $\left(C_{C r}\right)$ A crossover cell is also an ordinary cell.

$H \quad$ is the set of links between cells. It is the union of source links $\left(H_{R}=\{(i, j) \mid j\right.$ $\left.\left.\in C_{R}\right\}\right)$, sink links $\left(H_{S}=\left\{(i, j) \mid j \in C_{S}\right\}\right)$, ordinary links $\left(H_{O}=\left\{(i, j) \mid i \in\left(C_{O} \mathrm{U} C_{M}\right)\right.\right.$, $\left.\left.j \in\left(C_{O} \cup C_{D}\right)\right\}\right)$, merge links $\left(H_{M}=\left\{(i, j) \mid i \in\left(C_{O} \cup C_{C r}\right), j \in C_{M}\right\}\right)$, and diverge links $\left(H_{D}=\left\{(i, j) \mid i \in C_{D}, j \in\left(C_{O} \mathrm{U} C_{C r}\right)\right\}\right)$.

$x_{i}^{t} \quad$ is the number of vehicles in cell $i$ at time $t$.

$Q_{i}^{t} \quad$ is the maximum flow in cell $i$ at time $t$.

$N_{i}^{t} \quad$ the maximum number of vehicles that can be accommodated in cell $i$ at time $t$.

$d_{i}^{t} \quad$ Demand from source $i$ at time $t$.

$y_{i j}^{t} \quad$ is the number of vehicles transferred from cell $i$ to cell $j$ at time $t$

$\mathrm{MaxCr}$ is the maximum number of crossovers.

$T \quad$ is the total time of analysis.

$\Gamma(i)$ is the function defining the cells downstream of cell $i$, the inverse of $\Gamma$ defines all the cells upstream of cell $i$.

$\operatorname{Min} \quad Z=\sum_{i \in C \backslash C_{S}} \sum_{t \in T} x_{i}^{t} \Delta t$

Subject to:

$$
\begin{array}{ll}
x_{i}^{t}=x_{i}^{t-1}+\sum_{k \in \Gamma^{-1}(i)} y_{k i}^{t-1}-\sum_{k \in \Gamma(i)} y_{i k}^{t-1} & \forall i \in C \backslash\left(C_{R} \cup C_{S}\right), \forall t \in T \\
x_{i}^{t}=x_{i}^{t-1}+d_{i}^{t}-\sum_{k \in \Gamma(i)} y_{i k}^{t-1} & \forall i \in C_{R}, \forall t \in T
\end{array}
$$




$$
\begin{array}{ll}
x_{i}^{t}=x_{i}^{t-1}+\sum_{k \in \Gamma^{-1}(i)} y_{k i}^{t-1} & \forall i \in C_{S}, \forall t \in T \\
\sum_{k \in \Gamma(i)} y_{i k}^{t} \leq x_{i}^{t} & \forall i \in C \backslash C_{S}, \forall t \in T \\
\sum_{k \in \Gamma^{-1}(i)} y_{k i}^{t} \leq Q_{i}^{t} & \forall i \in C \backslash C_{R}, \forall t \in T \\
\sum_{k \in \Gamma(i)} y_{i k}^{t} \leq Q_{k}^{t} & \forall i \in C \backslash C_{S}, \forall t \in T \\
\sum_{i \in \Gamma^{-1}(k)} y_{i k}^{t} \leq N_{k}^{t}-x_{k}^{t} & \forall i \in C \backslash C_{R}, \forall t \in T \\
x_{i}^{t} \leq \delta_{i}^{t} N_{i}^{t} & \forall i \in C_{C r}, \forall t \in T \\
\sum_{i \in C_{C r}} \delta_{i}^{t} \leq M a x C r & \forall i \in C_{C r}, \forall t \in T \\
x_{i}^{t} \geq 0 & \forall i \in C \\
y_{i k}^{t} \geq 0 & \forall(i, j) \in H \\
0 \leq \delta_{i}^{t} \leq 1 & \delta_{i}^{t} \text { is Integer } \\
x_{i}^{0}=\bar{x}_{i} & \forall i \in C \\
y_{i j}^{0}=\bar{x}_{i j} & \forall(i, j) \in H \\
&
\end{array}
$$

Equation 6-1 in the model is the total system time. The optimization model's objective is to minimize the total system time.

Equations 5-2 represents the flow conservation constraint for the merge, diverge and ordinary cells. Equation 6-3 and 6-4, represent the flow conservation constraints for the source and sink cells respectively. 
Equations 6-5 and 6-6 are constraints defining the sending ability of the cell to the next cell. Equations 6-7 and 6-8 are constraints defining the ability to receive vehicles from earlier cells. Equations 6-5, 6-6, 6-7 and 6-8 ensure that the number of vehicles moving from one cell to the next cell needs to be less than the sending ability of cells upstream and the receiving ability of cells downstream.

Equation 6-9 introduces a binary variable $\delta_{i}^{t}$ in the constraint. The variable ensures that there can be no vehicle in the crossover cell during the entire time period the crossover is not operational.

If $\delta_{i}^{t}=0$, then equation 6-9 is:

$x_{i}^{t} \leq 0$

Else

$x_{i}^{t} \leq N_{i}^{t}$

Therefore the vehicles can not use the crossover to access the contraflow lanes, when $\delta_{i}^{t}$ is zero.

Equation 6-10 is a constrain dictating that the number of operational crossovers do not exceed the maximum allowed number of crossovers (MaxCr). As mentioned earlier the number of crossovers is constrained by the amount of manpower available to maintain operations at crossovers.

Equations 6-11 and 6-12 are the non negative constraints. Equation 6-13 states that $\delta_{i}$ is a binary variable. Equations 6-14 and 6-15 are the initial conditions. 
The model also has the ability to determine optimal crossover locations during every time step, depending on the demand and traffic conditions. A dynamic crossover can especially be useful under circumstances of unforeseen lane blockages due to incidents or vehicles running out of gas.

One of the problems associated with solutions from the System Optimal solution for CTM is that the optimal solution contains traffic holding in the cells. Traffic holding in cells occurs due to the relaxation of traffic flow propagation constraints. Shen et.al. (2006) showed that for the optimal holding determined by the SO assignment has an equivalent no-holding solution. They also describe an algorithm to convert a holding solution to a no-holding case. This implies that the optimal crossovers determined through the optimization model described will be equivalent (Same total system time) no-holding case. The model was modeled using MATHPROG and LPSOLVE solver (APPENDIX D)

\subsection{Solution Approach}

This section determines the optimal crossover locations for the contraflow plans for Interstate-4, using the model described in the last section.

\subsubsection{Optimal Crossover Location}

The total system times for different possible network configurations are provided in Table 6-2. 
Table 6-2: Optimal crossovers for different cases

\begin{tabular}{|l|c|c|}
\hline Maximum Operational Crossovers & One Crossover & Two Crossovers \\
\hline Crossovers Operational & cr2 & cr1,cr2 \\
\hline Total Vehicle Time (veh-hrs) & $1,064,958$ & 912,024 \\
\hline
\end{tabular}

As can be observed from Table 6-2, the optimal crossover was found to be cr2, under the constraint that only one crossover can be operational. Under the constraint that a maximum of two crossovers can be operational, having both cr1 and cr2 open provided the best results.

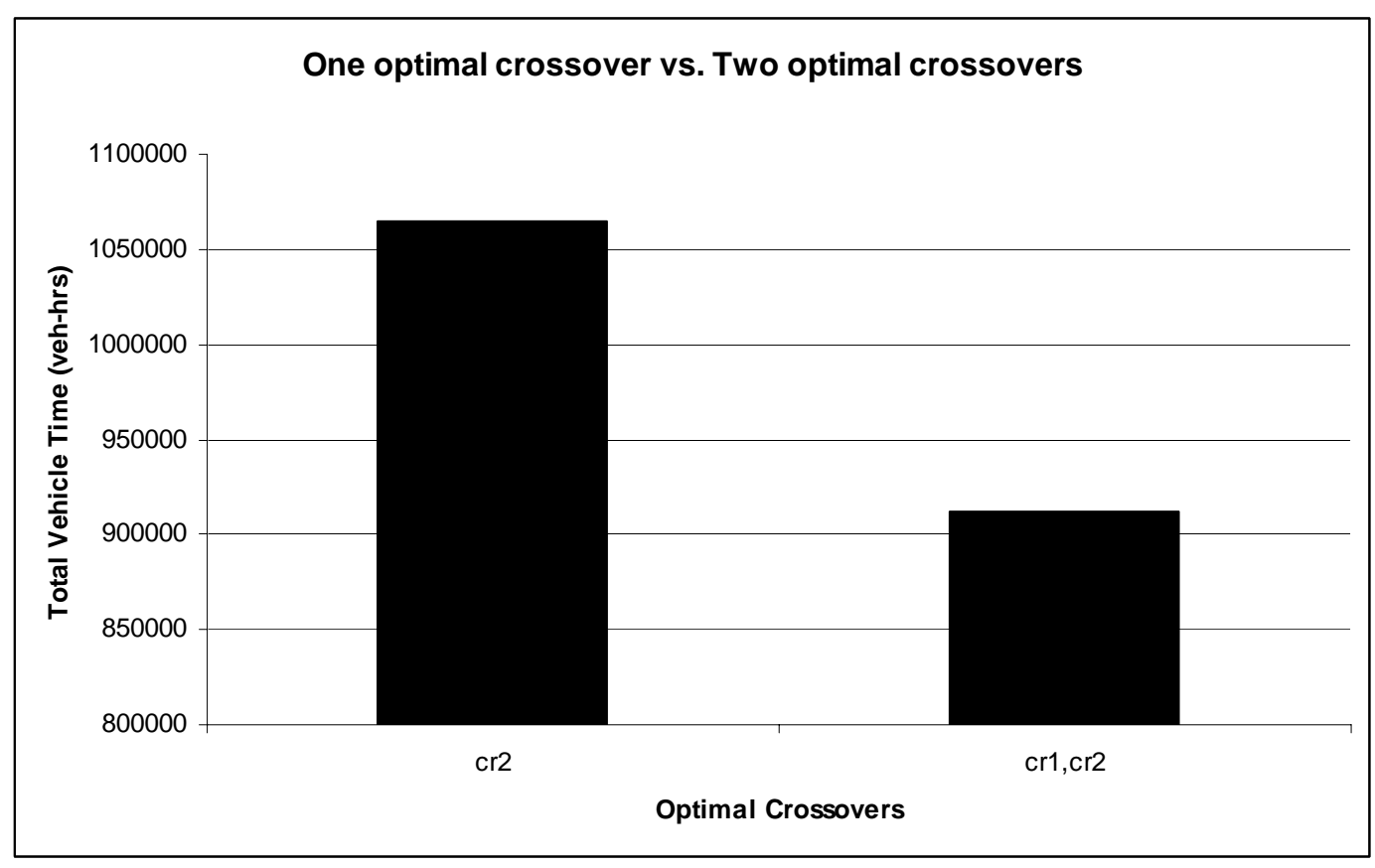

Figure 6-2: Comparison of having one optimal crossover with two optimal crossovers.

The results from Table 6-2 are shown in Figure 6-2. It can be clearly seen that providing an extra crossover helps improve operations significantly. Having crossover cr1 open in addition to crossover cr2 reduces the number of vehicles originating from Tampa merging with vehicles from Plant City. This helps alleviate the bottleneck at 
Plant City. A $14.3 \%$ drop in total vehicle time is observed by having both cr1 and cr2 operational as compared to having just cr2 open.

\subsubsection{Dynamic Crossover for Incidents}

To test the benefits of dynamic crossovers, capacity drops were introduced in cells at time $t$ equals 0 . It was assumed that the incident remains for one hour (10 time steps). At time $t$ equals 0 , the cells had vehicles equal to the maximum flow in them. It is assumed that it takes emergency management officials 18 minutes (3 time steps) in order to close crossovers and put into operation other crossovers. After 3 time steps into the incident it is possible to have a different configuration of crossovers, and after the incident is cleared another different set of configuration is possible. This is ensured by adding constraints 6-16 to 6-21

$$
\begin{array}{ll}
\delta_{i}^{t}=\delta_{i}^{t^{\prime}} & \forall t, t^{\prime} \leq 3 \\
\delta_{i}^{t}=\delta_{i}^{t^{\prime}} & \forall 3 \leq t, t^{\prime} \leq \text { incident_time } \\
\delta_{i}^{t}=\delta_{i}^{t^{\prime}} & \text { incident_time }+1 \leq \forall t, t^{\prime} \leq T
\end{array}
$$

'incident time' is the time required to clear the incident from the roadway. During the period 0 to 'incident_time' it is assumed that the flow in the cell affected by the incident drops to 'incident_flow'. For the purpose of the study it is assumed to drop to 1000veh/hr.

$\sum_{k \in \Gamma(i)} y_{i k}^{t} \leq$ incident_flow $\forall i \in$ incident_cell, $\forall t \leq$ incident_time

Constraint 6-19 ensures that during the period the incident is being cleared the maximum possible flow through that cell ('incident_cell') is less than or equal to the reduced capacity ('incident_flow'). 
The optimal dynamic crossover configuration under incident conditions analysis was carried out for two cases, when the maximum allowed crossovers are two and one. It is assumed at the beginning the operational crossovers are the optimal ones found from the base case. Therefore during the first 3 time steps cr1 and cr2 were operational, when there are a maximum of two crossovers allowed. For the case when a maximum of one crossover is allowed 'cr2' is operational in the first three time steps

\subsubsection{Maximum of Two Crossovers}

When the incident happens $(t=0)$, two crossovers 'cr1' and 'cr2' were operational in the first three time steps. The results are shown in Table 6-3. If the incident occurred on the normal lanes (cells $4,7,10$ ) the crossovers during the incident are 'cr2' and 'cr3'. After the incident has been cleared the optimal crossovers are 'cr1' and 'cr2'. It can be clearly seen that applying a dynamic crossover during the incident helps reduce the total vehicle hours, as compared to if the original crossovers were operational.

Table 6-3: Dynamic crossovers strategies for incidents, maximum crossovers allowed are two.

\begin{tabular}{|c|c|c|c|c|c|c|}
\hline $\begin{array}{c}\text { Incident } \\
\text { Cell }\end{array}$ & $\begin{array}{c}\text { Capacity } \\
\text { Drop (veh/hr) }\end{array}$ & $\begin{array}{c}\text { Operational } \\
\text { During } \\
\text { Incident }\end{array}$ & $\begin{array}{c}\text { Operational } \\
\text { After } \\
\text { Incident }\end{array}$ & $\begin{array}{c}\text { (Dynamic } \\
\text { Crossover) Total } \\
\text { vehicle Time } \\
\text { (veh-hrs) }\end{array}$ & $\begin{array}{c}\text { (Fixed Crossover } \\
\text { cr1, cr2) Total } \\
\text { vehicle Time (veh- } \\
\text { hrs) }\end{array}$ & $\begin{array}{c}\text { Reduction in } \\
\text { total vehicle } \\
\text { travel time } \\
\text { (veh-hrs) }\end{array}$ \\
\hline 204 & 1000 & $\mathrm{cr} 2, \mathrm{cr} 3$ & $\mathrm{cr} 1, \mathrm{cr} 2$ & 1051403 & 1054139 & 2736 \\
\hline $\mathbf{2 0 8}$ & 1000 & $\mathrm{cr} 2, \mathrm{cr}$ & $\mathrm{cr} 1, \mathrm{cr} 2$ & 1063721 & 1067667 & 3946 \\
\hline $\mathbf{4}$ & 1000 & $\mathrm{cr} 2, \mathrm{cr} 3$ & $\mathrm{cr} 1, \mathrm{cr} 2$ & 1051403 & 1054139 & 2736 \\
\hline $\mathbf{7}$ & 1000 & $\mathrm{cr} 2, \mathrm{cr} 3$ & $\mathrm{cr} 1, \mathrm{cr} 2$ & 1051669 & 1054805 & 3136 \\
\hline $\mathbf{1 0}$ & 1000 & $\mathrm{cr} 2, \mathrm{cr} 3$ & $\mathrm{cr} 1, \mathrm{cr} 2$ & 1084058 & 1087206 & 3148 \\
\hline $\mathbf{2 1 1}$ & 1000 & $\mathrm{cr} 1, \mathrm{cr} 2$ & $\mathrm{cr} 1, \mathrm{cr} 2$ & 1076191 & 1076191 & 0 \\
\hline
\end{tabular}

In case the incident occurred on the contraflow cells 204 (between Tampa and Plant City) and 208 (between Plant City and Lakeland) the optimal dynamic crossover 
configuration are similar to when incidents are on the normal lanes. If there is an incident on the contraflow lanes after Lakeland (cell 211) there is no need to change the crossovers. The original crossover locations provided the best operations.

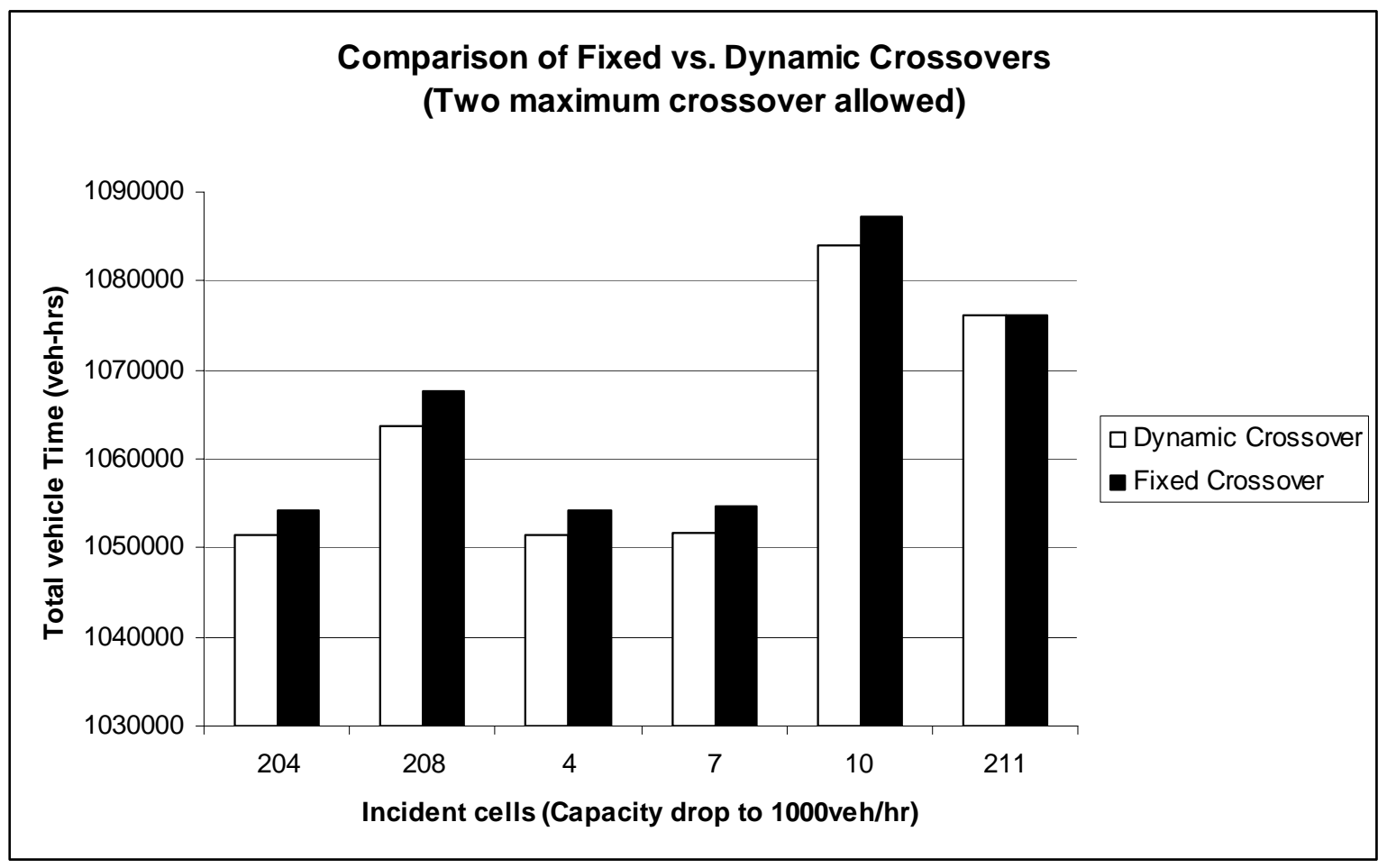

Figure 6-3: Comparison of total vehicle time between fixed crossovers and dynamic crossovers, for a maximum of two crossovers

The results in Table 6-3 have been shown in Figure 6-3. Figure 6-3 compares the total vehicle times between having a fixed crossover to a dynamic crossovers in case of an incident. It is clearly seen that in most cases having a dynamic crossover reduces the total vehicle time.

\subsubsection{Maximum of Two Crossovers}

When the incident happens $(t=0)$, one crossover ('cr2') was operational in the first three time steps. The results are shown in Table 6-4. Table 6-4 compares the total 
vehicle time observed for a dynamic crossover during an incident with a fixed crossover. The reduction in total system time has also been shown in the table.

Table 6-4: Dynamic crossovers strategies for incidents, maximum crossovers allowed are one.

\begin{tabular}{|c|c|c|c|c|c|c|}
\hline $\begin{array}{c}\text { Incident } \\
\text { Cell }\end{array}$ & $\begin{array}{c}\text { Capacity } \\
\text { Drop (veh/hr) }\end{array}$ & $\begin{array}{c}\text { Operational } \\
\text { During } \\
\text { Incident }\end{array}$ & $\begin{array}{c}\text { Operational } \\
\text { After } \\
\text { Incident }\end{array}$ & $\begin{array}{c}\text { (Dynamic } \\
\text { Crossover) Total } \\
\text { vehicle Time } \\
\text { (veh-hrs) }\end{array}$ & $\begin{array}{c}\text { (Fixed Crossover } \\
\text { cr2) } \\
\text { Time (veh-hrs) }\end{array}$ & $\begin{array}{c}\text { Reduction in } \\
\text { total vehicle } \\
\text { travel time } \\
\text { (veh-hrs) }\end{array}$ \\
\hline $\mathbf{2 0 4}$ & 1000 & $\mathrm{cr} 2$ & $\mathrm{cr} 2$ & 1188737 & 1188737 & 0 \\
\hline $\mathbf{2 0 8}$ & 1000 & $\mathrm{cr} 1$ & $\mathrm{cr} 2$ & 1192439 & 1196175 & 3736 \\
\hline $\mathbf{4}$ & 1000 & $\mathrm{cr} 1$ & $\mathrm{cr} 2$ & 1188415 & 1188737 & 322 \\
\hline $\mathbf{7}$ & 1000 & $\mathrm{cr} 1$ & $\mathrm{cr} 2$ & 1189081 & 1189403 & 322 \\
\hline $\mathbf{1 0}$ & 1000 & $\mathrm{cr} 3$ & $\mathrm{cr} 2$ & 1219490 & 1221804 & 2314 \\
\hline $\mathbf{2 1 1}$ & 1000 & $\mathrm{cr} 1$ & $\mathrm{cr} 2$ & 1193383 & 1198759 & 5376 \\
\hline
\end{tabular}

It is observed that when an incident occurs on cell 4 (normal cell between Tampa and Plant City), the optimal crossover during the duration of the incident is found to be 'cr1'. This is because vehicles can be directed to the contraflow lanes during the incident and minimal vehicles are affected by the bottleneck created by the incident. After the incident has been cleared the optimal crossover was found to be 'cr2'. Similar results were found when incidents occurred on cell 7 (normal cell between Plant City and Lakeland), cell 208 (contraflow cell between crossover 'cr2' and 'cr3') and cell 211 (contraflow cell after crossover 'cr3').

When an incident occurred on cell 10 (normal cell after Lakeland), crossover 'cr3' was found to be the optimal crossover during the incident. The reason for this is that having 'cr3' as an operational crossover allows large number of vehicles to divert onto the contraflow lanes, otherwise would have been delayed due to the bottleneck. An incident in cell 204 (contraflow cell between 'cr1' and 'cr2') has an optimal crossover as 'cr2'. 


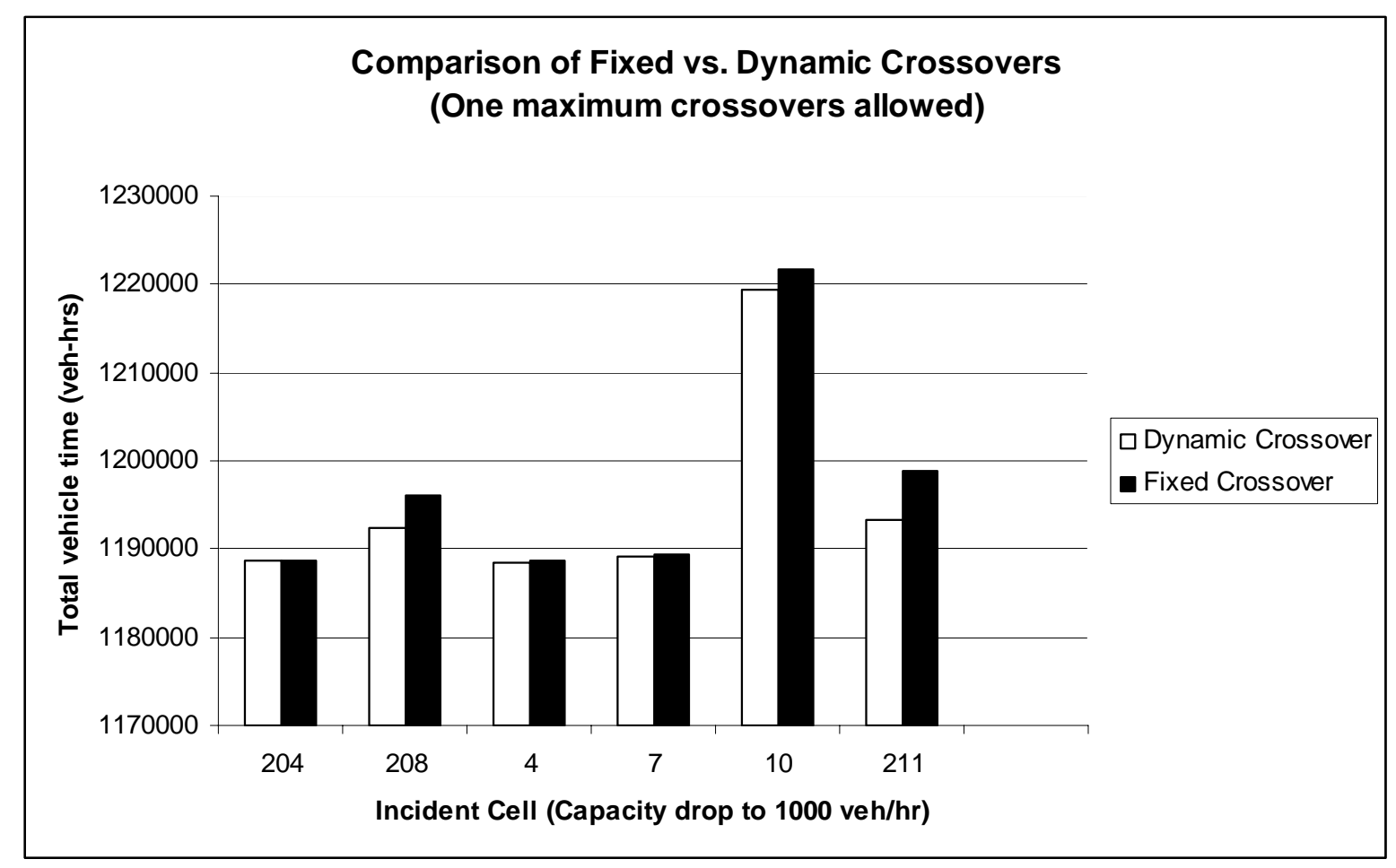

Figure 6-4: Comparison between fixed and dynamic crossovers, for one maximum crossover.

Figure 6-4 compares the total vehicle times between having a fixed crossover compared to a dynamic crossover. It can be seen that in general having a dynamic crossover helps reduce total vehicle time. Especially when there are incidents in cell 208 or cell 10 or cell 211 , dynamic crossovers help improves operations.

It is quite clear that having a dynamic crossover actually helps total system operations.

\subsection{Conclusion}

This chapter proposes an optimization model to determine optimal crossover locations for contraflow operations. The model proposed in this chapter extends the work done 
by Tuydes et. al. (2004, 2005) and Liu (2007) and explicitly models the crossover, therefore accounting for merge and diverge operations more effectively.

The model was utilized to determine optimal crossovers for contraflow operations on Interstate 4. Interstate 4 is an important evacuation route connecting Tampa to Orlando. It was found that under the restriction that the maximum number of crossovers is two, a crossover after Tampa and another after Plant City provided the best operations. Under the restriction of one crossover a crossover after Plant City provided the best operations.

A model for dynamic crossovers in case of incidents has also been presented as part of this chapter. The concept of dynamic crossover was tested when capacity is reduced on certain sections of the Interstate 4 due to incidents. It was seen that there are operational benefits of having a dynamic crossover. The model helps decide which crossovers should be placed in operation during an incident,

During evacuation, there are fluctuations in demands, vehicle breakdowns and other incidents that result in drop in capacity. This model proposed is fast and can be utilized as part of a real time system to determine which crossovers should be kept open. 


\section{CHAPTER 7 \\ STRATEGIES TO IMPROVE DISSIPATION INTO DESTINATION NETWORKS DURING EVACUATION}

\subsection{Overview}

Backups originating from destinations have been observed during evacuation. These backups usually occur due to congestion at the destination network, which result in spillbacks onto the evacuation routes. These spillbacks result in queuing and delays that hamper evacuation operations.

In order to develop stratefies for destination networks, it is important to understand network level relationships between flow/speed/concentration relationship and the speed-accumulation relationship (Greenshield's, Greenberg's and Bell-shaped model).

A strategy (Network Breathing Strategy) to improve dissipation of vehicles into the destination network is developed using these relationships between network level variables. The network breathing strategy is a cyclic process of allowing vehicles to enter the network till the network reaches congestion, which is followed by closure of their entry into the network until the network reaches an acceptable state. After which entrance into the network is allowed again. The intuitive understanding behind this methodology is to ensure that the network does not remain in congested conditions. The term 'Network Breathing' is analogous to the process of breathing, where vehicles are inhaled by the network (vehicles allowed in) and dissipated by the 
network (vehicles are not allowed in). It is shown that the network breathing improves the dissipation of vehicle into the destination network. This strategy could be visualized as a ramp metering scheme, except for that instead of having metering on on-ramps to control congestion on freeways, ramp meters are placed on off-ramps to meter vehicles into the destination network.

\subsection{Definitions}

This section summarizes all the relevant variables that are used throughout this chapter.

$Q_{i} \quad$ Flow on link $i$

$Q_{\text {Out }} \quad$ Total outflow from network

$Q_{\text {in }} \quad$ Total inflow into the network

$K_{i} \quad$ Concentration on link $i$

$K_{j} \quad$ Network level jam concentration

$v_{j} \quad$ Speed of the $\mathrm{j}^{\text {th }}$ vehicle on the network

$V_{i} \quad$ Average speed on link $i$

$V_{f} \quad$ Inverse of the average minimum time taken to travel a mile in the network, at free flow conditions.

$n_{i} \quad$ Number of vehicles on link $i$

$n \quad$ Total number of vehicles on the network (sum of all $n_{i}$ ) (Accumulation)

$n_{c} \quad$ Number of vehicles in the network, when the outflow from the network is the maximum 
$n_{p} \quad$ Maximum number of vehicles the network can accommodate at a given time

$l_{i} \quad$ Lane-mile of link $i$

$l \quad$ Total lane-mile in the network (sum of all $l_{i}$ )

$q_{p} \quad$ The average flow in the network when number of vehicles in the network is $n_{p}$

$x \quad$ Number of vehicles in the network after network relaxation

The three fundamental traffic variables speed, concentration and flow at network level are defined as average over all vehicles during an observation period $\varepsilon$. These were defined by Ardekani (1984) and Mahmassani et al. (1984, 1987). Average speed in a network is defined as the total number of vehicle miles traveled divided by the total number of vehicle hours in the network during an observation period $\varepsilon$. If there are $n$ vehicles in the network and the velocity of the $\mathrm{j}^{\text {th }}$ vehicle in the network is $v_{j}$, then the average velocity of vehicles in the network represented by $V$ is:

Total vehicle-mile $=\sum_{j=1}^{n} v_{j} \varepsilon$

Total vehicle-hours $=n \varepsilon$

$V=\frac{\sum_{j=1}^{n} v_{j} \varepsilon}{n \varepsilon}$

$\Rightarrow V=\frac{\sum_{j=1}^{n} v_{j}}{n}$

The average concentration $K$ in the network is defined as the total number of vehicles in the network per unit lane-mile. $l$ is the total lane-miles of roadway in the network. 


$$
K=\frac{n}{l}
$$

The average network flow $Q$ is defined as the average number of vehicles that pass through a random point in the network per unit time. The average network flow is given by:

$$
Q=\frac{\sum l_{i} Q_{i}}{\sum l_{i}}
$$

In Kalfastas and Peetas (2007) work on the cell transmission model they observed that on individual links the backward propagating wave speed is lower than the free flow speed, indicating that the link can never reach maximum jam density, since only a part of the available space would be filled up. Since a network is a combination of individual links, it is fair to assume that during maximum congestion, there exists a maximum accumulation $\left(n_{p}\right)$ in the network and it corresponds to some minimum outflow $\left(q_{p}\right)$. In Ardekani's (1984) field study a maximum concentration of 30 vehicles/lane-mile was observed in the network.

With the next generation of technology of Vehicle Infrastructure Integration (V.I.I.), data of the network will be available during every time instant. Hence the average velocity, flow and density of the network would be known at every time instant. This will help provide real time state of the network, enabling us to develop real time strategies for the network.

\subsection{Macroscopic Properties}

Measurements and relationships between macroscopic variables: flow, concentration and speed have been extensively studied for traffic streams both in theory and in field 
(Edie (1965) and Gazis (1974)). The relationships between these macroscopic variables at a network scale have been studied in simulation experiments (Mahmassani et. al. (1984, 1987) and Williams et. al. $(1985,1987))$ and field studies (Ardekani (1984)). This section provides theoretical proofs for the validity of relationships at a network scale. These relationships are then validated using microscopic simulation (VISSIM) for a network shown in Figure 7-1. The network is a small grid network of two lane one-way roads, the entire length of the roadway is 2.12 miles. The intersections consisted of two phase signals with a cycle length of 60 seconds. The simulation for the network for multiple runs with each run of 3240 seconds. An input of $2000 \mathrm{veh} / \mathrm{hr}$ was provided at each input. The average concentrations, speeds, flows, inflows and outflows were averaged over 120 seconds for the network. The demands were allocated to routes from origin to destinations. We also assume a fixed percentage of demand for each route on the network, to ensure that the average trip lengths are constant.

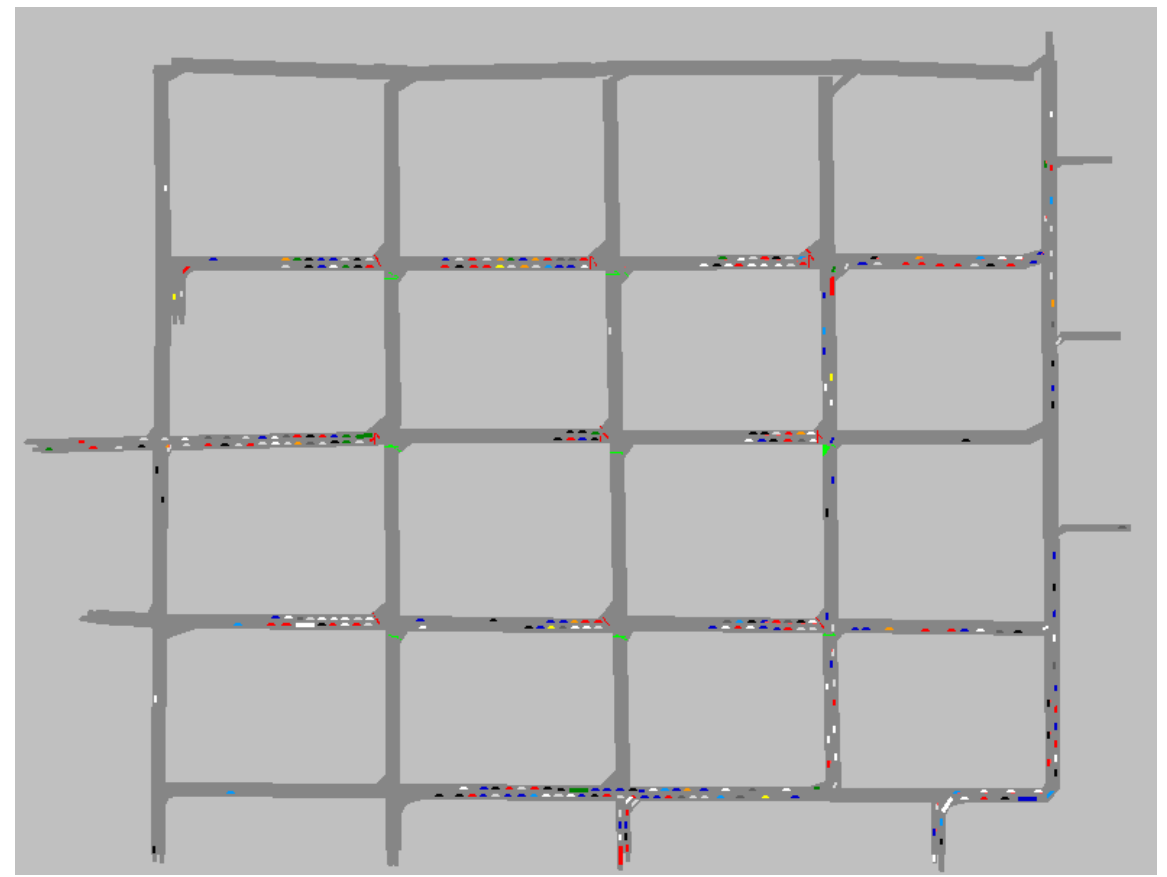

Figure 7-1: Simulation network considered for the study 


\subsubsection{Fundamental Network Speed/Flow/Concentration Relationship}

This subsection derives the fundamental speed/flow/concentration relationship on a general network.

On an individual link $i$ of length $l_{i}$ in the network, it is known that:

$Q_{i}=K_{i} V_{i}$

Where $V_{i}$ is the average velocity on link $i$ defined by Equation (7-6)

$V_{i}=\frac{\sum_{\text {vehicle } j \text { is in Link } i} v_{j}}{n_{i}}$

Multiplying both sides of equation (7-5) with $l_{i}$, we get:

$l_{i} Q_{i}=l_{i} K_{i} V_{i}$

Summing both sides of equation (7-7) over all links $i$ in the network and dividing by the total lane-miles in the network, we get:

$\frac{\sum l_{i} Q_{i}}{\sum l_{i}}=\frac{\sum l_{i} K_{i} V_{i}}{\sum l_{i}}$

It is observed that the left hand side of equation (7-8) is the definition for average network flow. It is also observed that $l_{i} K_{i}$ is the number of vehicles in link $i$. Substituting $l_{i} K_{i}$ with $n_{i}$, and the definition of average network flow in equation (7-8).

$Q=\frac{\sum\left(l_{i} K_{i}\right) V_{i}}{\sum l_{i}}=\frac{\sum\left(n_{i}\right) V_{i}}{\sum l_{i}}$

$\Rightarrow Q=\left(\frac{\sum n_{i}}{\sum n_{i}}\right)\left(\frac{\sum\left(n_{i}\right) V_{i}}{\sum l_{i}}\right)=\left(\frac{\sum n_{i}}{\sum l_{i}}\right)\left(\frac{\sum\left(n_{i} V_{i}\right)}{\sum n_{i}}\right)$

Substitute network concentration and definition of $V_{i}$ from equation (7-6) in equation (7-10). 
$Q=K\left(\frac{\sum\left(n_{i}\left(\frac{\sum_{\text {vehicle } j \text { is in Link } i} v_{j}}{n_{i}}\right)\right)}{\sum n_{i}}\right)$

$\Rightarrow Q=K\left(\frac{\sum_{\text {vehicle } j \text { is in Link } i} v_{j}}{\sum n_{i}}\right)$

In equation (7-12), $\sum_{\text {vehicle } j} \sum_{\text {is in Link } i} v_{j}$ is the sum of velocities of all vehicles on the network. Hence by definition $\left(\frac{\sum_{\text {vehicle } j \text { is in Link } i} v_{j}}{\sum n_{i}}\right)$ is the average velocity on the network.

$\Rightarrow Q=K V$

Equation (7-13) is the fundamental network speed/flow/concentration relationship.

The interesting aspect of equation (7-13) is that there are no inherent assumptions involved in the derivations, indicating that the fundamental network speed/flow/concentration relationship holds for a network in any state. The fundamental relationship for speed/flow/concentration should hold when the vehicles are non-homogenously loaded in the network or when the network is in a transient state.

Using data of network density and average network speed from the simulation runs the average network flow was calculated using equation (7-13) and was compared to 
the observed average network flow from the simulation. A plot (Figure 7-2) between the calculated and observed average network, show a perfect regression fit for $y=x$.

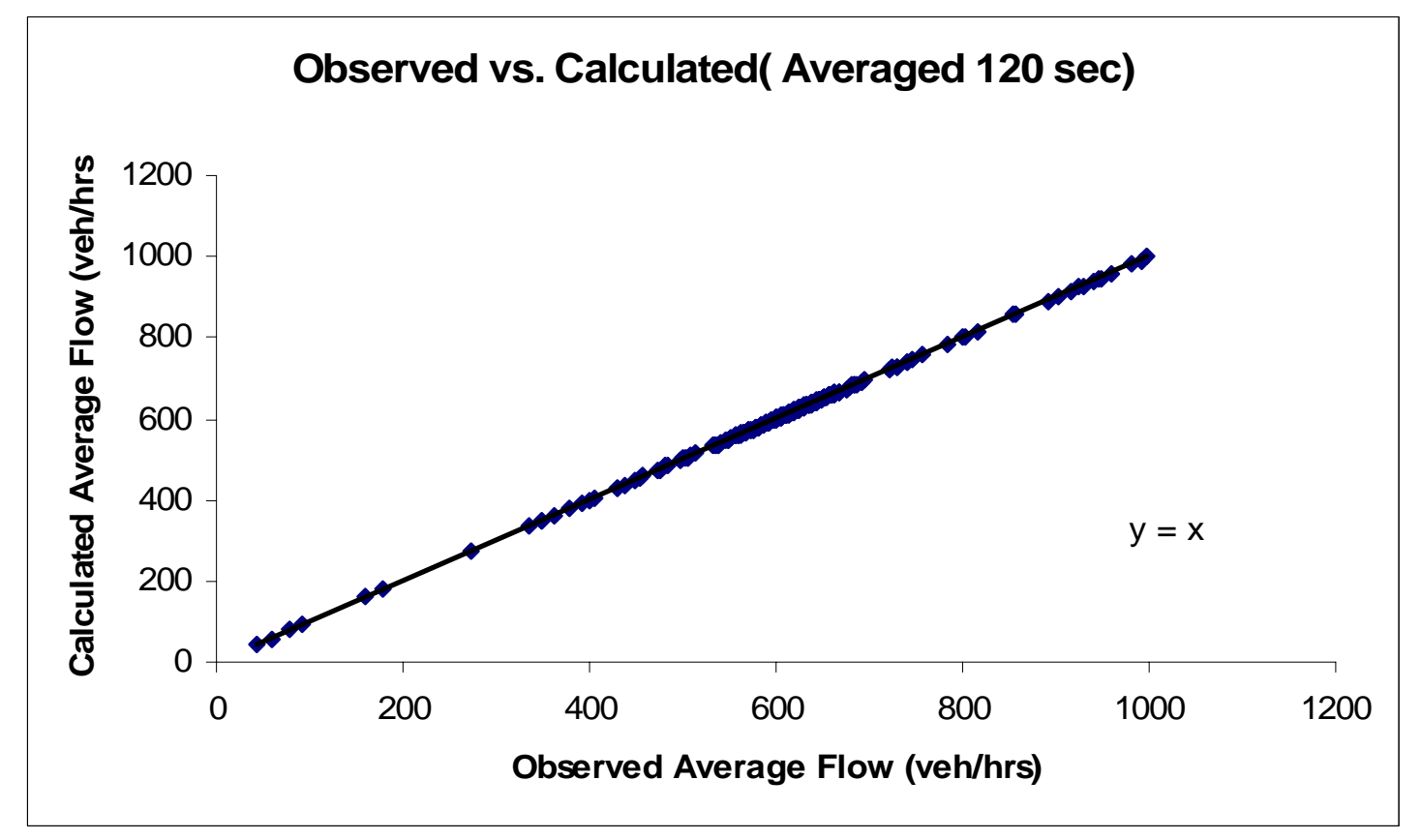

Figure 7-2: Observed flow vs. flow calculated using speed and density in equation 7-13.

\subsubsection{Speed-Accumulation Relationship at Network Level}

This section derives the Greenshield's, Greenberg's and the Bell-shaped model (Drake et. al. (1967)) to describe the relationship between average network speed and accumulation in a homogenous network (a network in which the concentration, jam concentration and free flow speeds do not significantly differ between different links). The theoretical results are validated through simulation for the network described earlier. A plot was constructed for data points, such that vehicles are homogenously distributed. 


\subsubsection{Greenshield's model}

To derive the Greenshield's model for a network, it is assumed that the speed density relationship on an individual link $i$ in a homogenous network follows the Greenshield's model.

$V_{i}=V_{f}\left(1-\frac{K_{i}}{K_{j}}\right)$

Since the free flow speed $\left(V_{f}\right)$ and jam density $\left(K_{j}\right)$ do not significantly vary between links of the network.

$$
\begin{aligned}
& \Rightarrow \sum\left(n_{i} V_{i}\right)=V_{f}\left(\sum n_{i}-\frac{\sum\left(n_{i} K_{i}\right)}{K_{j}}\right) \\
& \Rightarrow \frac{\sum\left(n_{i} V_{i}\right)}{\sum n_{i}}=V_{f}\left(\frac{\sum n_{i}}{\sum n_{i}}-\frac{\sum\left(n_{i} K_{i}\right)}{K_{j} \sum n_{i}}\right)
\end{aligned}
$$

Since the link densities do not significantly differ between links and is approximately equal to the network density $K_{i} \sim K$.

$$
\begin{aligned}
& \Rightarrow V=V_{f}\left(1-\frac{\sum\left(n_{i} K\right)}{K_{j} \sum n_{i}}\right)=V_{f}\left(1-\frac{K \sum n_{i}}{K_{j} \sum n_{i}}\right)=V_{f}\left(1-\frac{(n / l)}{\left(n_{j} / l\right)}\right) \\
& \Rightarrow V=V_{f}\left(1-\frac{n}{n_{j}}\right)
\end{aligned}
$$

This proves that Greenshield's relationship holds for average network speed and accumulation in a homogenous network.

\subsubsection{Greenberg's model}

To derive the Greenberg's model for a network, it is assumed that the speed density relationship on an individual link $i$ in a homogenous network follows the Greenberg's model. 
$V_{i}=-V_{f} \ln \left(\frac{K_{i}}{K_{j}}\right)$

Since the free flow speed $\left(V_{f}\right)$ and jam density $\left(K_{j}\right)$ do not significantly vary between links of the network.

$\Rightarrow \sum\left(n_{i} V_{i}\right)=-\sum n_{i} V_{f} \ln \left(\frac{K_{i}}{K_{j}}\right)$

$\Rightarrow \frac{\sum\left(n_{i} V_{i}\right)}{\sum n_{i}}=\frac{-\sum n_{i} V_{f} \ln \left(\frac{K_{i}}{K_{j}}\right)}{\sum n_{i}}$

Since the link densities do not significantly differ between links and is approximately equal to the network density $K_{i} \sim K$.

$\Rightarrow \frac{\sum\left(n_{i} V_{i}\right)}{\sum n_{i}}=\frac{-\sum n_{i} V_{f} \ln \left(\frac{K_{i}}{K_{j}}\right)}{\sum n_{i}}=-\frac{\sum n_{i}}{\sum n_{i}} V_{f} \ln \left(\frac{K}{K_{j}}\right)=-V_{f} \ln \left(\frac{(n / l)}{\left(n_{j} / l\right)}\right)$

$V_{i}=-V_{f} \ln \left(\frac{n}{n_{j}}\right)$

This proves that Greenberg's relationship holds for average network speed and accumulation in a homogenous network.

\subsubsection{Bell-shaped Relationship}

To derive the Bell-shaped model for a network, it is assumed that the speed density relationship on an individual link $i$ in a homogenous network follows the Bell-shaped model.

$V_{i}=V_{f} \exp \left[-\alpha\left(\frac{K}{K_{j}}\right)^{d}\right]$ 
Since the free flow speed $\left(V_{f}\right)$ and jam density $\left(K_{j}\right)$ do not significantly vary between links of the network.

$$
\begin{gathered}
\Rightarrow \sum\left(n_{i} V_{i}\right)=\sum n_{i} V_{f} \exp \left[-\alpha\left(\frac{K_{i}}{K_{j}}\right)^{d}\right] \\
\Rightarrow \frac{\sum\left(n_{i} V_{i}\right)}{\sum n_{i}}=\frac{\sum n_{i} V_{f} \exp \left[-\alpha\left(\frac{K_{i}}{K_{j}}\right)^{d}\right]}{\sum n_{i}}
\end{gathered}
$$

Since the link densities do not significantly differ between links and is approximately equal to the network density $K_{i} \sim K$.

$$
\begin{aligned}
& \frac{\sum\left(n_{i} V_{i}\right)}{\sum n_{i}}=\frac{\sum n_{i} V_{f} \exp \left[-\alpha\left(\frac{K}{K_{j}}\right)^{d}\right]}{\sum n_{i}}=\frac{\sum n_{i}}{\sum n_{i}} V_{f} \exp \left[-\alpha\left(\frac{K}{K_{j}}\right)^{d}\right]=V_{f} \exp \left[-\alpha\left(\frac{(n / l)}{\left(n_{j} / l\right)}\right)^{d}\right] \\
& V_{i}=V_{f} \exp \left[-\alpha\left(\frac{n}{n_{j}}\right)^{d}\right]
\end{aligned}
$$

This proves that relationship proposed by Drake, Shofer and May (1967) holds for average network speed and accumulation in a homogenous network.

The plot (Figure 7-3) for the simulation results were fitted with the Greenberg's, Greenshield's and Bell-shaped model. When the results were fitted with a linear regression the R-square was found to be 0.79 . A logarithmic fit showed to perform better with an R-square of 0.93 . The fit for the Bell-shaped model proposed by Drake, Shofer and May (1967) performed the best with an R-square of 0.964. The Bellshaped fit for the results showed to perform significantly better in explaining the speed-accumulation relationship than Greenberg's model and Greenshield's model. 


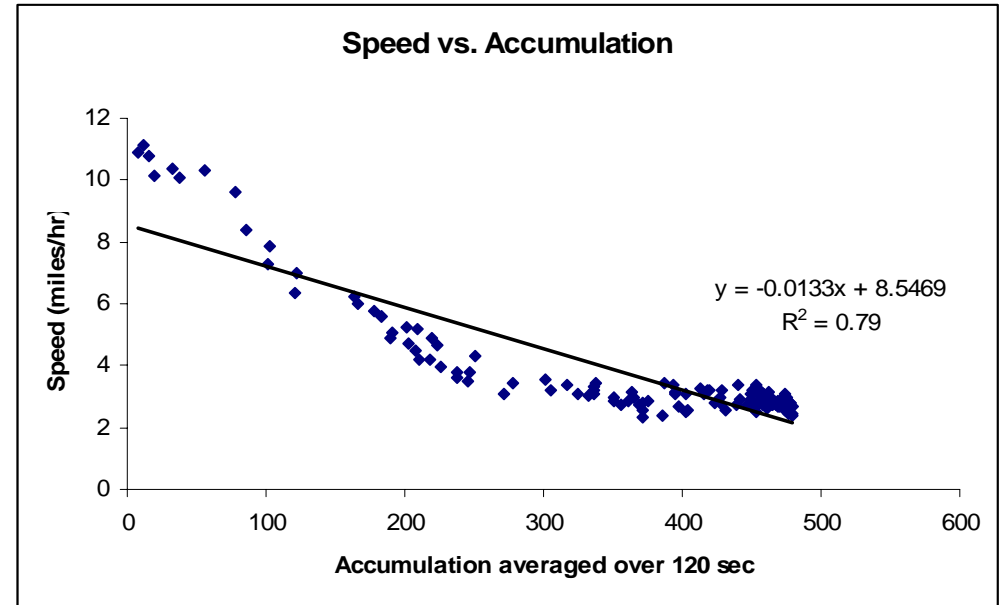

Figure 7-3a: Model fit for Greenshield's model for speed-accumulation relationship

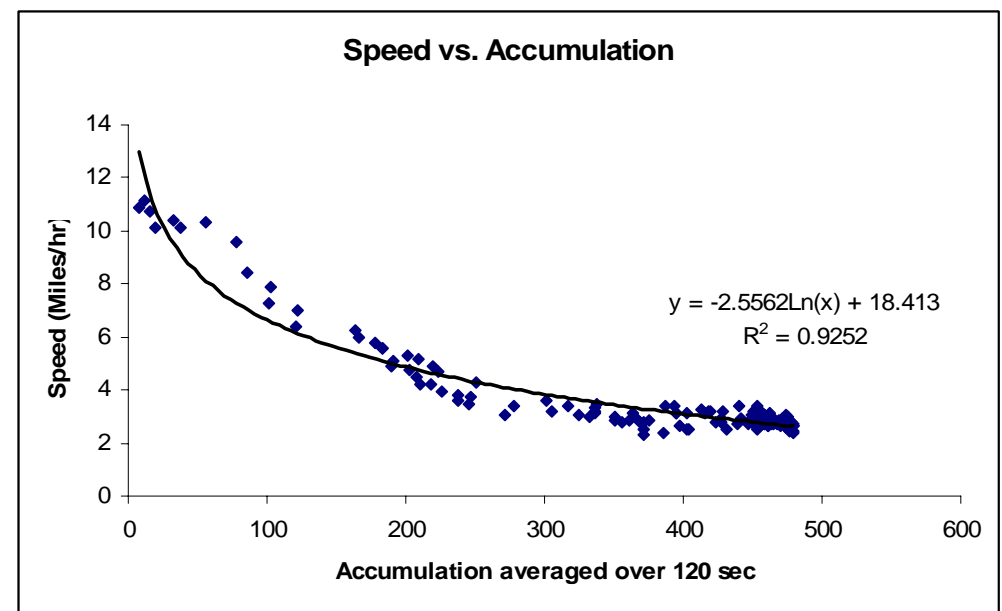

Figure 7-3b: Model fit for Greenberg's model for speed-accumulation relationship

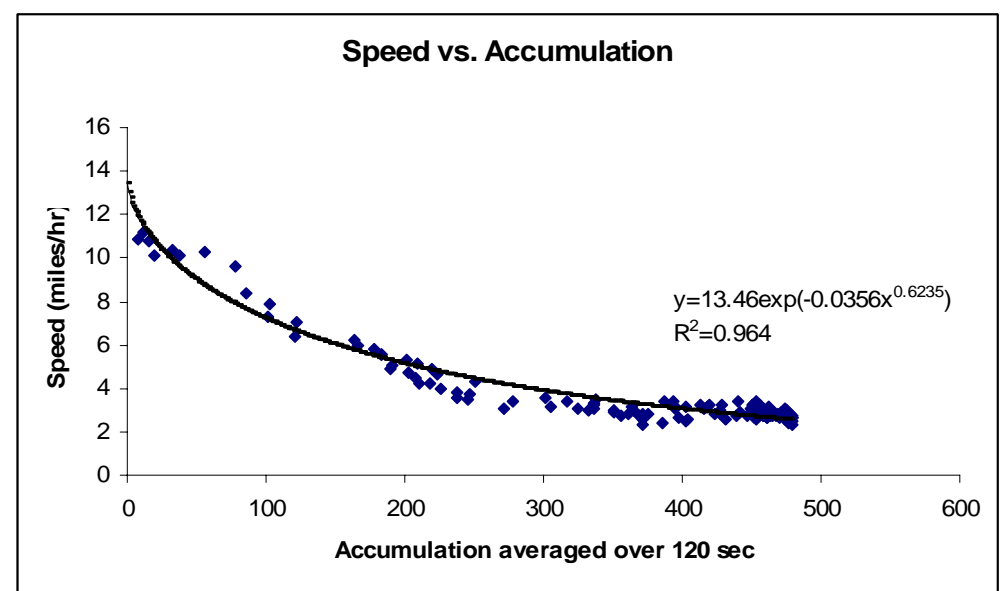

Figure 7-3c: Model fit for Bell-shaped model for speed-accumulation relationship Figure 7-3: Model fits for various speed-density relationships 


\subsubsection{Outflow-Accumulation Relationship at Network Level}

To understand the relationship between outflow and accumulation, the outflow and accumulation averaged over 120 seconds collected during the simulation of the network described earlier was plotted (Figure 7-4).

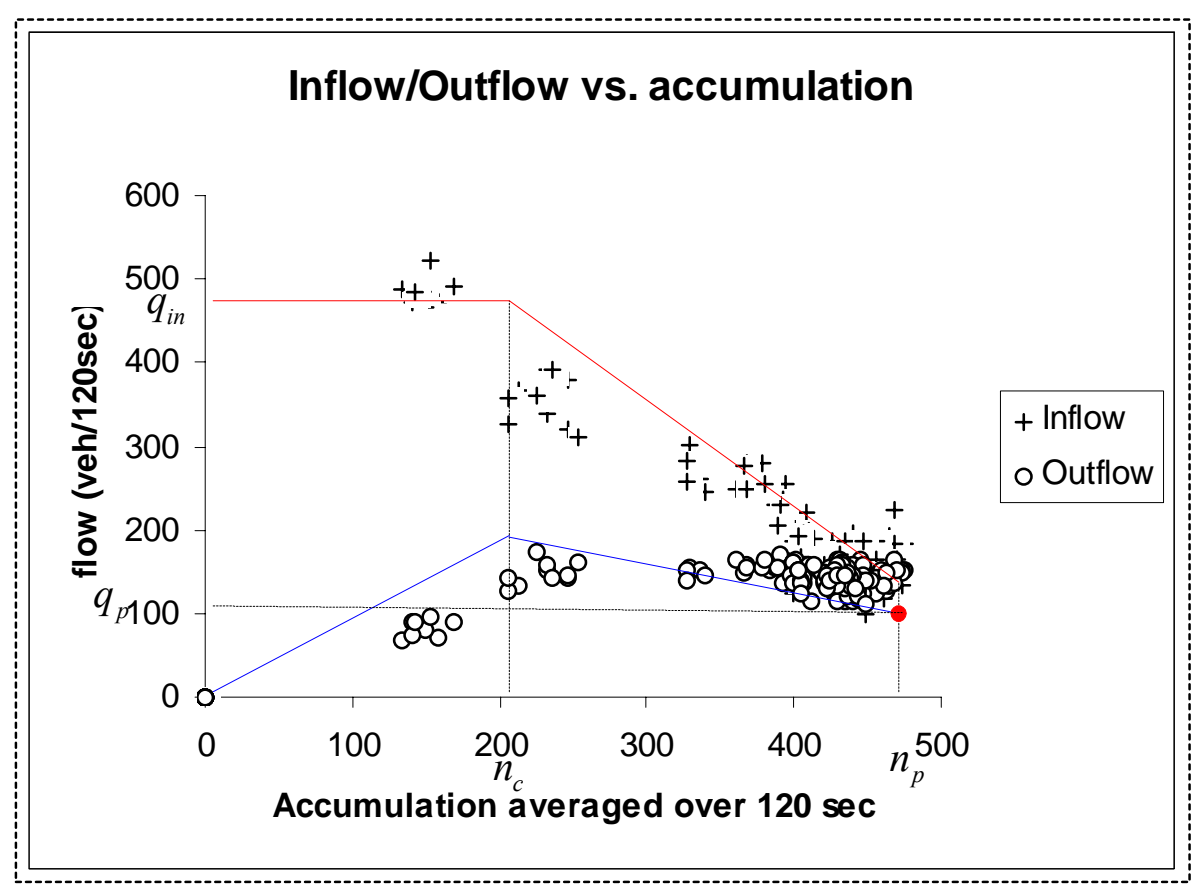

Figure 7-4: Plot of Inflow and outflow vs. accumulation and the trend assumed

The plot shows two distinct regimes. The first regime corresponds to the constrained regime, where the outflow increases to a maximum value ( $\left.q_{c}=178 \mathrm{veh} / 120 \mathrm{sec}\right)$ as the accumulation increases. This maximum outflow corresponds to an accumulation of $n_{c}$ equal to 212 vehicles. The second regime corresponds to the constrained regime, where the outflow decreases from its maximum value as the accumulation increases. The reason for the reduction in outflow during the constrained regime is due to blockage of exits by vehicles accessing other exits. Observing the trend in Figure 7-4, it is fair to assume a piecewise linear relationship to describe the two regimes of the 
outflow-accumulation relationship (Figure 7-5). The piecewise formulation describing the outflow-accumulation relationship is written as:

$$
Q_{\text {out }}(n)=\left\{\begin{array}{lr}
\lambda n & \forall n \leq n_{c} \\
-\alpha n+\beta & \forall n \text { s.t. } n_{p} \geq n>n_{c}
\end{array}\right.
$$

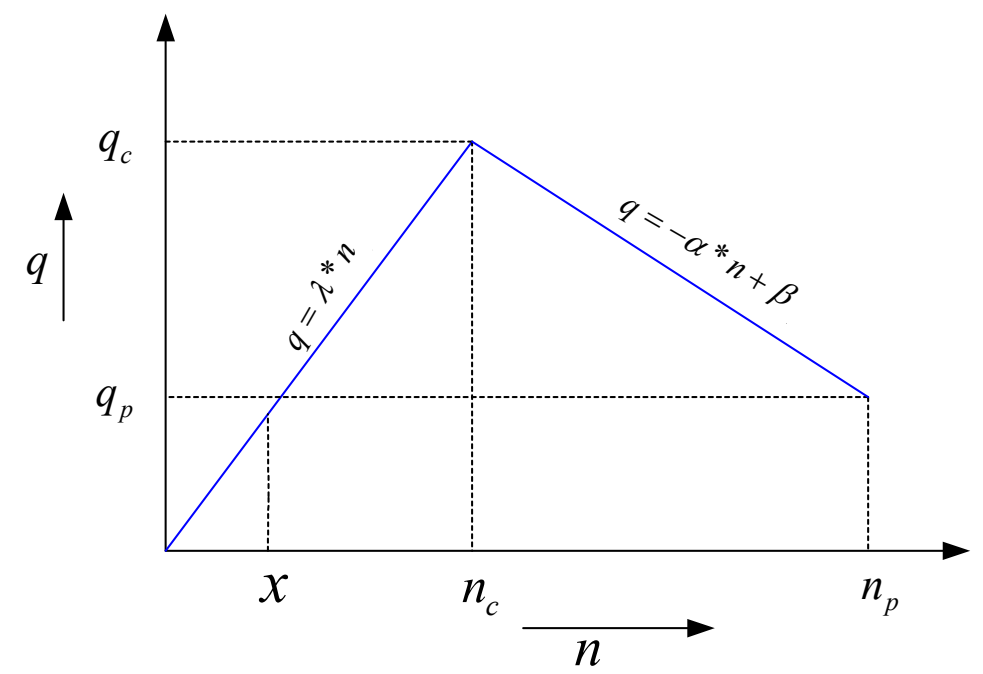

Figure 7-5: Conceptualization of relationship between outflow and accumulation

For this network $\lambda$ was equal to $0.84, \alpha$ was equal 0.084 to and $\beta$ was found to be 179. It was observed that the maximum accumulation was 480 vehicles.

\subsubsection{Inflow-Accumulation Relationship at Network Level}

Simulation studies by Geroliminis and Daganzo (2007) showed that the dependence of inflow on accumulation had a trend similar to as seen in Figure 7-4. The inflow remains constant until the accumulation reaches $n_{c}$ and then begins to decrease. The accumulation $n_{c}$ corresponds to the boundary of the constrained and unconstrained outflow. During the unconstrained regime vehicles have an inflow equal the maximum possible flow $q_{i n}$, since none of the entries into the network are blocked. The moment the constrained conditions begin to set in, the outflow reduces leading to 
queuing of vehicles and blocking of inflows, this result in the inflow being constrained. Under the constrained regime the inflow keeps reducing, as the accumulation increases until the maximum accumulation $\left(n_{p}\right)$ allowed in the network. The moment the number of vehicles in the network reaches $n_{p}$, the inflow drops to the outflow $q_{p}$. Under the assumption that the network can have a maximum of $n_{p}$ accumulation, if the inflow is greater than outflow $\left(q_{p}\right)$ the accumulation would increase to a value greater than $n_{p}$, resulting in a violation of the assumption. Therefore the inflow will be equal to the outflow at the accumulation $n_{p}$. Therefore there is a discontinuity for the inflow at $n_{p}$. It will be later seen in this chapter (Section 7.4) that if the inflow has a continuous trend and the constrained regime of the inflow intersects the outflow at the maximum accumulation $\left(n_{p}\right)$, then infinite time would be taken to reach congested conditions (accumulation of $n_{p}$ ). In reality networks do reach congested conditions and are regularly observed in road networks around the world. To get around this problem of infinite convergence to congestion, discontinuity was assumed at the maximum accumulation $\left(n_{p}\right)$. The inflow into the network is greater than $q_{p}$ just before an accumulation of $n_{p}$, due to stochastic effects there are fluctuations in the accumulations, there might be periods when the total accumulation might be just lower than the maximum accumulation $\left(n_{p}\right)$, therefore the traffic inflow needs to stop for brief periods, so as to maintain an average inflow of $q_{p}$. These kinds of stop and go behavior with large oscillations in flows (Traffic Flow Theory Monograph, 2006) have been observed in congested conditions and can be explained by such a formulation. Therefore it is fair to assume a discontinuity. The relationship between the inflow and accumulation is shown in Figure 7-6, and can be formulated as: 
$Q_{i n}(n)=\left\{\begin{array}{l}q_{i n} \\ -\gamma n+\sigma \\ q_{p}\end{array}\right.$

$$
\begin{array}{r}
\forall n \text { s.t. } n \leq n_{c} \\
\forall n \text { s.t. } n_{p}>n>n_{c} \\
n=n_{p}
\end{array}
$$

A plot describing the conceptualization of the trends of the outflow-accumulation relationship and the inflow-accumulation relationship are shown in contrast to the observed values in Figure 7-4. Since the inflow was large the network quickly progressed towards constrained condition. As can be seen in Figure 7-4, the vehicles remained in unconstrained regime for a brief period, during which the inflow was found to be 483 vehicles $/ 120 \mathrm{sec}$. The inflow of vehicles just before $n_{p}$ was taken to be $155 \mathrm{veh} / 120 \mathrm{sec}$ and the value of outflow at accumulation $n_{p}\left(q_{p}\right)$ was found to be around $138 \mathrm{veh} / 120 \mathrm{sec}$, which was also the value of the inflow at an accumulation of $n_{p} . \gamma$ was found to be 0.87 and $\sigma$ was equal to 573 . These values were calibrated for Do-nothing strategy.

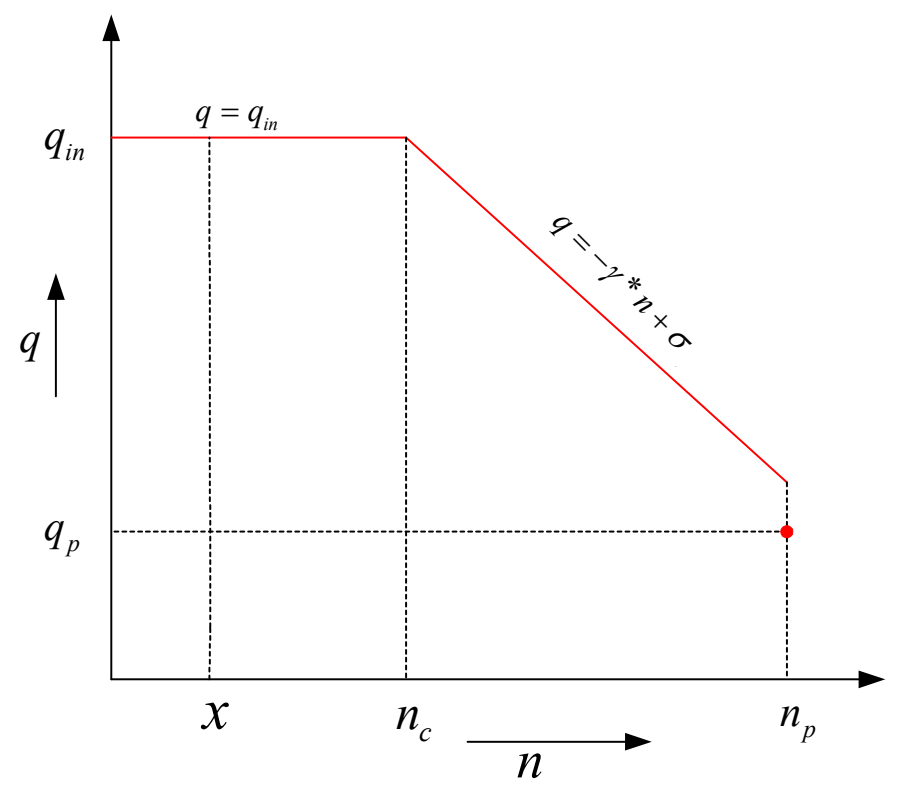

Figure 7-6: Plots describing relationships between inflow and accumulation 


\subsection{Modeling and Methodology}

This section presents a formal methodology for the network breathing strategy. In the network breathing strategy the inflow is allowed into the network until the network reaches jam conditions, after which the network is allowed to relax, implying that inflow into the network is shutdown. The intuitive reason in adopting this cyclical approach is to ensure that no sustained constrained flow $\left(q_{p}\right)$ at maximum accumulation $\left(n_{p}\right)$ exists.

The dynamics of the number of vehicles (Accumulation) in the network can be described by a differential equation (equation 7-19). The differential equation basically states the rate of change of accumulation is the difference between the inflow and the outflow. If the outflow is greater than the inflow then the accumulation will decrease with time, if the outflow is less than the inflow the accumulation will increase with time. It is assumed that the maximum inflow $\left(q_{i n}\right)$ is greater than the maximum outflow $\left(q_{c}\right)$.

$$
\frac{d n}{d t}=Q_{\text {in }}(n)-Q_{\text {out }}(n)
$$

When vehicles initially enter the network the outflow and inflow correspond to the unconstrained regime $\left(n<n_{c}\right)$. Therefore the time taken to dissipate vehicles during the unconstrained regime when accumulation grows from 0 to $n_{c}, t_{s}$ is shown in equation 7-21.

$$
\begin{aligned}
& \int_{0}^{n_{c}} \frac{d n}{\left(q_{i n}-\lambda n\right)}=\int_{0}^{t_{s}} d t \\
& t_{s}=-\frac{1}{\lambda} \ln \left(1-\frac{\lambda n_{c}}{q_{i n}}\right)
\end{aligned}
$$


After the accumulation in the network has reached $n_{c}$, the equations describing the inflow and outflow shift to the constrained regime, where $n>n_{c}$. Since the maximum accumulation that can be reached in the network is $n_{p}$. The time taken for the accumulation in the network to grow from $n_{c}$ to $n_{p}$ is represented by $t_{d}$, in equation 7-

22.

$\int_{0}^{t_{d}} d t=\int_{n_{c}}^{n_{p}} \frac{d n}{((-\gamma n+\sigma)-(-\alpha n+\beta))}=\int_{n_{c}}^{n_{p}} \frac{d n}{((\alpha-\gamma) n+(\sigma-\beta))}$

$t_{d}=\frac{1}{(\alpha-\gamma)} \ln \left(\frac{(\alpha-\gamma) n_{p}+(\sigma-\beta)}{(\alpha-\gamma) n_{c}+(\sigma-\beta)}\right)$

If the network has an accumulation at some intermediary value $x$ then the time taken in the constrained regime for the accumulation to reach the maximum accumulation $n_{p}$ is represented by $t_{d}(x)$ and is shown in equation 7-23. $t_{d}(x)$ is the time taken to reach $n_{p}$ under constrained conditions, therefore the minimum value $x$ can have during constrained conditions is $n_{c}$, but if $x \leq n_{c}$, then the time in the constrained region is $t_{d}$ in equation $7-22$.

$t_{d}(x)= \begin{cases}\frac{1}{(\alpha-\gamma)} \ln \left(\frac{(\alpha-\gamma) n_{p}+(\sigma-\beta)}{(\alpha-\gamma) n_{c}+(\sigma-\beta)}\right) & \forall x \leq n_{c} \\ \frac{1}{(\alpha-\gamma)} \ln \left(\frac{(\alpha-\gamma) n_{p}+(\sigma-\beta)}{(\alpha-\gamma) x+(\sigma-\beta)}\right) & \forall x>n_{c}\end{cases}$

It will be interesting to observe here the formulation of $t_{d}(x)$ in equation $7-23$. The numerator inside the logarithmic term of equation $7-23$, is the difference between the inflow and the outflow at the maximum accumulation $\left(n_{p}\right)$, if the inflow describing the constrained region intersected the outflow at $n_{p}$ without discontinuity, the value of the 
numerator would tend to 0 , making the value of $t_{d}(x)$ at $n_{p}$ infinite. Indicating that it would take infinite time to reach jam conditions, which is not true. For this reason it would be fair to assume a discontinuity at $n_{p}$ for inflow.

According to the network breathing strategy proposed, once the network is congested with the maximum accumulation possible the network relaxation is started. During this process the inflow is shutdown, therefore the accumulation in the network begins to reduce. This increases the outflow. The basic idea behind this approach is to maintain an inflow greater than the inflow at the maximum accumulation. This helps increase the inflow into the network.

If the network is relaxed to an accumulation of $x$, the time taken to reach an accumulation of $x$ from $n_{p}$ depends on whether $x \leq n_{c}$ or $x>n_{c}$ and is represented by $t_{b}(x)$. If $x<n_{c}$ then during the reduction of accumulation from $\mathrm{n}_{\mathrm{p}}$ to $\mathrm{n}_{\mathrm{c}}$ the outflow will correspond to the constrained regime. After which the outflow will correspond to the unconstrained regime. Therefore the time taken to reach $x$ if $x \leq n_{c}$ is the sum of the time taken in the two regimes. This is shown in equation 7-24

$$
\begin{aligned}
& t_{b}(x)=\int_{n_{p}}^{n_{c}} \frac{d n}{(0-(-\alpha n+\beta))}+\int_{n_{c}}^{x} \frac{d n}{(0-\lambda n)}=\int_{n_{p}}^{n_{c}} \frac{d n}{(\alpha n-\beta)}+\int_{n_{c}}^{x} \frac{d n}{-\lambda n} \quad \forall x \leq n_{c} \\
& t_{b}(x)=\frac{1}{\alpha} \ln \left(\frac{\alpha n_{c}-\beta}{\alpha n_{p}-\beta}\right)-\frac{1}{\lambda} \ln \frac{x}{n_{c}} \quad \forall x \leq n_{c}
\end{aligned}
$$

If $x>n_{c}$, then the drop in accumulation in the network from $n_{p}$ to $x$ occurs in the constrained regime, therefore the outflow corresponds to the constrained regime. Hence the second term in the R.H.S. of equation 7-24 is dropped, and since the 
network is relaxed to $x$. $\left(x>n_{c}\right), n_{c}$ is replaced with $x$. Therefore the time taken to relax when $x>n_{c}$ is given by equation 7-25.

$$
\begin{aligned}
& t_{b}(x)=\frac{1}{\alpha} \ln \left(\frac{\alpha x-\beta}{\alpha n_{p}-\beta}\right) \quad \forall x>n_{c} \\
& \therefore t_{b}(x)= \begin{cases}\frac{1}{\alpha} \ln \left(\frac{\alpha n_{c}-\beta}{\alpha n_{p}-\beta}\right)-\frac{1}{\lambda} \ln \frac{x}{n_{c}} & \forall x \leq n_{c} \\
\frac{1}{\alpha} \ln \left(\frac{\alpha x-\beta}{\alpha n_{p}-\beta}\right) & \forall x>n_{c}\end{cases}
\end{aligned}
$$

After the network relaxation process, the inflow is allowed back into the network, due to which the accumulation begins to increase. $t_{n}(x)$ is defined as the time for the network accumulation to grow from $\mathrm{x}$ to $n_{c}$ under the unconstrained regime. This is shown in equation 7-27.

$$
\begin{aligned}
& \int_{x}^{n_{c}} \frac{d n}{\left(q_{\text {in }}-\lambda n\right)}=\int_{0}^{t_{n}} d t \\
& t_{n}(x)=-\frac{1}{\lambda} \ln \left(\frac{\lambda n_{c}-q_{\text {in }}}{\lambda x-q_{\text {in }}}\right) \quad \forall x \leq n_{c}
\end{aligned}
$$

The time taken for the accumulation to grow back to $n_{p}$ is the sum of the time taken for the accumulation to grow from $x$ to $n_{c}$ under unconstrained regime and the time taken for accumulation to grow from $n_{c}$ to $n_{p}$ under the constrained regime. If $x>n_{c}$, the accumulation to which network was relaxed lies in the constrained regime, since $t_{n}(x)$ is defined for unconstrained conditions, $t_{n}(x)$ is taken to be 0 for $x>n_{c}$. The functional form for $t_{n}(x)$ is given in equation 7-28. 


$$
t_{n}(x)= \begin{cases}-\frac{1}{\lambda} \ln \left(\frac{\lambda n_{c}-q_{\text {in }}}{\lambda x-q_{\text {in }}}\right) & \forall x \leq n_{c} \\ 0 & \forall x>n_{c}\end{cases}
$$

Since the inflow remains constant during the unconstrained regime the number of vehicles dissipated into the network during unconstrained conditions is the product of $q_{\text {in }}$ and the time spent in the unconstrained region. To determine the number of vehicles dissipated into the network during the network breathing process, it is required to determine the increase in accumulation during constrained conditions.

From equation $7-18$, the inflow during congested conditions can be described by equation 7-29.

$$
\begin{array}{ll}
Q_{i n}=-\gamma n+\sigma & \forall n>n_{c} \\
\frac{d n_{i n}}{d t}=-\gamma n+\sigma & \forall n>n_{c} \\
\frac{d n_{i n}}{d n} \frac{d n}{d t}=-\gamma n+\sigma & \forall n>n_{c} \\
\frac{d n_{i n}}{d n}=\frac{-\gamma n+\sigma}{\left(\frac{d n}{d t}\right)} & \forall n>n_{c}
\end{array}
$$

Utilizing equation 7-19 and inserting the equations describing the inflows and outflows during the constrained regime. The rate of change of accumulation in the network during constrained conditions can be described by equation 7-33.

$$
\frac{d n}{d t}=(\alpha-\gamma) n+(\sigma-\beta) \quad \forall n>n_{c}
$$


To derive a differential equation (equation 7-34) describing the dynamics of the number of vehicles dissipated into the network with respect to the accumulation equation 7-33 is replaced in equation 7-32.

$\frac{d n_{i n}}{d n}=\frac{-\gamma n+\sigma}{((\alpha-\gamma) n+(\sigma-\beta))} \quad \forall n>n_{c}$

To determine the number of vehicles dissipated into the network from an accumulation of $x$ to $n_{p}\left(n_{\text {in }}(x)\right)$ under constrained conditions, is shown in equation 39.

$$
\begin{aligned}
& n_{i n}(x)=\int_{x}^{n_{p}} \frac{-\gamma n+\sigma}{((\alpha-\gamma) n+(\sigma-\beta))} d n \quad \forall n>n_{c} \\
& n_{i n}(x)=\frac{-\gamma\left(n_{p}-x\right)}{(\alpha-\gamma)}+\frac{\gamma}{(\alpha-\gamma)}\left(\frac{\sigma}{\gamma}+\frac{(\sigma-\beta)}{(\alpha-\gamma)}\right) \ln \left(\frac{n_{p}+\frac{(\sigma-\beta)}{(\alpha-\gamma)}}{x+\frac{(\sigma-\beta)}{(\alpha-\gamma)}}\right) \quad \forall x \geq n_{c}
\end{aligned}
$$

When the accumulation grows from an unconstrained region, the dissipation of vehicles will be $q_{\text {in }} t_{n}(x)$, after which the number of vehicles dissipated under constrained conditions is $n_{i n}\left(n_{c}\right)$. Therefore, for $x<n_{c}, n_{i n}(x)$ is defined as $n_{i n}\left(n_{c}\right)$. The functional form for $\mathrm{n}_{i n}(x)$ is given in equation 7-36.

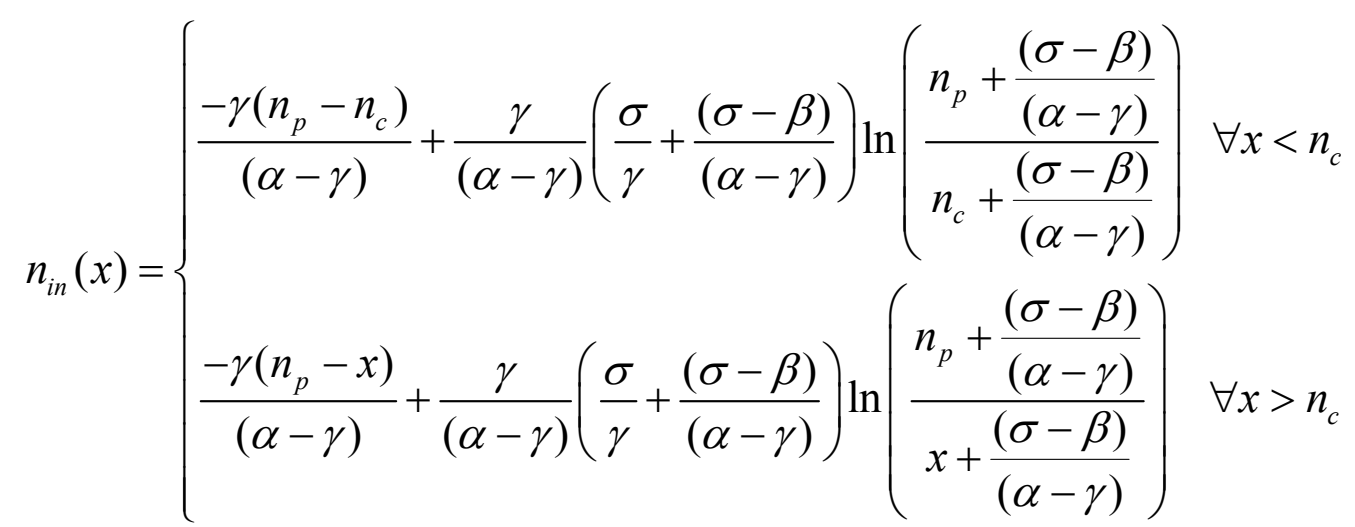


Our objective is to dissipate the maximum number of vehicles into the destination network during time $T$. The total time can then be written as the sum of the initial time taken to reach an accumulation of $n_{p}$ from 0 and the product of the number of network breathing cycles taken and the time spent in each network breathing scheme. The time taken for the network breathing scheme is the sum of time required to relax the network to an accumulation of $x\left(t_{b}(x)\right)$, the time required to get back to $n_{c}$ $\left(t_{n}(x)+t_{d}(x)\right)$. The cycles might not be able to complete the entire time period, hence during the rest of the time $(d e l)$ the outflow is equal to the inflow $\left(q_{p}\right)$. Hence $T$ is written as equation 7-37.

$T=t_{s}+t_{d}\left(n_{c}\right)+m\left(t_{b}(x)+t_{d}(x)+t_{n}(x)\right)+d e l$

The number of network breathing cycles in the process of dissipation is shown in equation 7-38.

$$
m=\left\lfloor\frac{\left(T-t_{s}-t_{d}\left(n_{c}\right)\right)}{\left(t_{b}(x)+t_{d}(x)+t_{n}(x)\right)}\right\rfloor
$$

The excess time left $(\mathrm{del})$ after the network breathing cycles is given by equation 7 39.

$$
d e l=T-\left(t_{s}+t_{d}\left(n_{c}\right)+\left\lfloor\frac{\left(T-t_{s}-t_{d}\left(n_{c}\right)\right)}{\left(t_{b}(x)+t_{d}(x)+t_{n}(x)\right)}\right\rfloor\left(t_{b}(x)+t_{d}(x)+t_{n}(x)\right)\right)
$$

During this time the accumulation in the network is at the maximum and the outflow is equal to the inflow at $q_{p}$. Therefore the number of vehicles dissipated into the network during this period $(\mathrm{del})$ is given by equation $7-40$. 
$\operatorname{excess} N= \begin{cases}\operatorname{del}^{*} q_{p} & \text { del }>0 \\ 0 & \text { del } \leq 0\end{cases}$

The total number of vehicles dissipated into the network during time $T$, can be written as the sum of vehicles dissipated into the network during unconstrained conditions, constrained conditions, and the number of vehicles dissipated during each cycle and during time del.

$N=q_{i n} t_{s}+n_{i n}\left(n_{c}\right)+m\left(q_{i n} t_{n}(x)+n_{i n}(x)\right)+\operatorname{excess} N$

Replacing value of $m$ in equation 7-41 we get equation 7-42.

$N=q_{i n} t_{s}+n_{i n}\left(n_{c}\right)+\left\lfloor\frac{\left(T-t_{s}-t_{d}\left(n_{c}\right)\right)}{\left(t_{b}(x)+t_{d}(x)+t_{n}(x)\right)}\right\rfloor\left(q_{i n} t_{n}(x)+n_{i n}(x)\right)+\operatorname{excess} N(7-42)$

To determine the strategy that maximizes the dissipation of vehicles into the network. $N$ in equation 7-42 is maximized in order to determine the accumulation to which the network should be relaxed. Using this value the relaxation time and the time for network inhalation can be calculated, which can then be used to meter the inflow into the network.

\subsection{Results}

To test the proposed above methodology the relationships between the outflows and inflows with the accumulations were calibrated for the network earlier described (Figure 7-1). The values observed during the analysis of the outflow vs. accumulation and inflow vs. accumulation, were used to calibrate the equation describing these models. The data was extracted using a MATLAB code (APPENDIX E). 
To determine the accumulation to which the network should be relaxed during the network breathing strategy, so that the number of vehicles dissipated into the network is maximized, equation 45 was maximized. The time unit taken was 120 seconds, since all flows and number of vehicles were averaged over 120 seconds. The maximization of equation 45 indicated that the network should be relaxed for a period of 2.25 units $(2.25 * 120 \mathrm{sec})$ to an accumulation of 148 vehicles. A plot (Figure 7-7) constructed between the relaxation time and the number of vehicles dissipated into the network indicates that the dissipation of number of vehicles drops significantly quickly after the maximum. Therefore to be on the conservative side the network was relaxed for 1 unit of time (120 seconds) after which the inflow was allowed for 360 seconds. In the figure it can be clearly observed that benefits of the network breathing are only seen for relaxation times less than thresh.

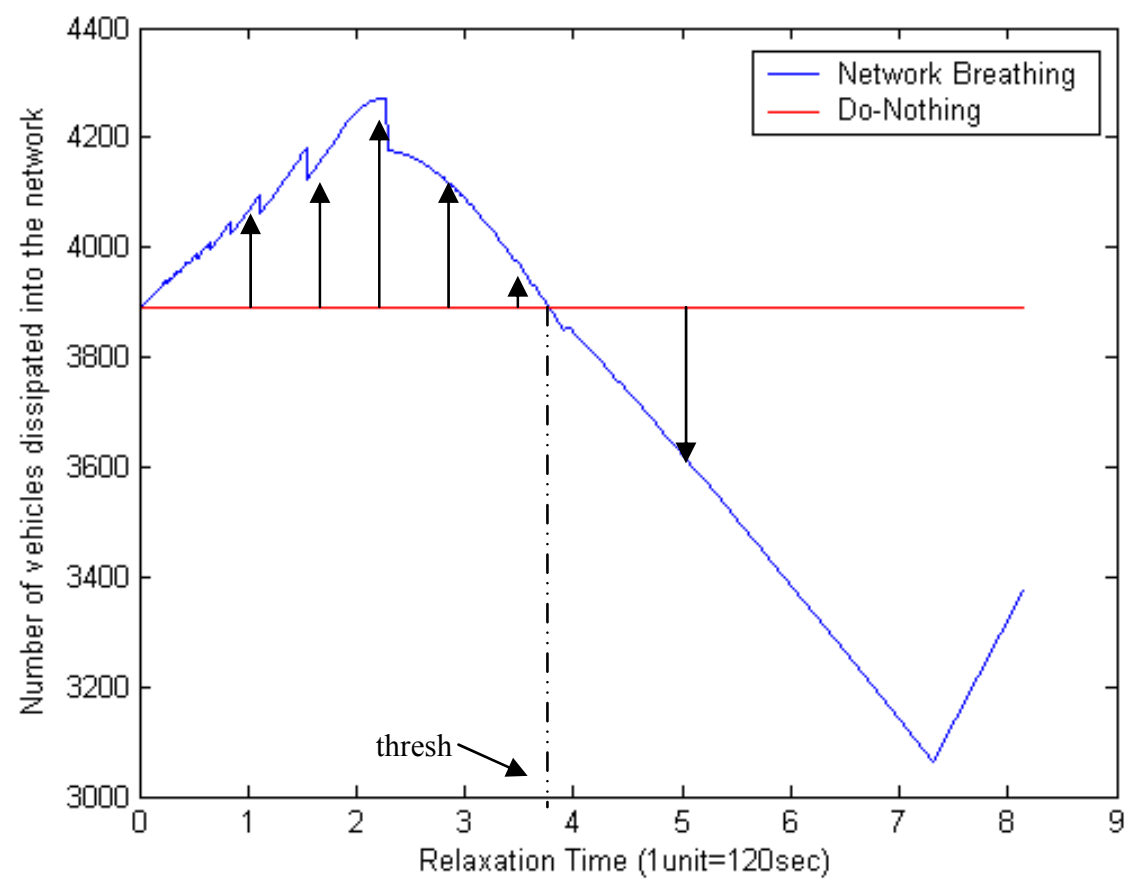

Figure 7-7: The plot between the number of vehicles dissipated into the network and time allowed for the network to relax 
The simulation was run for 3240 seconds for multiple runs. It was found that the average number of vehicles dissipated during the do-nothing scenario for the same time period was 3922 vehicles and for the network breathing scenario, where the network was relaxed for 120 seconds and inflow allowed for 360 seconds had a statistically significant increase in the dissipation of vehicles in the network to 4076 an increase of 154 vehicles in 3240 seconds. The simulation results showed that the network breathing strategy performs very well. Figure 7-8 indicates the results of the observed and predicted number of vehicles dissipated vs. the estimated. The errors printed above the observed and predicted number of vehicles in Figure 7-8, is less than $1 \%$, indicating a good performance of our modeling methodology.

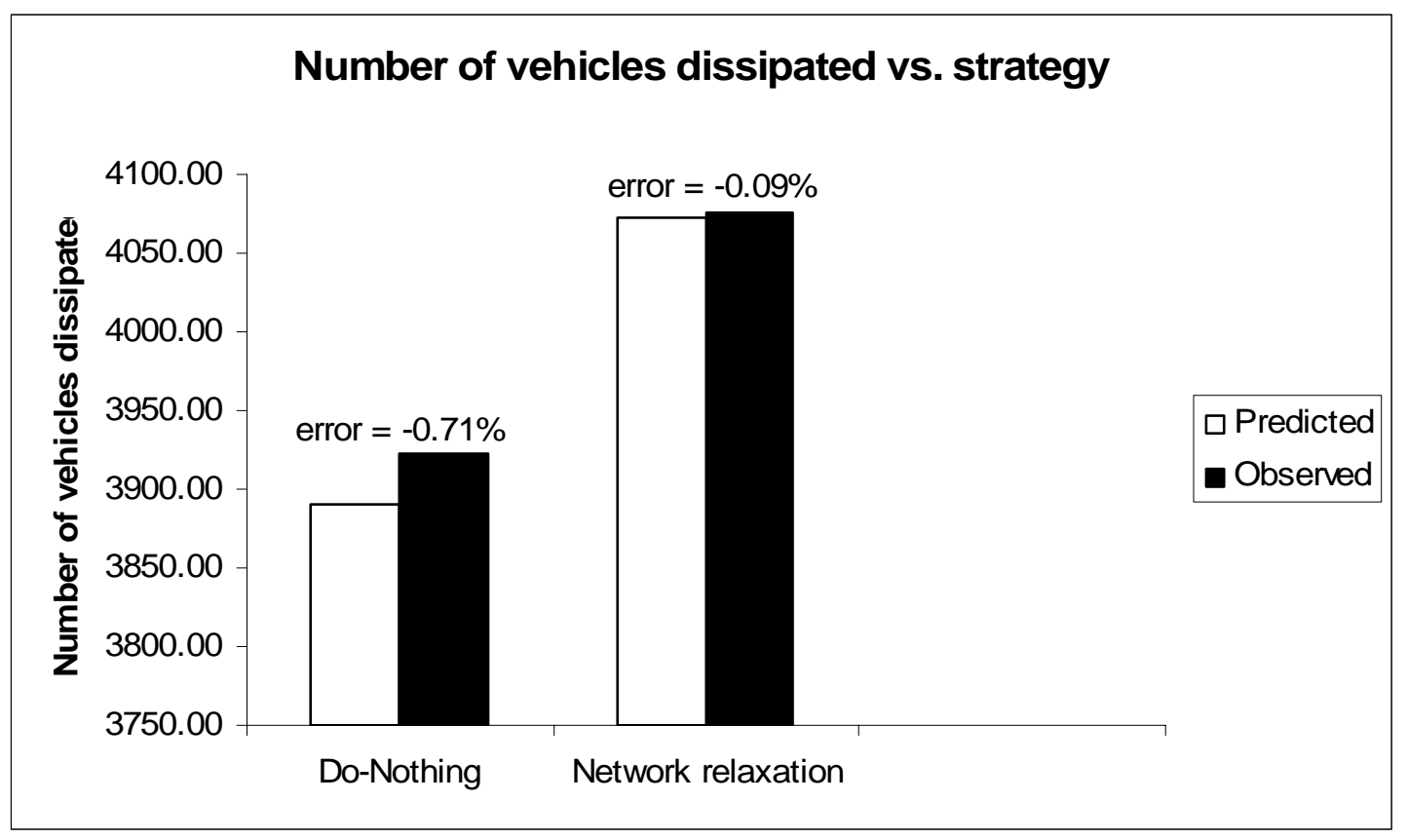

Figure 7-8: Results between prediction of number of vehicles dissipated into the network through theoretical methodology and actual observed number of vehicles dissipated. 


\subsection{Conclusion}

This chapter provides a theoretical basis to various relationships observed previously between average network level variables in simulation and field experiments. It then utilizes these relationships to develop network scale strategies that increase the dissipation of the number of vehicles into the network.

Using the theoretical framework for the network breathing strategy, the relaxation time and the network inhalation times were determined and tested using simulation. The network breathing strategy considerably outperformed a do-nothing scenario. One of the main advantages of the network breathing strategy is that it does not required real time feedback. If the properties of the network are known earlier, then the methodology described earlier can be used to come up with a prescription for relaxation time and network inhalation time. Under emergency conditions when the real time feedback might fail such an approach will be very useful. The network breathing strategy can be implemented using signals of cycle length determined by the relaxation time and the network inhalation time.

Most of the microscopic simulation studies do not consider the effect of the destination network. This results in a myopic analysis resulting in a gap between the expectations from simulation analysis and reality. The macroscopic relationships and modeling discussed need to be used in conjunction with microscopic simulation, in order for the models to incorporate effects of destination nodes.

During Evacuation it is crucial to keep the traffic moving at an acceptable rate and reduce delays. With present strategies vehicles wanting to exit onto a particular 
destination, are constrained by the state of the destination network. This results in backups which result in reduction of flows on the mainstream evacuation route, hindering flow of vehicles wanting to go to a destination further downstream on the evacuation route. The network breathing scheme can be used to effectively increase the dissipation into the destination networks. During the closure of the inflow into one destination network the vehicles can be redirected to another destination, hence improving the flow on the evacuation routes. 


\section{CHAPTER 8 \\ SUMMARY, CONCLUSIONS AND FUTURE SCOPE}

The research conducted on evacuation behavior resulted in concluding that evacuation behavior is significantly affected by recent preceding hurricane. The most interesting finding in the model for mobilization time (i.e., variable "delay") related to the variables that were found to be insignificant. These variables include pet ownership (“pets"), number of kids ("num_kids"), presence of very old individuals (age > 80 years; variable "eighty_plus") in the household, and need for special assistance ("assist"). It indicates that following a major hurricane the households, which generally take more time to evacuate, make arrangements to better prepare themselves. It likely reduces their mobilization times during a subsequent hurricane. As part of a future study, it would be interesting to analyze how the reduced mobilization times relate to the evacuation demand (generally represented by an Scurve) during a subsequent storm. It was observed that initial portion of the S-curve(s) representing cumulative evacuation response was indeed higher for hurricane Frances compared to hurricane Charley. What proportion of this increased evacuation response rate may be attributed to the households with reduced mobilization times remains to be studied. Furthermore, the increase in overall evacuation participation that might result from a preceding hurricane also needs to be considered in planning for subsequent hurricanes. Survey data that combines information on characteristics of evacuees and non-evacuees from a storm affected region would have to be used for these future investigations. The effects of a previus hurricane on evacuation of a subsequent hurricane should be considered and should be studied as a worst-case scenario. 
There is also a significant need to understand driving behavior under evacuation conditions. If better understood, strategies could be identified to reduce fuel consumptions and having vehicle breakdowns due to no fuel.

A comparison of the mesoscopic simulation model (CTM) with a microscopic simulation model (VISSIM) suggested that CTM runs much faster than VISSIM, CTM took 7.5 minutes as compared to 100 hours in VISSIM. CTM also provided a reasonable level of accuracy. This indicates that CTM is an ideal tool that can be used for a real time decision support system to determine dynamic crossovers due to an unforeseen incident.

The optimization model proposed for optimal scheduling of evacuation order could result in significant benefits in system time. The optimization model can be made part of a real time framework, where real time data is used to evaluate when the next evacuation order should be delivered.

An optimization model to determine optimal location of crossovers was developed. It was utilized to determine optimal crossover locations along Interstate-4. A model for dynamic crossovers in case of incidents has also been presented as part of this chapter. The concept of dynamic crossover was tested when capacity is reduced on certain sections of the Interstate 4 due to incidents. It was seen that there are operational benefits of having a dynamic crossover. The model helps decide which crossovers should be placed in operation during an incident. The proposed optimization model could be utilized as part of a real time system to determine which crossovers should be kept open. 
Finally relationships between network level variables were theoretically derived and tested using simulation. A new strategy called Network Breathing Strategy was proposed to improve dissipation into destination networks.

One of the main advantages of the network breathing strategy is that it does not required real time feedback. If the properties of the network are known earlier, then the methodology described earlier can be used to come up with a prescription for relaxation time and network inhalation time. Under emergency conditions when the real time feedback might fail such an approach will be very useful. The network breathing strategy can be implemented using signals of cycle length determined by the relaxation time and the network inhalation time.

Most of the microscopic simulation studies do not consider the effect of the destination network. This results in a myopic analysis resulting in a gap between the expectations from simulation analysis and reality. The macroscopic relationships and modeling discussed need to be used in conjunction with microscopic simulation, in order for the models to incorporate effects of destination nodes.

The optimal scheduling of evacuation orders and crossover locations as well as the concept of the dynamic crossover could be integrated with the network breathing strategy, for efficient evacuation operations. A real time integrated framework for a decision support system is presented in Figure 8-1. 


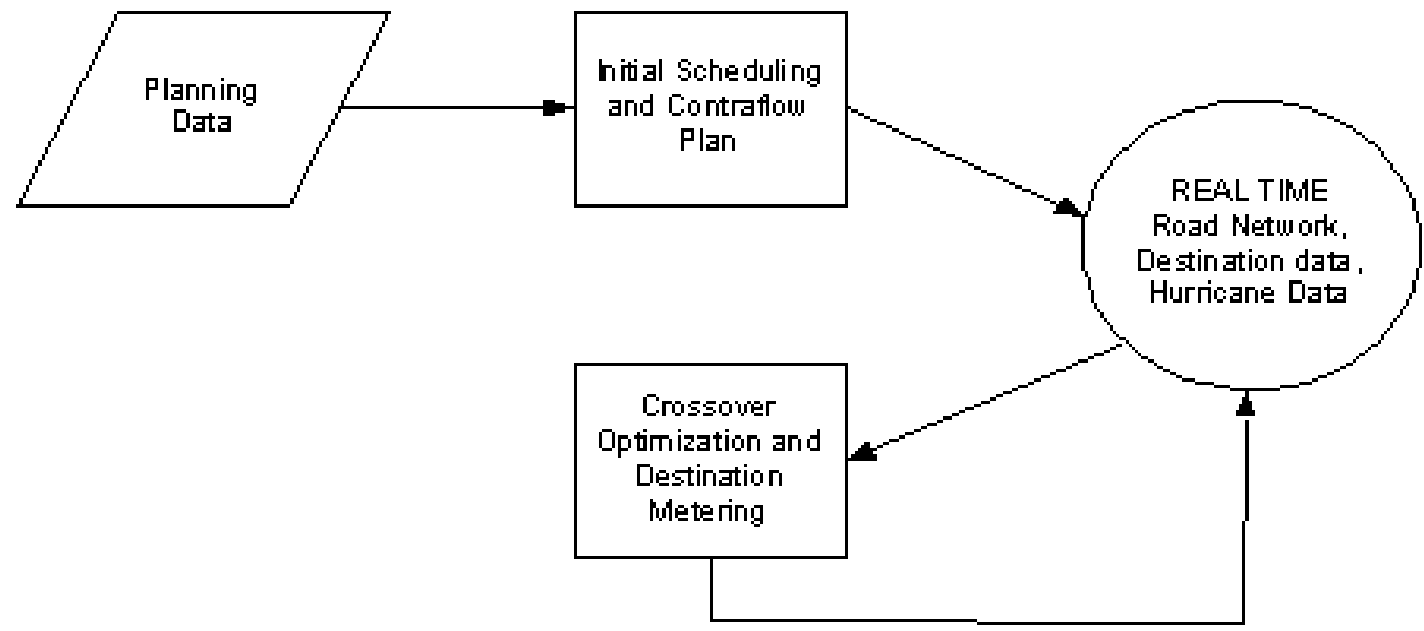

Figure 8-1: Real Time Integrated Framework

The planning data contains the initial estimates of demand and evacuation routes. These are utilized to determine the optimal scheduling of evacuation orders and crossover points for contraflow. These are implemented. Based on the hurricane data and traffic data these optimal decisions are reevaluated, as well as the destination metering scheme is developed in real time.

Such a real time decision support system will provide emergency management officials a fast a robust tool that will in turn help make evacuation plans flexible, with the ability to react to any eventuality. 
APPENDIX A 
SAS code for Data Analysis of Frances data

proc freq data=airport.frances;

tables ID Q5 Q29 Q30 Q31 Q32 Q39 Q40 Q127 Q128 Q129 Q130 Q131 Q132 Q133

Q134 Q135 Q136 Q137 Q138 Q139 Q140 Q143 Q144 Q145 Q148 Q149 Q150 Q156

Q157 Q159;

run;

proc print data=airport.frances;

run;

proc freq data=vinayak.FRANCES2;

where q39=3;

table q39*hour;

run;

proc freq data=vinayak.FRANCES2;

table q39;

run;

proc freq data=vinayak.FRANCES2;

where $\mathrm{q} 156=6$;

table q156*q39;

run;

proc freq data=vinayak.FRANCES2;

table Q39; 
run;

DATA vinayak.FRANCES2;

set vinayak.FRANCES2;

if region $=10$ then Charley $1=1$;

if region $=11$ then Charley $1=1$;

if region $=13$ then Charley $1=2$;

if region $=7$ then Charley $1=3$;

if region $=12$ then Charley $1=4$;

if region $=8$ then Charley $1=5$;

if region $=9$ then Charley $1=5$;

if region in $(10,11,13,7)$ charley $2=1$;

if region in $(8,9,12)$ charley $2=0$;

run;

DATA TRIAL;

SET VINAYAK.FRANCES;

$\mathrm{HOUR}=(\mathrm{Q} 29-2) * 24+12 *(\mathrm{Q} 32-1)+\mathrm{Q} 31$; 
IF HOUR $<0$ THEN HOUR $=0$;

RUN;

PROC UNIVARIATE data=VINAYAK.FRANCES2;

class q157;

where q157 in $(8,11)$;

VAR HOUR;

HISTOGRAM;

RUN;

If $($ Date_left $=1)$

then time $=0$;

else

HOUR $=($ Date_left-2 $) * 24+12 *($ AM/PM -1) $)+$ Time_left

Date_Left (Q29)

Time_Left (Q31)

$\mathrm{AM} / \mathrm{PM}(\mathrm{Q} 32)$

proc freq data $=$ vinayak.frances;

tables Q31 Q32 q31*q32;

run;

proc freq data $=$ TRIAL;

tables q157; 
run;

proc freq data=TRIAL;

tables hour*q157 /nofreq norow nocol;

run;

proc freq data=vinayak.q39;

tables q130;

run;

proc freq data=vinayak.q39;

tables q127;

run;

data vinayak.q39;

set vinayak.frances2;

if q39 in $(1,2)$ then d_delay $=1$;

if q39 in $(3,4)$ then d_delay $=2$;

if q39 in $(5,6)$ then d_delay $=3$;

if q39 in $(7,8)$ then delete;

run;

data vinayak.frances3;

set vinayak.frances2;

drop q133 q30 q150 q40 q145 q129 q131 q132 q159 q5;

run;

data vinayak.frances3; 
set vinayak.frances3;

if q29 in $(8,9)$ then $\mathrm{q} 29=$.;

if $\mathrm{q} 31=99$ then $\mathrm{q} 31=$;

if $\mathrm{q} 39$ in $(7,8)$ then $\mathrm{q} 39=$;

if q127 in $(8,9)$ then $\mathrm{q} 127=$;

if q134 in $(88,99)$ then q134=.;

if q135 in $(88,99)$ then q135=.;

if q136 in $(0,0.1)$ then $\mathrm{q} 136=1$;

if $\mathrm{q} 136=88$ then $\mathrm{q} 136=$;

if $\mathrm{q} 137=$. then $\mathrm{q} 137=0$;

if $\mathrm{q} 137=88$ then $\mathrm{q} 137=$;

if $\mathrm{q} 138=$, then $\mathrm{q} 138=0$;

if $\mathrm{q} 138=88$ then $\mathrm{q} 138=$;

if $\mathrm{q} 139=3$ then $\mathrm{q} 139=$;

if $\mathrm{q} 140=3$ then $\mathrm{q} 140=$;

if $\mathrm{q} 143=3$ then $\mathrm{q} 143=$;

if $\mathrm{q} 148=7$ then $\mathrm{q} 148=$;

run;

DATA vinayak.frances3;

SET VINAYAK.FRANCES3;

$\mathrm{HOUR}=(\mathrm{Q} 29-2) * 24+12 *(\mathrm{Q} 32-1)+\mathrm{Q} 31$;

Time_day $=12 *(\mathrm{Q} 32-1)+\mathrm{Q} 31$;

if $\mathrm{q} 31=$. then Time_day=.;

IF HOUR $<0$ THEN HOUR $=0$; 
RUN;

data vinayak.frances3;

set vinayak.frances3;

if $\mathrm{q} 29=$. then $\mathrm{HOUR}=$.;

if $\mathrm{q} 31=$. then $\mathrm{HOUR}=$;

run;

data vinayak.frances3;

set vinayak.frances3;

if $\mathrm{q} 156=6$ then surge $=0$;

else surge $=1$;

if q149 $=6$ then irevealed $=0$;

else irevealed $=1$;

if q144 in $(1,2,3,5)$ then assist $=1$;

else assist $=0$;

if $\mathrm{q} 144=4$ then assist $=$;

if $q 127=1$ then type_struct $=1$;

if $q 127=2$ then type_struct $=2$;

if $\mathrm{q} 127=3$ then type struct $=3$;

if $\mathrm{q} 127=4$ then type_struct $=4$;

if q127 in $(5,6)$ then type_struct $=5$;

if q127 $=7$ then type_struct $=6$; 
if $\mathrm{q} 127=$. then type_struct $=$.;

if (type_struct $=5$ and q130=1) then MHstrength=1;

if $\mathrm{q} 130=2$ then MHstrength $=2$;

if $\mathrm{q} 130=3$ then MHstrength=.;

if type_struct $<5$ then MHstrength=3;

if q157 in $(7,8,9,11)$ then evac_issue $=1$;

else evac_issue $=0$;

if q157 in $(8,9)$ then storm_arr=1;

if q157 in $(12,13,7)$ then storm_arr=2;

if q157 in $(10,11)$ then storm_arr=3;

run;

data vinayak.q39;

set vinayak.frances3;

if q39 in $(1,2)$ then d_delay $=1$;

if q39 in $(3,4)$ then d_delay $=2$;

if q39 in $(5,6)$ then d_delay $=3$;

if $\mathrm{q} 39=$. then delete;

run;

proc freq data=vinayak.frances3;

tables Q128;

run; 
data vinayak.q39_final;

set vinayak.q39_s_ns;

if $\mathrm{q} 135<3$ then fla $\_$years $=1$;

if $2<\mathrm{q} 135<8$ then fla_years $=2$;

if $7<$ q135 $<13$ then fla $\_$years $=3$;

if $12<$ q135 $<18$ then fla_years $=4$;

if $17<\mathrm{q} 135<23$ then fla_years $=5$;

if $q 135>22$ then fla_years $=6$;

if $\mathrm{q} 134<3$ then hom $\_$years $=1$;

if $2<\mathrm{q} 134<8$ then hom $\_$years $=2$;

if $7<\mathrm{q} 134<13$ then hom_years $=3$;

if $12<\mathrm{q} 134<18$ then hom_years $=4$;

if $17<\mathrm{q} 134<23$ then hom_years $=5$;

if q134 $>22$ then hom_years $=6$;

if $\mathrm{q} 148=2$ then white $=1$; else white $=0$;

if $22<=$ time_day $<=24$ then time_class $=1$;

if $0<=$ time_day $<=5$ then time_class $=1$;

if $5<$ time_day $<=10$ then time_class $=2$;

if $10<$ time_day $<=15$ then time_class $=3$;

if $15<$ time_day $<=19$ then time_class $=4$;

if $19<$ time_day $<=22$ then time_class $=5$; 
run;

proc freq data=vinayak.q39_s_ns;

table q157*q156*hour;

run;

data vinayak.q39_final;

set vinayak.q39_final;

if q157 in $(10,11,13,7)$ then charley=1;

if $\mathrm{q} 157$ in $(8,9,12)$ then charley $=0$;

run;

proc freq data=vinayak.q39_final;

tables SURGE*q157;

RUN;

proc freq data=vinayak.q39_final;

tables q138*q137;

RUN;

proc freq data=vinayak.q39_final;

tables q138*charley;

RUN;

proc freq data=vinayak.q39_final;

tables q138*region;

RUN;

proc freq data=vinayak.q39_final;

tables q143; 
RUN;

proc freq data=vinayak.q39_final;

tables assist*q138;

RUN;

proc freq data=vinayak.q39_final;

tables assist*q137;

RUN;

proc freq data=vinayak.q39_final;

tables assist*q140;

RUN;

proc freq data=vinayak.q39_final;

tables q144;

RUN;

proc freq data=vinayak.q39_final;

tables q137 q138 q140;

RUN;

proc freq data=vinayak.q39_final;

tables assist;

RUN;

proc freq data=vinayak.q39_final;

tables assist*q140;

RUN;

proc freq data=vinayak.q39_final;

tables Eighty_plus; 
RUN;

proc freq data=vinayak.q39_final;

tables q39;

RUN;

data vinayak.q39_final;

set vinayak.q39_final;

if q157 in $(10,11,12,13)$ then charley_new $=1$;

if q157 in $(7,8,9)$ then charley_new $=0$;

run;

data vinayak.q39_final;

set vinayak.q39_final;

if q157 $=11$ then charley_ordinal $=4$;

if $q 157=12$ then charley_ordinal $=3$;

if $q 157=10$ then charley_ordinal $=2$;

if $q 157=13$ then charley_ordinal $=1$;

if q157 in $(8,9,7)$ then charley_ordinal $=0$;

run;

data vinayak.q39_final;

set vinayak.q39_final;

if $($ surge $=1$ and q157 in $(7,8,9))$ then surge_coast $=1$;

if $($ surge $=1$ and q157 in $(10,11))$ then surge_coast $=2$;

if surge $=0$ then surge_coast $=3$;

run; 
proc freq data=vinayak.q39_final;

tables q139*q134;

RUN;

proc freq data=vinayak.q39_final;

tables q139*q135;

RUN;

proc freq data=vinayak.q39_final;

tables STORM_ARR*q139;

RUN;

proc freq data=vinayak.q39_final;

tables q139*surge;

RUN;

/***FINAL MODELS JULY 14 2007*/

proc qlim data=vinayak.q39_final;

class type_struct Q157 q149 surge_coast;

model charley_ordinal $=$ Q137 Eighty_plus Q139 Q136 Q140 Q149

type_struct MHstrength fla_years /discrete ;

model d_delay_5level=Q137 Eighty_plus Q139 Q136 Q140 Q149

assist type_struct MHstrength fla_years surge_coast/discrete;

run; 
proc freq data=vinayak.q39_final;

tables surge_coast;

run;

proc freq data=vinayak.q39_final;

tables q149;

run;

proc freq data=vinayak.q39_final;

tables type_struct;

run;

proc freq data=vinayak.q39_final;

tables charley_ordinal;

run;

proc freq data=vinayak.q39_final;

tables charley_ordinal Q137 Eighty_plus Q139 Q136 Q140 Q149

type_struct MHstrength fla_years d_delay_5level assist fla_years surge_coast; run; 
APPENDIX B 


\section{MATLAB Code for I-4 Cell Transmission Model}

function $[\mathrm{s}, \mathrm{x}, \mathrm{xc}, \mathrm{y}, \mathrm{yc}, \mathrm{ys}]=$ SimulationI4

$\mathrm{S} 1(1: 2800)=0$

$\mathrm{S} 2(1: 2800)=0$;

$\mathrm{S} 3(1: 2800)=0$;

$\mathrm{x}(1: 71,1: 2800)=0 ; \mathrm{y}(1: 70,1: 2800)=0$

$\mathrm{N}(1: 71)=633$;

$\mathrm{Q}(1: 71)=96$;

$\operatorname{xmd}(1: 71,1: 2800)=0 ; y m(1: 70,1: 2800)=0 ; y d(1: 70,1: 2800)=0$

$\operatorname{Nmd}(1: 71)=411$;

$\operatorname{Qmd}(1: 71)=61$;

$\mathrm{xc}(1: 71,1: 2800)=0 ; \mathrm{yc}(1: 70,1: 2800)=0$

$\operatorname{Nc}(1: 71)=633$

$\mathrm{Qc}(1: 71)=64$

$\mathrm{s}(1: 3,1: 2800)=0 ; \mathrm{ys}(1: 3,1: 2800)=0$;

Qs $(1)=67$;

Qs(2)=36;

Qs(3)=36;

$S 1(1)=61645$; 
$\mathrm{s}(1,1)=\mathrm{S} 1(1)$

$\mathrm{S} 2(1)=11972$;

$\mathrm{s}(2,1)=\mathrm{S} 2(1)$

$\mathrm{S} 3(1)=32739$;

$\mathrm{s}(3,1)=\mathrm{S} 3(1)$

for $\mathrm{i}=2: 2800$

$$
\text { for } \mathrm{j}=1: 70
$$

$y(j, i-1)=f l o w(x(j, i-1), \min (Q(j), Q(j+1)), \operatorname{alpha}(x(j+1, i-1), Q(j)) *(N(j+1)-x(j+1, i-$

1)));

$y c(j, i-1)=$ flow $(x c(j, i-1), \min (Q c(j), Q c(j+1))$, alpha $(x c(j+1, i-1), Q(j)) *(N c(j+1)-$ $\mathrm{xc}(\mathrm{j}+1, \mathrm{i}-1))) ; \%$ Contraflow

end ys $(1, i-1)=$ flow $(s(1, i-1), Q s(1),(N(1)-x(1, i-1)))$;

$[\operatorname{yd}(1, \mathrm{i}-1), \mathrm{y}(4, \mathrm{i}-1)] \quad=\quad \operatorname{diverge}(\mathrm{x}(4, \mathrm{i}-1), \mathrm{xmd}(1, \mathrm{i}-1), \mathrm{x}(5, \mathrm{i}-$ 1),Q(4),Qc(4),Q(5), alpha(x(4,i-1),Q(4)),N(5),Nc(4),0.3,0.7);\% Contraflow

$$
[\mathrm{y}(27, \mathrm{i}-1), \mathrm{ys}(2, \mathrm{i}-1)] \quad=\quad \operatorname{merge}(\mathrm{x}(27, \mathrm{i}-1), \mathrm{s}(2, \mathrm{i}-1), \mathrm{x}(28, \mathrm{i}-
$$

1), Q(27), Qs(2), Q(28), alpha(x(27,i-1),Q(27)), N(28),0.6,0.4);

$$
[\mathrm{y}(40, \mathrm{i}-1), \mathrm{ys}(3, \mathrm{i}-1)] \quad=\quad \operatorname{merge}(\mathrm{x}(40, \mathrm{i}-1), \mathrm{s}(3, \mathrm{i}-1), \mathrm{x}(41, \mathrm{i}-
$$

1),Q(40),Qs(3),Q(41),alpha(x(40,i-1),Q(40)),N(41),0.6,0.4);

$[\mathrm{yc}(4, \mathrm{i}-1), \mathrm{ym}(1, \mathrm{i}-1)]=\operatorname{merge}(\mathrm{xc}(4, \mathrm{i}-1), \mathrm{xmd}(1, \mathrm{i}-1), \mathrm{xc}(5, \mathrm{i}-$

1), Qc(4), $\operatorname{Qmd}(1), \mathrm{Qc}(5), \operatorname{alpha}(\mathrm{x}(4, \mathrm{i}-1), \mathrm{Qc}(4)), \mathrm{Nc}(5), 0.3,0.7)$; \%Contraflow 


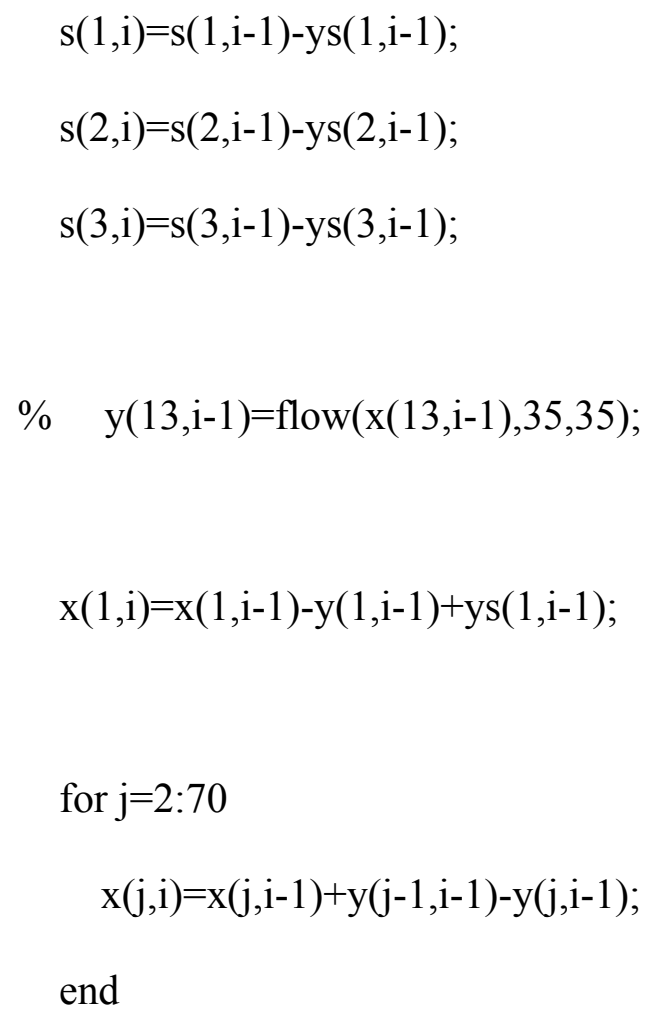


$\mathrm{xc}(71, \mathrm{i})=\mathrm{xc}(71, \mathrm{i}-1)+\mathrm{yc}(70, \mathrm{i}-1)-\mathrm{xc}(71, \mathrm{i}-1)$

end 
APPENDIX C 


\section{Optimization model for Evacuation Scheduling}

\section{$\underline{\text { Schedul.mod }}$}

param T;

set source_cell;

set ord_cell;

set merge_cell;

set diverge_cell;

set sink_cell;

set source_connect within (source_cell cross (ord_cell union merge_cell union diverge_cell));

set ord_connect within ((ord_cell union merge_cell) cross (ord_cell union diverge_cell));

set merge_connect within ((ord_cell union source_cell union merge_cell) cross merge_cell);

set diverge_connect within (diverge_cell cross (ord_cell union diverge_cell));

set sink_connect within (ord_cell cross sink_cell);

set cell within (source cell union ord cell union merge cell union diverge cell union sink cell);

set Link within (ord_connect union merge_connect union diverge_connect union source_connect union sink_connect);

set evacorder within $\{$ source cell cross $(0 . . \mathrm{T})\}$; 
param Q $\{$ cell $\}$;

param Nmax $\{$ cell $\}$;

param $d\{(i, j)$ in evacorder, $0 . . T\}$;

var $x\{i$ in cell, $t$ in $0 . . T\}>=0$;

var y $\{(\mathrm{i}, \mathrm{j})$ in Link, $\mathrm{t}$ in $0 . . \mathrm{T}\}>=0$;

var order\{evacorder\} binary;

minimize Total_cost:

$\operatorname{sum}\{\mathrm{i}$ in (source_cell union ord_cell union merge_cell union diverge_cell), $\mathrm{t}$ in $0 . . \mathrm{T}\}$

$x[i, t]$

subject to initial_condition_link $\{(\mathrm{i}, \mathrm{j})$ in Link $\}$ :

$y[i, j, 0]=0 ;$

subject to initial_condition_cell $\{\mathrm{i}$ in cell $\}$ :

$x[i, 0]=0 ;$

subject to conservation_ord_cell $\{\mathrm{i}$ in (ord_cell union merge_cell union diverge_cell), $\mathrm{t}$ in $1 . . \mathrm{T}\}$ :

$x[i, t]=x[i, t-1]-\operatorname{sum}\{(i, j)$ in (source_connect union ord_connect union merge_connect union diverge_connect union sink_connect) $\} \mathrm{y}[\mathrm{i}, \mathrm{j}, \mathrm{t}-1]+\operatorname{sum}\{(\mathrm{j}, \mathrm{i})$ in (source_connect union ord_connect union merge_connect union diverge_connect union sink_connect) $\} \mathrm{y}[\mathrm{j}, \mathrm{i}, \mathrm{t}-1]$ 
subject to phi_cell_1 $\{(i, j)$ in (ord_connect union source_connect union merge_connect), $\mathrm{t}$ in $0 . . \mathrm{T}\}$ :

$\mathrm{y}[\mathrm{i}, \mathrm{j}, \mathrm{t}]<=\mathrm{x}[\mathrm{i}, \mathrm{t}]$

subject to phi_cell_2 $\{(\mathrm{i}, \mathrm{j})$ in (ord_connect union source_connect union merge_connect), $\mathrm{t}$ in $0 . . \mathrm{T}\}$ :

$\mathrm{y}[\mathrm{i}, \mathrm{j}, \mathrm{t}]<=\mathrm{Q}[\mathrm{i}]$

subject to phi_cell_11 $\{$ i in diverge_cell, $t$ in $0 . . T\}$ :

$\operatorname{sum}\{(\mathrm{i}, \mathrm{j})$ in diverge_connect $\} \mathrm{y}[\mathrm{i}, \mathrm{j}, \mathrm{t}]<=\mathrm{x}[\mathrm{i}, \mathrm{t}]$;

subject to phi_cell_12 $\{\mathrm{i}$ in diverge_cell, $\mathrm{t}$ in $0 . . \mathrm{T}\}$ :

$\operatorname{sum}\{(\mathrm{i}, \mathrm{j})$ in diverge_connect $\} \mathrm{y}[\mathrm{i}, \mathrm{j}, \mathrm{t}]<=\mathrm{Q}[\mathrm{i}]$;

subject to Rec_cell_1 $\{(\mathrm{i}, \mathrm{j})$ in (ord_connect union diverge_connect),t in $0 . . \mathrm{T}\}$ :

$y[i, j, t]<=(\operatorname{Nmax}[j]-x[j, t])$

subject to Rec_cell_2 $\{(\mathrm{i}, \mathrm{j})$ in (ord_connect union diverge_connect),t in $0 . . \mathrm{T}\}$ :

$\mathrm{y}[\mathrm{i}, \mathrm{j}, \mathrm{t}]<=\mathrm{Q}[\mathrm{j}]$;

subject to Rec_cell_11 $\{\mathrm{j}$ in merge_cell,t in $0 . . \mathrm{T}\}$ :

$\operatorname{sum}\{(\mathrm{i}, \mathrm{j})$ in merge_connect $\} \mathrm{y}[\mathrm{i}, \mathrm{j}, \mathrm{t}]<=(\mathrm{Nmax}[\mathrm{j}]-\mathrm{x}[\mathrm{j}, \mathrm{t}])$

subject to Rec_cell_12 $\{\mathrm{j}$ in merge_cell,t in $0 . . T\}$ :

$\operatorname{sum}\{(i, j)$ in merge_connect $\} y[i, j, t]<=Q[j]$; 
subject to sink_1 $\{(\mathrm{i}, \mathrm{j})$ in $($ sink_connect $), \mathrm{t}$ in $0 . . \mathrm{T}\}$ :

$\mathrm{y}[\mathrm{i}, \mathrm{j}, \mathrm{t}]<=\mathrm{x}[\mathrm{i}, \mathrm{t}]$

subject to sink_2 $\{(\mathrm{i}, \mathrm{j})$ in (sink_connect), $\mathrm{t}$ in $0 . . \mathrm{T}\}$ :

$\mathrm{y}[\mathrm{i}, \mathrm{j}, \mathrm{t}]<=\mathrm{Q}[\mathrm{i}]$

subject to conservation_source_cell $\{\mathrm{i}$ in source_cell, $(\mathrm{i}, \mathrm{j})$ in source_connect,t in $1 . . \mathrm{T}\}$ :

$x[\mathrm{i}, \mathrm{t}]=\mathrm{x}[\mathrm{i}, \mathrm{t}-1]-\mathrm{y}[\mathrm{i}, \mathrm{j}, \mathrm{t}-1]+\operatorname{sum}\{(\mathrm{i}, \mathrm{k})$ in evacorder $\}(\operatorname{order}[\mathrm{i}, \mathrm{k}] * \mathrm{~d}[\mathrm{i}, \mathrm{k}, \mathrm{t}])$

subject to uniqueness_order $\{\mathrm{i}$ in source_cell $\}$ :

$\operatorname{sum}\{(i, j)$ in evacorder $\}$ order $[i, j]=1$; 
APPENDIX D 


\section{Optimization model for optimal crossover}

\section{$\underline{\text { Crossover.mod }}$}

param T;

set source_cell;

set ord_cell;

set merge_cell;

set diverge_cell;

set sink_cell;

set crossover;

set source_connect within (source_cell cross (ord_cell union merge_cell union diverge_cell));

set ord_connect within ((ord_cell union merge_cell union crossover) cross (ord_cell union diverge_cell));

set merge_connect within ((ord_cell union source_cell union merge_cell union crossover) cross merge_cell);

set diverge_connect within (diverge_cell cross (ord_cell union diverge_cell union crossover));

set sink_connect within (ord_cell cross sink_cell);

set cell within (source_cell union ord_cell union merge_cell union diverge_cell union sink_cell union crossover);

set Link within (ord_connect union merge_connect union diverge_connect union source_connect union sink_connect); 
param Q $\{$ cell $\}$;

param Nmax $\{$ cell $\}$;

param xcap $\{$ cell $\}$;

param ycap $\{(\mathrm{i}, \mathrm{j})$ in Link $\}$;

param d $\{\mathrm{i}$ in source_cell, $0 . . \mathrm{T}\}$;

param xcap1 $\{$ cell $\}$;

set incident within cell;

param incident_time;

param flow_incident;

var $x\{i$ in cell, $t$ in $0 . . T\}>=0$;

var y $\{(\mathrm{i}, \mathrm{j})$ in Link, $\mathrm{t}$ in $0 . . \mathrm{T}\}>=0$;

var order \{crossover\} binary;

minimize Total_cost:

$\operatorname{sum}\{\mathrm{i}$ in (source_cell union ord_cell union merge_cell union diverge_cell union crossover), $\mathrm{t}$ in $0 . . \mathrm{T}\} \mathrm{x}[\mathrm{i}, \mathrm{t}]$;

subject to cr_occ $\{\mathrm{i}$ in crossover, $\mathrm{t}$ in $0 . . \mathrm{T}\}$ :

$\mathrm{x}[\mathrm{i}, \mathrm{t}]<=\operatorname{order}[\mathrm{i}] * \mathrm{Nmax}[\mathrm{i}]$

subject to initial_condition_link $\{(\mathrm{i}, \mathrm{j})$ in Link $\}$ :

$y[i, j, 0]=y c a p[i, j]$ 
subject to initial_condition_cell $\{$ i in cell $\}$ :

$x[i, 0]=x \operatorname{cap}[i]$

subject to conservation_ord_cell $\{i$ in (ord_cell union merge_cell union diverge_cell union crossover), $\mathrm{t}$ in $1 . . \mathrm{T}\}$ :

$x[i, t]=x[i, t-1]-\operatorname{sum}\{(i, j)$ in (source_connect union ord_connect union merge_connect union diverge_connect union sink_connect) $\} \mathrm{y}[\mathrm{i}, \mathrm{j}, \mathrm{t}-1]+\operatorname{sum}\{(\mathrm{j}, \mathrm{i})$ in (source_connect union ord_connect union merge_connect union diverge_connect union sink_connect) $\} \mathrm{y}[\mathrm{j}, \mathrm{i}, \mathrm{t}-1]$;

subject to phi_cell_1 $\{(\mathrm{i}, \mathrm{j})$ in (ord_connect union source_connect union merge_connect), $\mathrm{t}$ in $0 . . \mathrm{T}\}$ :

$\mathrm{y}[\mathrm{i}, \mathrm{j}, \mathrm{t}]<=\mathrm{x}[\mathrm{i}, \mathrm{t}]$

subject to phi_cell_2 $\{(i, j)$ in (ord_connect union source_connect union merge_connect), $\mathrm{t}$ in $0 . . \mathrm{T}\}$ :

$\mathrm{y}[\mathrm{i}, \mathrm{j}, \mathrm{t}]<=\mathrm{Q}[\mathrm{i}] ;$

subject to phi_cell_11 $\{$ i in diverge_cell, $t$ in $0 . . T\}$ :

$\operatorname{sum}\{(\mathrm{i}, \mathrm{j})$ in diverge_connect $\} \mathrm{y}[\mathrm{i}, \mathrm{j}, \mathrm{t}]<=\mathrm{x}[\mathrm{i}, \mathrm{t}]$;

subject to phi_cell_12 $\{\mathrm{i}$ in diverge_cell, $\mathrm{t}$ in $0 . . \mathrm{T}\}$ :

$\operatorname{sum}\{(i, j)$ in diverge_connect $\} y[i, j, t]<=Q[i] ;$ 
subject to Rec_cell_1 $\{(\mathrm{i}, \mathrm{j})$ in (ord_connect union diverge_connect),t in $0 . . \mathrm{T}\}$ : $y[i, j, t]<=(N \max [j]-x[j, t])$

subject to Rec_cell_2 $\{(\mathrm{i}, \mathrm{j})$ in (ord_connect union diverge_connect),t in $0 . . \mathrm{T}\}$ : $\mathrm{y}[\mathrm{i}, \mathrm{j}, \mathrm{t}]<=\mathrm{Q}[\mathrm{j}] ;$

subject to Rec_cell_11 $\{\mathrm{j}$ in merge_cell,t in $0 . . \mathrm{T}\}$ :

$\operatorname{sum}\{(\mathrm{i}, \mathrm{j})$ in merge_connect $\} \mathrm{y}[\mathrm{i}, \mathrm{j}, \mathrm{t}]<=(\mathrm{Nmax}[\mathrm{j}]-\mathrm{x}[\mathrm{j}, \mathrm{t}])$

subject to Rec_cell_12 $\{\mathrm{j}$ in merge_cell,t in $0 . . \mathrm{T}\}$ :

$\operatorname{sum}\{(i, j)$ in merge_connect $\} y[i, j, t]<=Q[j]$;

subject to sink_1 $\{(\mathrm{i}, \mathrm{j})$ in $($ sink_connect $), \mathrm{t}$ in $0 . . T\}$ :

$\mathrm{y}[\mathrm{i}, \mathrm{j}, \mathrm{t}]<=\mathrm{x}[\mathrm{i}, \mathrm{t}]$

subject to sink_2 $\{(\mathrm{i}, \mathrm{j})$ in (sink_connect), $\mathrm{t}$ in $0 . . \mathrm{T}\}$ :

$\mathrm{y}[\mathrm{i}, \mathrm{j}, \mathrm{t}]<=\mathrm{Q}[\mathrm{i}] ;$

subject to conservation_source_cell $\{\mathrm{i}$ in source_cell, $(\mathrm{i}, \mathrm{j})$ in source_connect,t in $1 . . \mathrm{T}\}$ : $x[i, t]=x[i, t-1]-y[i, j, t-1]+d[i, t] ;$

subject to uniqueness_order $\{\mathrm{t}$ in $0 . . \mathrm{T}\}$ :

sum $\{i$ in crossover $\}$ order $[i]<=2$; 
APPENDIX E 


\section{Destination Network and MATLAB code for data extraction}

clear all;

A=xlsread('DATA1.xls','Data');

$[1, \mathrm{~m}]=\operatorname{size}(\mathrm{A})$

$\mathrm{q}=1$;

for $\mathrm{p}=1: 1$

if $(\mathrm{A}(\mathrm{p}, 3)>0)$

$\mathrm{C}(\mathrm{q},:)=\mathrm{A}(\mathrm{p},:)$

$\mathrm{q}=\mathrm{q}+1$

end;

end;

$j=120$;

$\mathrm{i}=1$;

$[1, \mathrm{~m}]=\operatorname{size}(\mathrm{C})$

$\mathrm{p}=\mathrm{C}(1,2)$;

$\mathrm{k}=1$;

while $(\mathrm{i}<=1)$

tempd $=0$;

tempv $=0$;

temps $=0$;

$\operatorname{dist}=0$;

Qout $=0$;

Qin=0;

num $=0$; 
while $\mathrm{p}==\mathrm{j}$

$\mathrm{p}=\mathrm{C}(\mathrm{i}, 2)$;

if $((\mathrm{C}(\mathrm{i}, 1)==37)\|(\mathrm{C}(\mathrm{i}, 1)==28)\|(\mathrm{C}(\mathrm{i}, 1)==26)\|(\mathrm{C}(\mathrm{i}, 1)==49)\|(\mathrm{C}(\mathrm{i}, 1)==42) \|$ $(\mathrm{C}(\mathrm{i}, 1)==34) \|(\mathrm{C}(\mathrm{i}, 1)==53))$

Qout=Qout $+\mathrm{C}(\mathrm{i}, 5)$;

end

if $((\mathrm{C}(\mathrm{i}, 1)==31)\|\quad(\mathrm{C}(\mathrm{i}, 1)==66)\|(\mathrm{C}(\mathrm{i}, 1)==30)\|(\mathrm{C}(\mathrm{i}, 1)==1)\|(\mathrm{C}(\mathrm{i}, 1)==7) \|$

$(\mathrm{C}(\mathrm{i}, 1)==13) \|(\mathrm{C}(\mathrm{i}, 1)==64))$

Qin= $=$ in $+C(i, 5)$;

end

$\operatorname{dist}=\operatorname{dist}+\mathrm{C}(\mathrm{i}, 3)$;

num $=$ num $+C(i, 3) * C(i, 6)$;

temps $=$ temps $+\mathrm{C}(\mathrm{i}, 3) * \mathrm{C}(\mathrm{i}, 4)$;

tempd $=$ tempd $+\mathrm{C}(\mathrm{i}, 3) * \mathrm{C}(\mathrm{i}, 6)$;

tempv $=$ tempv $+\mathrm{C}(\mathrm{i}, 3) * \mathrm{C}(\mathrm{i}, 5)$;

$\mathrm{i}=\mathrm{i}+1$;

end

$\mathrm{D}(\mathrm{k}, 1)=$ temps $/$ dist;

$\mathrm{D}(\mathrm{k}, 2)=$ tempv/dist;

$\mathrm{D}(\mathrm{k}, 3)=\mathrm{tempd} / \mathrm{dist}$;

$\mathrm{D}(\mathrm{k}, 4)=\mathrm{Qin}$;

$\mathrm{D}(\mathrm{k}, 5)=$ Qout;

$\mathrm{k}=\mathrm{k}+1$;

$j=j+120$;

end 


\section{REFERENCES}

Alsnih, R. and Stopher, P. R., (2004) "Review of procedures associated with devising emergency evacuation plans", Transportation Research Record (1865), pp. 89-97.

Ardekani, S. A. (1984). "The Two-Fluid characterization of Urban Traffic: Theory Observation, and Experiment”, Ph.D. Dissertation, University of Teas at Austin.

Baker, E. J., (1991) "Hurricane Evacuation Behavior” International Journal of Mass Emergencies and Disasters, Vol. 9, No. 2, pp. 287-310.

Buckley, D.G. and J.G Wardrop, (1980). "Some General Properties of a Traffic Network", Australian Road Research, Vol. 10, No.1.

Chiu, Y.C., Villalobos, J., Gautam, B., Zheng, H. (2006) "Modeling and Solving the Optimal Evacuation Destination-Route-Flow-Staging Problem for No-Notice Extreme Events “, TRB 2006 Annual Meeting CD-ROM.

Daganzo, C., (1994a), “The Cell Transmission Model: A Dynamic Representation of Highway Traffic Consistent with Hydrodynamic Theory", Transportation Research Part B, Vol. 28B, No. 4, pp. 269-187.

Daganzo, C., (1994b), "The Cell Transmission Model, Part II: Network Traffic", Transportation Research Part B, Vol. 29B, No. 2, pp. 79-93. 
Daganzo, F. C. (2007). "Urban gridlock: Macroscopic modeling and mitigation approaches", Transportation Part B, 41, 49-62

Drake J., Schofer J.and May A. D. (1967) “A Statistical Analysis of Speed-Density Hypotheses", Proceedings of the Third International Symposium on the Theory of Traffic Flow, American Elsevier.

Drabek T. E. (1983) 'Shall we leave? A study of family reactions when disaster strikes.' Emergency Mgmt. Rev., 1 (Fall), pp. 25-29.

Edie, L. C. (1965). Discussion of Traffic Stream Measurements and Definitions. Proceedings of the Second International Symposium on the Theory of Traffic Flow, OECD, pp. 139-154.

Fitzpatrick, C., Mileti, D, S., (1991), “Motivating Public Evacuation”, International Journal of Mass Emergencies and Disasters, Vol. 9, No. 2, pp. 7-18.

Fu, X., (2004) “Development of Dynamic Travel Demand Models for Hurricane Evacuation", Ph. D. Dissertation, Louisiana State University

Fu, H. and Wilmot, C. (2004). "Sequential Logit Dynamic Travel Demand Model for Hurricane Evacuation.” Transportation Research Record, No.1882, pp.19-26.

Fu, H. and Wilmot, C. (2006). "Survival Analysis Based Dynamic Travel Demand Models For Hurricane evacuation" 85 $5^{\text {th }}$ TRB Annual Meeting CD-ROM, 2006. 
Fu, H., Wilmot, C. and Zhang, H. (2007). "Modeling the Hurricane Evacuation Response Curve" 86 ${ }^{\text {th }}$ TRB Annual Meeting CD-ROM, 2007.

Gazis, D.C. (1974). Traffic Science. Wiley, New York.

Geroliminis, N. and Daganzo, C.F. (2007). "Macroscopic modeling of traffic in cities", TRB 2007 Annual Meeting CD-ROM.

Greene W. H. (2003) Econometric Analysis, 5th edition Englewood Cliffs: Prentice Hall, Upper Saddle River, New Jersey.

Heath, S.E., Kass, P.H., Beck, A.M., and Glickman, L.T. (2001), "Human and Petrelated Risk Factors for Household Evacuation Failure During a Natural Disaster”, American Journal of Epidemiology, Volume 153, Number 7, pp. 659-665.

Howell, S. E. and Bonner, D. E. (2005). "Citizen Hurricane Evacuation Behavior in Southeastern Louisiana: A Twelve Parish Survey” Available:

http://poli.uno.edu/unopoll/Summary\%20Report\%20July\%2019\%202005\%20(2).pdf Accessed: June 4, 2007

Hultaker, O. (1983). "Family and Disaster" International Journal of Mass Emergencies and Disasters, Vol. 1, No. 1, pp. 7-18 
Kalafatas, G., Peeta, S., (2007) “An Exact Graph Structure for Dynamic Traffic Assignment: Formulation, Properties, Computational Experience.” TRB 2007, Annual Meeting CD-ROM.

Liu, Y., (2007) “An Integrated Optimal Control System for Emergency Evacuation”, Ph.D. dissertation, University of Maryland

Mahmassani H., J. C. Williams and R. Herman, (1984). "Investigation of NetworkLevel Traffic Flow Relationships: Some Simulation Results", Transportation Research Record 971, Transportation Research Board.

Mahmassani H., J. C. Williams and R. Herman, (1987). "Performance of Urban Traffic Networks", Transportation and Traffic Theory (Proceedings of the Tenth International Symposium on Transportation and Traffic Theory, Cambridge Massachusetts), N. H. Gartner, N. H. M. Wilson, editors, Elsevier

Mahmassani H. J., Jayakrishnan R. and Herman R (1990). "Network Traffic Flow Theory: Microscopic Simulation Experiments on Supercomputers", Transportation Research Part-A, Vol. 24A, No.2, pp 149-162.

Mahmassani, H. S. and Sbayati, H. (2006) "Optimal Scheduling of Evacuation Operations" Transportation Research Board's 85 ${ }^{\text {th }}$ Annual Meeting, Washington, D. C. 
Mikami, S., Ikeda, K. (1985). "Human Response to Disasters", International Journal of Mass Emergencies and Disasters, Vol. 3, No. 1, pp. 106-132.

Mitchell, S. and Radwan, A. E. (2006) "Heuristic Prioritization of Emergency Evacuation Staging to Reduce Clearance Time", Transportation Research Board's $85^{\text {th }}$ Annual Meeting, Washington, D. C.

Ozbay, K. , Yazici, M. A. and Chien, S. I. (2006) “ Study of Network-Wide Impacts of Various Demand Generation Methods under hurricane Evacuation Conditions", Transportation Research Board's $85^{\text {th }}$ Annual Meeting, Washington, D. C

PBS\&J (2000), “Analysis of Florida’s One-Way Operations for Hurricane Evacuation", Compendium of route by route Technical Memoranda

Petruccelli, U. 2003. "Urban evacuation in seismic emergency conditions" ITE J., 73(8), 34-38.

Prigogine, I. and R. Herman, (1971). "Kinetic Theory of Vehicular Traffic", American Elsevier.

Quarantelli, E. L. (1985). "Realities and mythologies in disaster films." Communications: The European Journal of Communication, 11, pp. 31-44.

Shen, W., Nie, Y., Zhang, H. M. (2007), “A Dynamic Network Simplex Method For Designing Evacuation Plans”, TRB 2007 Annual Meeting CD-ROM 
Sorensen, J. H., Mileti, D. S. (1988) "Warning and Evacuation: Answering some basic questions,” Industrial Crisis Quarterly, Vol. 2, pp. 195-209.

Sorensen, J. H. (1991), "When Shall We Leave? Factors Affecting The Timing of Evacuation Departures" International Journal of Mass Emergencies and Disasters, Vol. 9, No. 2, pp.153-165

Theodoulou, G., (2003) "Contraflow Evacuation on Westbound I-10 out of the city of New Orleans.” Thesis, Louisiana State University

Theodoulou, G., Wolshon, B. (2004) “Modeling and Analyses of Freeway Contraflow to Improve Future Evacuations.” TRB 2004 Annual Meeting CD-ROM

Tierney, K., Bevc, C., Kuligowski, E., (2006), "Metaphors Matter: Disaster Myths, Media frames, and their consequences in Hurricane Katrina", ANNALS, AAPSS, Vol. 604. No.1, pp 57-81

Tuydes, H., Ziliaskopoulos, A., (2004), "Network Re-design to Optimize Evacuation Contraflow," Presented at 82nd Annual Meeting of the Transportation Research Board, Washington, D.C

Tuydes, H., Ziliaskopoulos, A., (2005) "The Network Evacuation Problem and Solution Algorithms," Presented at the 2005 INFORMS Annual Meeting, San Francisco 
US Army Corps of Engineers, “Alabama Hurricane Evacuation Study Technical Data Report: Behavioral Analysis,” Final Report, 2000.

U.S. Department of Transportation in cooperation with U.S. Department of Homeland Security, (2006) "Catastrophic Hurricane Evacuation Plan Evaluation: A Report to Congress"

Vogt BM. (1991), “Issues in nursing home evacuations”, Int J Mass Emerg Disasters, Volume 9, pp. 247-65.

Williams, J. C., H. S. Mahmassani, and R. Herman, (1985). “Analysis of Traffic Network Flow Relations and Two-Fluid Model Parameter Sensitivity”, Transportation Research Record 1005, Transportation Research Board.

Williams, J. C., H. S. Mahmassani, and R. Herman, (1987). "Urban Traffic Network Flow Models", Transportation Research Record 1112, Transportation Research Board

Wolshon, B., (2001), “One-way-out: contraflow Freeway Operation for Hurricane Evacuation," National Hazards Review, Volume 2, No. 3

Wolshon, B., Urbina, E. (2003), "National Review of Hurricane evacuation plans and policies: a comparison and contrast of state practices," Transportation Research Part A: Policy and Practice, Volume 37, issue 3 
Zahavi, Y. (1972a). "Traffic Performance Evaluation of Road Networks by the $\alpha_{\text {- }}$ Relationship.” Traffic Engineering and Control, Vol. 14, No. 5.

Zahavi, Y. (1972b). "Traffic Performance Evaluation of Road Networks by the $\alpha_{\text {- }}$ Relationship, Part 2.” Traffic Engineering and Control, Vol. 14, No. 6

Ziliaskopoulos, A.K., (2000) “A linear programming model for the single destination system optimum dynamic traffic assignment problem”, Transportation Science 34 (1), $37-49$

Revised Monograph on Traffic Flow Theory, website, Turner-Fairbank Highway Research Center, Available: http://www.tfhrc.gov/its/tft/tft.htm, Accessed September 13,2006

Transcript of News Hour with Jim Lehrer, Posted: September 23, 2005. "Rita Evacuation in Texas" Available:http://www.pbs.org/newshour/bb/weather/julydec05/bus 9-23.html Accessed: June 5, 2007

Available:http://chps.sam.usace.army.mil/USHESDATA/Assessments/2004Storms/20 04 hurricane season_page.htm, Accessed: June 30, 2007.

Available: http://support.sas.com/rnd/app/papers/qlim.pdf, Accessed: June 30, 2007.

U.S.Census, Available:http://quickfacts.census.gov/qfd/states/12/1238250.html , Accessed: July 21, 2007 
Minutes of the SE U.S. Regional Transportation Analysis Meeting, Held in the FEMA Region IV Office in Atlanta, On March 7-8, 2000 Available: http://www.sam.usace.army.mil/pd/hes/minutes7-8Mar2000.htm, Accessed: July 6, 2007

VISSIM, Available: http://www.ptvamerica.com/vissim.html , Accessed: July 21, 2007 